Data de Depósito:

Assinatura:

\title{
Local branching aplicado ao problema de dimensionamento de lotes
}

\author{
Renato Andrade de Paiva
}

Orientadora: Franklina Maria Bragion de Toledo

Dissertação apresentada ao Instituto de Ciências Matemáticas e de Computação - ICMC-USP, como parte dos requisitos para obtenção do título de Mestre em Ciências de Computação e Matemática Computacional.

USP - São Carlos

Fevereiro/2010 


\title{
Local branching aplicado ao problema de dimensionamento de lotes
}

\author{
Renato Andrade de Paiva
}


Dedico, com prazer e satisfação, aos meus pais, Osvaldo e Suzy. 


\section{Agradecimentos}

Agradeço primeiramente aos meus pais Osvaldo Leite Simões de Paiva e Suzy Moura de Andrade pela educação, incentivo e apoio durante os momentos difíceis.

Ao meu tio Marinho Gomes de Andrade e a Katiane Silva Conceição por todo o apoio, carinho, cuidado e ensinamentos. Agradeço por terem tomado conta de mim durante todo este tempo.

À minha orientadora Franklina Maria Bragion de Toledo por toda a paciência e dedicação que teve comigo durante estes dois anos de mestrado.

Aos meus familiares por estarem sempre na torcida pela minha vitória.

Aos amigos Otavio Carneiro Leão Neto, Luiz Armando e Jenifer Souza pelos momentos de força, nas horas de sufoco, de alegria e de vitórias.

Aos amigos José Maurício, Keylha Cristina, Roberto Xantre e a todos os outros, pelos conselhos e pela sincera amizade.

A todos os professores que contribuíram decisivamente para a minha, e nossa, formação acadêmica e profissional.

Ao Conselho Nacional de Desenvolvimento Científico e Tecnológico (CNPq).

E para não correr o risco de ser injusto, gostaria de agradecer a todos que de alguma forma participaram deste momento e contribuíram para a construção de quem eu sou hoje. 
"A mente que se abre a uma nova idéia jamais voltará ao seu tamanho original".

Albert Einstein 


\section{Resumo}

O planejamento da produção é uma atividade que avalia decisões para um melhor uso dos recursos disponíveis, visando satisfazer aos objetivos produtivos da empresa ao longo de um horizonte de planejamento. Este trabalho enfoca o problema de dimensionamento de lotes com restrições de capacidade (PDLC), que é uma das tarefas centrais envolvidas no planejamento da produção. O PDLC visa determinar o tamanho dos lotes a serem produzidos em períodos de tempo de um horizonte de planejamento. Os PDLC estudados neste trabalho contemplam duas características importantes: a presença de múltiplos itens e a existência de tempos de preparação para as máquinas. Além disso, são consideradas restrições de capacidade e situações onde o atraso para atender a demanda é permitido (backlogging). Alguns dos modelos estudados permitem que a preparação do ambiente de produção para um dado item possa ser mantida de um período para o seguinte, o que propiciaria a economia de até uma preparação a cada período. Esta característica é chamada de preservação de preparação (carry-over). Também existem situações onde a preparação de uma máquina começa em um período e termina no período seguinte. Na literatura, esta característica é chamada de set-up crossover. Este trabalho tem três metas centrais: a) avaliar diferentes configurações do software comercial ILOG CPLEX 11 para a solução dos PDLC estudados; b) estudar a influência na solução dos PDLC quando se acrescenta a possibilidade de atraso na demanda, de preservação de preparação e de set-up crossover; c) aplicar local branching para resolver os problemas estudados. Para resolver as instâncias propostas, foram utilizados o software comercial ILOG CPLEX 11 e um programa em C++ que foi desenvolvido neste trabalho. Foram utilizados exemplos encontrados na literatura para avaliar as propostas, e bons resultados foram obtidos.

Palavras-chave: dimensionamento de lotes; local branching; crossover; carry-over. 


\section{Abstract}

The production planning is an activity that evaluates the decision for a better use of the available resources, in order to satisfy the productive objectives of the company over a planning horizon. This work focuses on the capacitated lot-sizing problem (CLSP), which is one of the central tasks involved in production planning. The CLSP means to determine the size of the lots to be produced in time periods of a planning horizon. The CLSP studied in this work contemplate two complicating characteristics: the presence of multiple items and the existence of set-up times for the machines. Besides that, capacity constraints and situations where backlog of the demand is allowed are also considered (backlogging). Some of the studied models allow the set-up of the production environment for a given item to be carried over to the next period, which could result in economy of a set-up in each period (carry-over). There are situations where the set-up of a machine starts in one period and crosses over to the next period (set-up crossover). This work has three main goals: a) evaluate different configurations of the commercial software ILOG CPLEX 11 to solve the different kinds of CLSP studied; b) study the influence of the solution of the CLSP when you consider the possibility of backlogging, set-up carry-over and set-up crossover; c) apply local branching to solve the studied problems. To solve the proposed instances, we used the commercial solver ILOG CPLEX 11 and the program in C++ developed in this work. The examples used to test both programs are found in the literature, and good results were obtained.

Keywords: lotsizing; local branching; crossover; carry-over. 


\section{Sumário}

1. Introdução 1

2. Alguns modelos para o PDL $\quad 5$

2.1. PDL sem restrição de capacidade $\quad 7$

2.2. PDL com restrições de capacidade $\quad 8$

2.3. PDL com preservação de preparação 10

2.4. PDL com set-up crossover 17

3. Local branching 23

3.1. Local branching para o PDL 28

4. Testes Computacionais $\quad 31$

4.1. Experimentos computacionais com o CPLEX 33

4.1.1. PDL com limite de capacidade e custo de preparação 34

4.1.2. PDL com atraso na demanda $\quad 38$

4.1.3. PDL com preservação de preparação 41

4.1.4. PDL com preservação de preparação e set-up crossover 45

4.1.5. Conclusão 49

4.2. Experimentos computacionais para a implementação proposta 49

4.2.1. PDL com limite de capacidade e custo de preparação 50

4.2.2. PDL com atraso na demanda

4.2.3. PDL com preservação de preparação 51

4.2.4. PDL com preservação de preparação e set-up crossover 53

4.2.5. Conclusão 54

4.3. Efeito da solução inicial

4.4. Características do PDL 58

5. Conclusões e Pesquisas Futuras $\quad 63$

$\begin{array}{ll}\text { Referências Bibliográficas } & 67\end{array}$

Apêndice A - Resultados Detalhados $\quad 71$ 


\section{Lista de Figuras}

Figura 2.1 - Esquema de produção considerando tempo de preparação (Adaptada da fonte: 6 Sung e Maravelias, 2008).

Figura 2.2 - Figura ilustrando produção excedendo o período de tempo (Adaptada da fonte: 6 Sung e Maravelias, 2008).

Figura 2.3 - Esquema de produção de um item considerando tempo de preparação e carry- 7 over (Adaptada da fonte: Sung e Maravelias, 2008).

Figura 2.4 - Casos que são abordados pelo modelo proposto em Sung e Maravelias, 2008. 18 (Adaptado da fonte: Sung e Maravelias, 2008)

Figura 2.5 - Exemplo de condição em que o modo RP é ativado. (Adaptado da fonte: Sung 20 e Maravelias, 2008).

Figura 2.6 - Exemplo de ocorrência do set-up carry-over. (Adaptado da fonte: Sung e Maravelias, 2008).

Figura 2.7 - Exemplo de ocorrência do set-up crossover. (Adaptado da fonte: Sung e Maravelias, 2008).

Figura 3.1 - Exemplo do funcionamento do local branching. (Adaptado da fonte: Fischetti

e Lodi, 2003).

Figura 3.2 - Limite de tempo nos nós: caso 1. (Adaptado da fonte: Fischetti e Lodi, 2003). 26

Figura 3.3 - Limite de tempo nos nós: caso 2. (Adaptado da fonte: Fischetti e Lodi, 2003). 27

Figura 4.1 - Gráfico de Dolan e Moré para o grupo de exemplos “E”. 37

Figura 4.2 - Gráfico de Dolan e Moré para o grupo de exemplos “W”. 37

Figura 4.3 - Gráfico de Dolan e Moré para o grupo de exemplos “E”, considerando atraso 40 na demanda.

Figura 4.4 - Gráfico de Dolan e Moré para o grupo de exemplos "W”, considerando atraso 40 na demanda.

Figura 4.5 - Gráfico de Dolan e Moré para o grupo de exemplos "E”, considerando preservação de preparação.

Figura 4.6 - Gráfico de Dolan e Moré para o grupo de exemplos “W”, considerando 
preservação de preparação.

Figura 4.7 - Gráfico de Dolan e Moré para o grupo de exemplos "E”, considerando preservação de preparação e set-up crossover.

Figura 4.8 - Gráfico de Dolan e Moré para o grupo de exemplos "W”, considerando preservação de preparação e set-up crossover.

Figura 4.9 - Gráfico de Dolan e Moré para o grupo de exemplos “E”.

Figura 4.10 - Gráfico de Dolan e Moré para o grupo de exemplos "W".

Figura 4.11 - Gráfico de Dolan e Moré para o grupo de exemplos "E”, considerando preservação de preparação.

Figura 4.12 - Gráfico de Dolan e Moré para o grupo de exemplos "W", considerando preservação de preparação.

Figura 4.13 - Gráfico de Dolan e Moré para o grupo de exemplos "E”, considerando preservação de preparação e set-up crossover.

Figura 4.14 - Gráfico de Dolan e Moré para o grupo de exemplos "W", considerando preservação de preparação e set-up crossover.

Figura 4.15 - Comparação de tempo computacional da C++_PLB com e sem solução inicial para os exemplos dos grupos "E" e "W".

Figura 4.16 - Comparação de tempo computacional nos exemplos do grupo "E", considerando atraso na demanda.

Figura 4.17 - Comparação de tempo computacional nos exemplos do grupo "W", considerando atraso na demanda.

Figura 4.18 - Comparação do valor da melhor solução obtida: Grupos "E" e "W".

Figura 4.19 - Comparação do valor da melhor solução obtida: Grupo "F”.

Figura 4.20 - Comparação do valor da melhor solução obtida: Grupo "G”.

Figura 4.21 - Comparação do valor da melhor solução obtida: Grupo "X”.

Figura 5.1 - Comparação entre diferentes configurações do CPLEX 11.

Figura 5.2 - Comparação entre diferentes configurações da implementação em C++.

Figura 5.3 - Comparação entre desempenho do CPLEX e implementação em C++. 
Figura 5.4 - Comparação de ganho resultante das características propostas no PDLC.

Figura 5.5 - Grau de melhoria das soluções obtidas em cada um dos grupos de exemplos utilizando a implementação em C++.

Figura A.1 - Valores da função objetivo dos exemplos dos grupos "E" e "W", considerando atraso, preservação de preparação e set-up crossover.

Figura A.2 - Valores da função objetivo dos exemplos do grupo "F", considerando atraso, preservação de preparação e set-up crossover.

Figura A.3 - Valores da função objetivo dos exemplos do grupo “G”, considerando atraso, 78 preservação de preparação e set-up crossover.

Figura A.4 - Valores da função objetivo dos exemplos do grupo "X", considerando atraso, 78 preservação de preparação e set-up crossover. 


\section{Lista de Tabelas}

Tabela 4.1 - Dados dos grupos de instâncias propostas em Trigeiro et al. 1989

Tabela 4.2 - Tabela de resultados dos exemplos do grupo "E". 35

Tabela 4.3 - Tabela de resultados dos exemplos do grupo "W". 36

Tabela 4.4 - Tabela de resultados dos exemplos do grupo "E”, considerando atraso na 38 demanda.

Tabela 4.5 - Tabela de resultados dos exemplos do grupo "W", considerando atraso na demanda.

Tabela 4.6 - Tabela de resultados dos exemplos do grupo "E", considerando preservação de preparação.

Tabela 4.7 - Tabela de resultados dos exemplos do grupo "W", considerando preservação de preparação.

Tabela 4.8 - Tabela de resultados dos exemplos do grupo "E", considerando preservação de preparação e set-up crossover.

Tabela 4.9 - Tabela de resultados dos exemplos do grupo "W", considerando preservação de preparação e set-up crossover.

Tabela 4.10 - Comparação entre diferentes configurações do CPLEX 11.

Tabela 4.11 - Comparação entre diferentes configurações da implementação em C++.

Tabela 4.12 - Comparação entre desempenho do CPLEX e implementação em C++

Tabela 4.13 - Comparação de ganho resultante das características propostas no PDLC.

Tabela 4.14 - Grau de melhoria das soluções obtidas em cada um dos grupos de exemplos utilizando a implementação em C++.

Tabela A.1 - Tabela de resultados do programa em C++ nos exemplos do grupo "E".

Tabela A.2 - Tabela de resultados do programa em C++ nos exemplos do grupo "W".

Tabela A.3 - Tabela de resultados dos exemplos do grupo "E", considerando preservação de preparação. 
Tabela A.4 - Tabela de resultados dos exemplos do grupo "W”, considerando preservação de preparação.

Tabela A.5 - Tabela de resultados dos exemplos do grupo "E”, considerando preservação 75 de preparação e set-up crossover.

Tabela A.6 - Tabela de resultados dos exemplos do grupo "W", considerando preservação 76 de preparação e set-up crossover. 


\section{Capítulo 1}

\section{Introdução}

O planejamento da produção é uma atividade que avalia decisões para um melhor uso dos recursos disponíveis, visando satisfazer aos objetivos produtivos da empresa ao longo de um horizonte de planejamento.

Este trabalho enfoca o problema de dimensionamento de lotes (PDL), que é uma das tarefas centrais envolvidas no planejamento da produção. O PDL clássico visa determinar o tamanho dos lotes a serem produzidos em um horizonte de planejamento finito. A literatura destinada ao PDL é bastante rica, contendo boas revisões enfocando diversos aspectos do problema. Em Bahl et al. (1987) os autores fazem uma revisão do problema de dimensionamento de lotes, focando em determinar os requisitos de cada aplicação. Em Kuik et al. (1994) são apresentadas a definição de batching e sua aplicação no problema de dimensionamento de lotes. Em seguida, são definidos e explicados os parâmetros utilizados na criação do modelo apresentado pelos autores. Wolsey (1995) também aborda o problema de dimensionamento de lotes envolvendo um único item apenas. Em Drexl e Kimms (1997) os autores focam o problema de dimensionamento de lotes, fazendo uma revisão e apresentando novas extensões e possibilidades de integração com o problema de sequenciamento (scheduling). Em Karimi et al. (2003) são destacadas características que influenciam a classificação, a modelagem e a complexidade das decisões do PDL. As características destacadas pelo autor, tais como, horizonte de planejamento, número de estágios, número de itens, restrições de capacidade, itens perecíveis, tipo de demanda, estoque e preparação para produção (setup), determinam o grau de dificuldade para a solução dos problemas. Em Brahimi et al. (2006), os autores abordam detalhadamente o problema de dimensionamento de lotes com um único item, apresentando uma definição e mostrando diferentes enfoques e modelagens. Jans e Degraeve (2008) apresentam uma descrição do problema de dimensionamento de lotes voltado às indústrias, propõem um modelo e indicam em que pontos o modelo pode ser estendido para atender diferentes aplicações.

De fato, no tocante à dificuldade de resolução, constata-se que várias versões do PDL com restrição de capacidade apresentam uma elevada complexidade teórica. Mesmo problemas com um único item podem ser de difícil resolução, como mostrado por Florian et al. (1980), que provaram que vários problemas com um único item com restrições de 
capacidade e custos de preparação são NP-Díficil. Naturalmente, considerar a produção de mais de um item torna o problema mais complicado. Bitran e Yanasse (1992) provaram que vários casos de um único item que podem ser resolvidos em tempo polinomial tornam-se $N P$ Díficil quando um segundo item é introduzido.

Outro fator que dificulta o tratamento do PDLC é a consideração de tempos de preparação para as máquinas. O problema de encontrar uma solução factível quando se consideram os tempos de preparação das máquinas é NP-Completo (Maes et al., 1991). Estes mesmos autores mostram que se os tempos de preparação são nulos, encontrar uma solução factível é um problema que pertence à Classe P. Devido à dificuldade em tratar problemas com restrições de capacidade, com custo e tempo de preparação, poucos métodos exatos foram propostos para sua solução (Armentano et al., 1999; Diaby et al., 1992a; Souza e Armentano, 1994). No entanto, várias heurísticas foram propostas, das quais podemos destacar as apresentadas por Toledo e Armentano (2006), Diaby et al. (1992b), Trigeiro et al. (1989), Lozano et al. (1991) e Jans e Degreave (2007).

O PDLC estudado neste trabalho contempla duas características que tornam sua solução mais difícil: a presença de múltiplos itens e a existência de tempos de preparação para as máquinas. Alguns dos modelos apresentados permitem: que a demanda possa ser atendida com atraso (backlogging); que a preparação do ambiente de produção para um dado item possa ser mantida de um período para o outro, o que propicia a economia de até uma preparação a cada período (carry-over); e que a preparação de uma máquina possa começar em um período e terminar apenas no período seguinte (set-up crossover). Independente das características, o objetivo é encontrar um plano de produção que minimize os custos de produção, de preparação, de estoque e de atraso (caso seja permitido), respeitando os recursos disponíveis.

O problema estudado se insere na literatura no seguinte contexto: o problema com múltiplos itens, tempos de preparação e restrições de capacidade já foi estudado por Gopalakrishnan et al. (1995), Sox e Gao (1999), Gopalakrishnan et al. (2001), Porkka e Kuula (2003), Suerie e Stadtler (2003), Briskorn (2006) e Jans e Degreave (2008). Estes autores, porém, não consideram a possibilidade de backlogging. Já Karimi et al. (2006) abordaram o PDL com possibilidade de preservação de preparação e atraso na demanda. A modelagem mais recente foi a proposta em Sung e Maravelias (2008). Esta modelagem considera possibilidade de atraso, preservação de preparação e set-up crossover.

Neste trabalho são apresentadas diferentes modelagens para o PDLC com diferentes características. Estes problemas são estudados com três objetivos centrais. O primeiro é avaliar o desempenho de diferentes configurações do CPLEX quando aplicado à solução dos 
problemas de dimensionamento de lotes estudados. O segundo é estudar o impacto das três características discutidas na resolução e na qualidade da solução dos problemas. O terceiro é resolver os problemas estudados utilizando local branching.

O restante deste trabalho é estruturado da seguinte forma. No Capítulo 2 é apresentada uma revisão de modelos propostos na literatura, com foco principal nos problemas de dimensionamento de lotes considerando restrições de capacidade e preservação de preparação. No Capítulo 3 é descrita a estratégia local branching. Os testes computacionais são apresentados e discutidos no Capítulo 4 e no Capítulo 5 são apresentadas a conclusões e propostas de para futuras pesquisas. 


\section{Capítulo 2}

\section{Alguns Modelos para o PDL}

O problema de dimensionamento de lotes (PDL) consiste em planejar a produção de um ou mais itens para atender uma demanda (fixa ou dinâmica) em um determinado horizonte de planejamento. Para o problema estudado neste trabalho, o horizonte de planejamento é finito e é dividido em períodos, logo a quantidade produzida deve ser determinada a cada período. Cada item possui um custo associado à sua produção e antes que um item possa ser produzido é necessário fazer a preparação do ambiente produtivo para sua produção. A preparação está associada a um custo que pode ser constante ou variar de item para item. Há também a possibilidade de manter itens em estoque, o que gera custo associado a cada unidade estocada. Da mesma forma que os custos de preparação, os custos de estoque podem variar de item para item e de período para período. $\mathrm{O}$ estoque permite que haja a possibilidade de antecipar a produção de um período futuro, caso a relação entre o custo de estoque e o custo de preparação do período seguinte seja vantajoso. O objetivo é minimizar a soma dos custos de produção, de preparação e de estoque.

Alguns modelos apresentam restrições quanto à capacidade de produção de cada período, logo a quantidade de produtos que pode ser produzida é limitada. Em alguns casos, a preparação para produção de um item consome parte significativa da capacidade de produção e, portanto, deve também ser considerada no modelo. A capacidade pode, sem perda de generalidade, ser representada pelo tempo disponível para produção. Uma possibilidade para estes problemas é que o tempo de preparação seja tão curto que sequer seja levado em conta no planejamento da produção. Nestes casos, o tempo não é considerado no modelo. Porém, quando o tempo de preparação é significativo, é necessário contabilizá-lo ao produzir um produto. Este processo é ilustrado na Figura 2.1. 


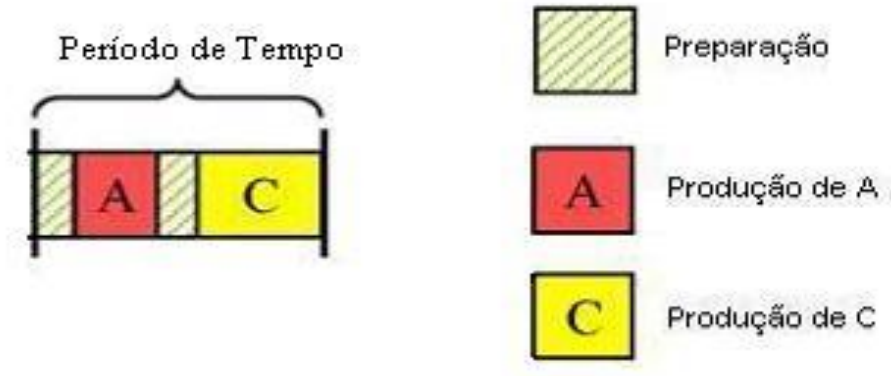

Figura 2.1 - Esquema de produção considerando tempo de preparação (Adaptada da fonte: Sung e Maravelias, 2008).

Note que o prazo para produção pode ser ultrapassado, ou seja, a demanda pode não ser atendida no período previsto devido ao tempo de preparação e à quantidade de preparações contidas no período, conforme visto na Figura 2.2.
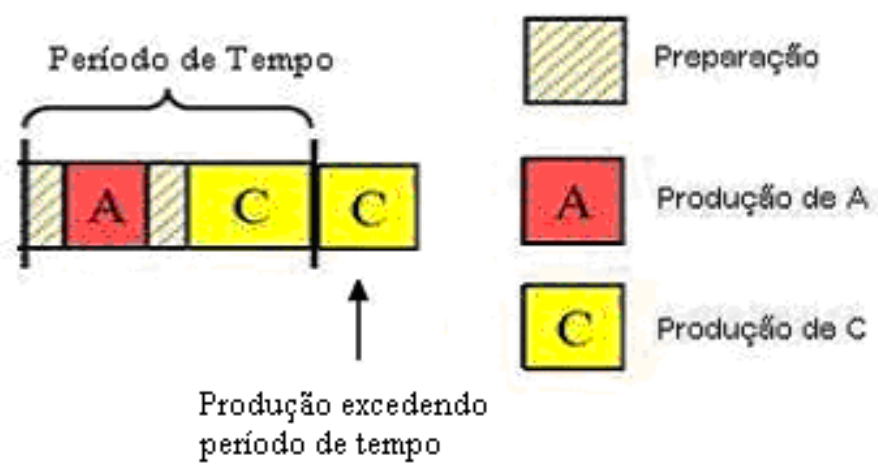

período de tempo

Figura 2.2 - Figura ilustrando produção excedendo o período de tempo (Adaptada da fonte: Sung e Maravelias, 2008).

Para tentar evitar esta situação, muitos modelos consideram a preservação de preparação (carry-over). O esquema de produção considerando a preservação de preparação pode ser visualizado na Figura 2.3. 


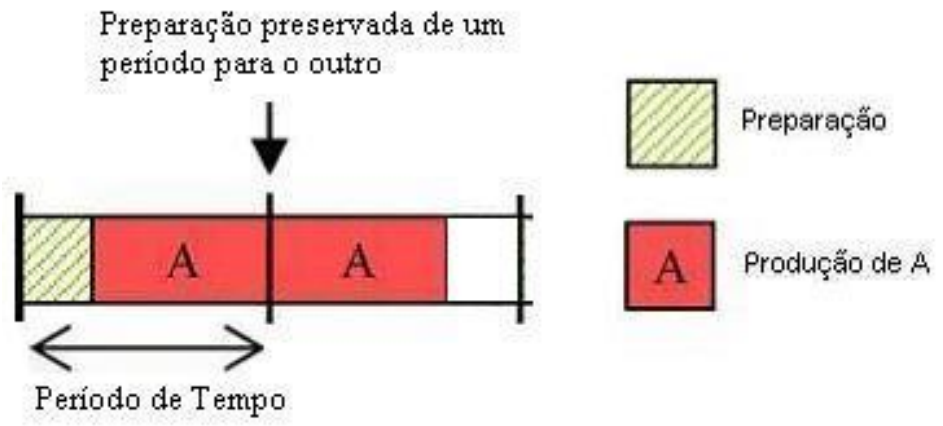

Figura 2.3 - Esquema de produção de um item considerando tempo de preparação e carry-over (Adaptada da fonte: Sung e Maravelias, 2008).

É importante enfatizar que o modelo escolhido para representar um problema deve sempre se adequar aos sistemas produtivos, podendo ser modificado e adaptado quando houver necessidade ou quando o grau de melhora for bastante significativo.

Como foi descrito anteriormente, para o PDL estudado são considerados: custos e tempos de preparação, custos de estoque e de atraso, restrições de capacidade, possibilidade de preservação de preparação e a possibilidade de iniciar uma preparação no final de um período e concluí-la no período seguinte. No entanto, nesta revisão bibliográfica, optou-se por primeiramente descrever o PDL sem restrições de capacidade, na sequiência o PDL com restrições de capacidade (PDLC) e, finalmente, o PDLC estudado. A fim de tornar a leitura mais fácil, todos os modelos são escritos utilizando a notação encontrada em Karimi et al. (2003).

\subsection{PDL sem restrição de capacidade}

O problema de dimensionamento de lotes sem restrição de capacidade com múltiplos itens consiste em determinar a quantidade a ser produzida de cada item em cada período de forma que o custo total de produção seja mínimo, ou seja, a soma dos custos de preparação, de produção e de estoque seja mínima. Como a produção não está limitada, o planejamento de um item não interfere no planejamento de outro, logo o problema pode ser resolvido considerando apenas um item por vez. Desta forma, este problema se resume ao PDL com um único item. Este problema pode ser resolvido na otimalidade em tempo $\mathrm{O}\left(n^{2}\right)$ pelo algoritmo proposto por Wagner e Within (1958). Uma revisão sobre este problema pode ser encontrada em Wolsey (1995). Mantendo a notação apresentada em Karimi et al. (2003), o PDL com um único item pode ser escrito pelo Modelo1, cujas variáveis e parâmetros são: 


$$
\begin{array}{ll}
T & =\text { número de períodos do horizonte de planejamento, } \\
p_{t} & =\text { custo de produção unitário do item no período } t ; \\
h_{t} & =\text { custo unitário de estoque do item no período } t ; \\
K_{t} & =\text { custo de preparaçãopara a produção do item no período } t ; \\
M_{t}=\sum_{k=t}^{T} d_{k} & =\text { limite superior da produção no período } t ; \\
x_{t} & =\text { quantidade do item produzida no período } t \text { (variável); } \\
I_{t} & =\text { estoque do item no final do período } t \text { (variável); } \\
z_{t} & =1 \text { se o item for produzido no período } t \text { e } 0 \text { caso contrário (variável). }
\end{array}
$$

\section{Modelo 1.}

$$
\begin{aligned}
& \operatorname{Min} \sum_{t=1}^{T}\left(K_{t} z_{t}+p_{t} x_{t}+h_{t} I_{t}\right) \\
& \text { s.a: } \quad x_{t}+I_{t-1}=d_{t}+I_{t} \quad t=1 \ldots T \\
& x_{t} \leq M_{t} z_{t} \quad t=1 \ldots T \text {; } \\
& z_{t} \in\{0,1\} \quad t=1 \ldots T \text {; } \\
& x_{t}, I_{t} \geq 0 \quad t=1 \ldots T \text {; }
\end{aligned}
$$

A função objetivo (2.1) visa minimizar a soma dos custos de preparação, de produção e de estoque. A restrição (2.2) representa o balanço de estoque, ou seja, o que foi produzido no período $t$ mais o que estava em estoque no final do período $t$ - 1 deve ser igual à demanda do período $t$ mais o que ficará em estoque no período $t$. As restrições (2.3) implicam que um item só pode ser produzido se for considerada sua preparação. As restrições (2.4) e (2.5) representam o domínio e as condições de não-negatividade das variáveis.

\subsection{PDL com restrições de capacidade}

Muitos dos problemas estudados na literatura apresentam algum tipo de limitação quanto à capacidade de produção, seja quanto à mão-de-obra disponível, seja quanto ao tempo de produção de cada máquina, entre outras possibilidades. Este conjunto de restrições é definido na literatura como restrições de capacidade (capacity constraints). O PDL com restrições de capacidade (também conhecido como PDLC) representa um grupo significativo de problemas reais e por isso vem sendo muito estudado nas últimas décadas. Boas revisões 
podem ser encontradas em Karimi et al. (2003), Drexl e Kimms (1997) e Bahl et al. (1987). Este problema, como discutido no Capítulo 1, é de difícil solução (Bitran e Yanasse, 1992).

O problema com restrições de capacidade é uma extensão do PDL da seção anterior, no entanto, quando a capacidade de produção é limitada, os vários itens que serão produzidos disputam os mesmos recursos e o problema não pode ser resolvido independentemente para cada um dos itens. Este problema pode ser modelado como apresentado no Modelo 2, cujos parâmetros e variáveis são:

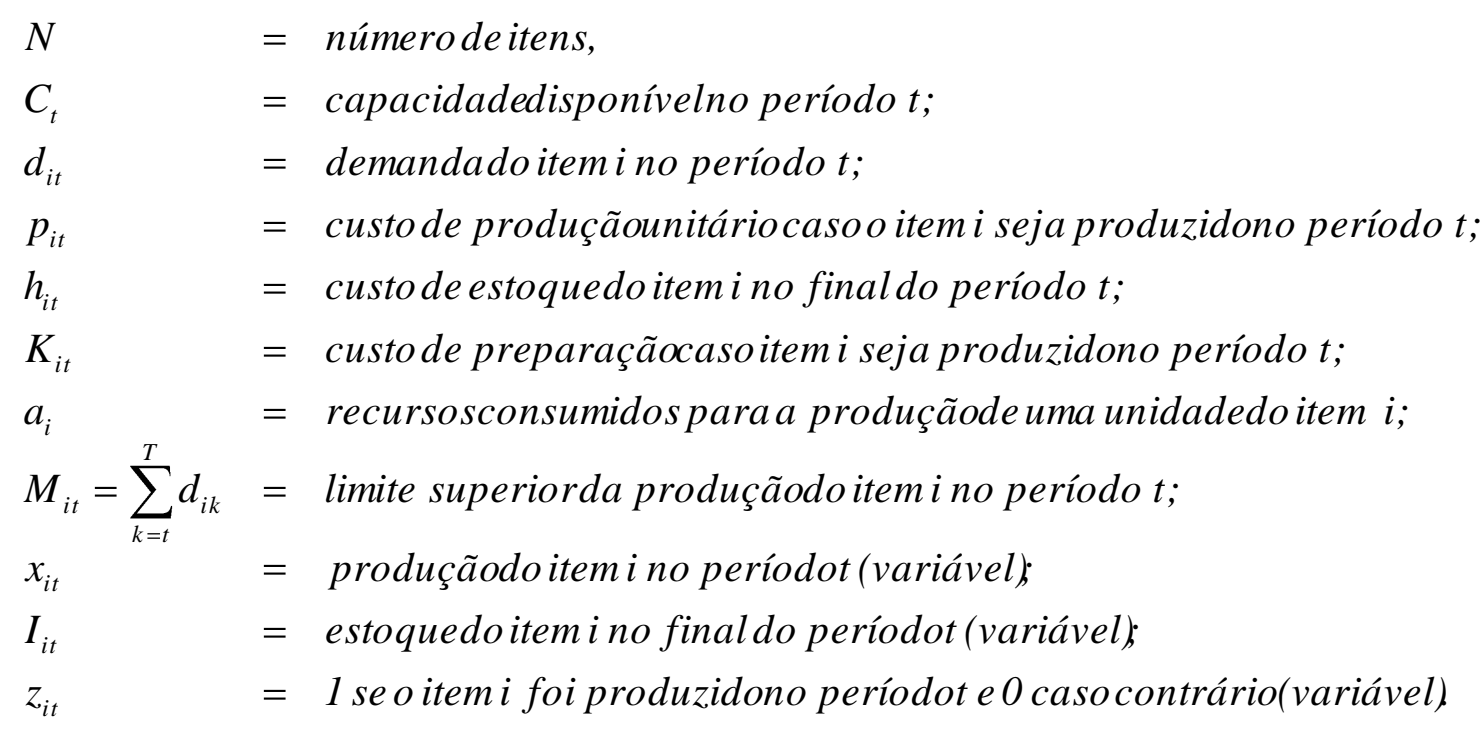

\section{Modelo 2.}

$$
\begin{array}{lll}
\text { Min } & \sum_{i=1}^{N} \sum_{t=1}^{T}\left(K_{i t} z_{i t}+p_{i t} x_{i t}+h_{i t} I_{i t}\right) & \\
\text { s.a: } & x_{i t}+I_{i t-1}=d_{i t}+I_{i t} & t=1 \ldots T \\
& x_{i t} \leq M_{i t} z_{i t} & t=1 \ldots T, i=1 \ldots N \\
& \sum_{i=1}^{N} a_{i} x_{i t} \leq C_{t} & t=1 \ldots T \\
& z_{i t} \in\{0,1\} & t=1 \ldots T, i=1 \ldots N \\
& x_{i t}, I_{i t} \geq 0 & t=1 \ldots T, i=1 \ldots N
\end{array}
$$

A função objetivo (2.6) e as restrições (2.7) e (2.8) equivalem, respectivamente, a (2.1), (2.2) e (2.3) do modelo anterior, porém contendo o índice $i$ associado às variáveis, indicando múltiplos itens. As restrições (2.9) foram adicionadas para representar a limitação 
de capacidade disponível em cada período. As restrições (2.10) e (2.11) representam o domínio e as condições de não-negatividade das variáveis.

Outra questão relevante para o PDLC é que a preparação para produção pode, além de gerar custos adicionais, incorrer em tempos de preparação para a produção de cada um dos itens. Como discutido anteriormente, o PDLC que considera os tempos de preparação das máquinas é um problema NP-Completo (Maes et al., 1991). Esta característica é facilmente incorporada ao modelo substituindo-se as restrições (2.9) pelo seguinte conjunto de restrições:

$$
\sum_{i=1}^{N}\left(a_{i} x_{i t}+q_{i t} z_{i t} \leq C_{t}\right) \quad t=1, \ldots, T
$$

em que:

$q_{i t}=$ tempo de preparação para a produção do item $i$ no período $t$.

\subsection{PDL com preservação de preparação}

Existe um ponto importante a ser observado no que diz respeito à produção. Se um item $i$ é produzido no final de um período $t$ - 1 e este mesmo item é o primeiro item a ser produzido no período $t$, é interessante considerar a possibilidade de preservar a preparação do item $i$ para o período $t$, economizando, portanto, o tempo e o custo de preparação. Este procedimento é conhecido na literatura como preservação de preparação (set-up carry-over).

Em Gopalakrishnan et al. (1995), os autores estudam o problema de uma indústria de produção de papel, onde o tempo de preparação para realizar uma troca de famílias é de 36 horas, ou seja, muito significativo. Os autores afirmam que muitos problemas deste tipo não possuem planejamentos que apresentem soluções factíveis caso não seja considerada a preservação de preparação. Destaca-se, no entanto, que existem situações práticas em que a preservação de preparação não é aplicável como, por exemplo, numa fundição em que o forno deve ser aquecido para iniciar o processo de fusão da liga, neste caso não é viável preservar o forno aquecido de um dia para o outro.

O problema estudado pelos autores tem restrições de capacidade e o modelo proposto considera a possibilidade de preservar a preparação do último item produzido no período $t-1$ caso este seja o primeiro item a ser produzido no período $t$. O modelo proposto pelos autores é descrito a seguir, em que: 
$\alpha_{i t}=1$ casoo item i sejao primeiro a ser produzidono períodot e o casocontrário;

$\beta_{i t}=1$ casoo item i sejao último a ser produzidono períodot e 0 casocontrário;

- 1 caso a máquinaesteja preparadapara a produçãodo item i no final do períodot

$\gamma_{i t}=$ eOcasocontrário;

$S_{i t}=1$ caso $\gamma_{i, t-1}=1$ e $\alpha_{i t}=0$, e 0 casocontrário;

$V_{i t}=1$ caso $\beta_{i t}=1$ e $\gamma_{i t}=0$, e 0 casocontrário;

$O_{i t}=1$ casoo períodoociosot sejautilizado para prepararo item i e O casocontrário,

$\omega_{t}=1$ casoocorra produçãode ao menos um item no períodot,

$\delta_{t}=$ Ocaso seja produzidoexatamenteumitem no períodot e $\geq 0$ casocontrário.

$N_{t}=$ quantidadede preparações no períodot,

$F_{t}=$ custo fixo quandoumitemé produzidono períodot,

$q=$ tempo de preparaçãoconstante,independente do item. 


\section{Modelo 3.}

$$
\begin{aligned}
& \operatorname{Min} \sum_{i} \sum_{t} h_{i t} I_{i t}+F_{t} \sum_{t} N_{t}+\sum_{i} \sum_{t} K_{t} z_{i t} \\
& \text { s.a: (2.7);(2.8);(2.10);(2.11); } \\
& \sum_{i} a_{i} x_{i t}+q N_{t} \leq C_{t} \quad t=1 \ldots T \text {; } \\
& N_{t}=\sum_{i} z_{i t}+\sum_{i} S_{i t}+\sum_{i} V_{i t}+\sum_{i} O_{i t}-1 \quad t=1 \ldots T ; \\
& S_{i t} \geq \gamma_{i, t-1}-\alpha_{i t} \quad i=1 \ldots N, t=1 \ldots T \text {; } \\
& V_{i t} \geq \beta_{i t}-\gamma_{i t} \quad i=1 \ldots N, t=1 \ldots T \text {; } \\
& O_{i t} \geq \gamma_{i t}-\gamma_{i, t-1}-\omega_{t} \quad i=1 \ldots N, t=1 \ldots T \text {; } \\
& z_{i t} \leq \omega_{t} \quad i=1 \ldots N, t=1 \ldots T \text {; } \\
& \sum_{i} z_{i t}-1 \leq(P-1) \delta_{t} \quad t=1 \ldots T \text {; } \\
& \omega_{t} \leq \sum_{i} \alpha_{i t} \leq 1 \quad t=1 \ldots T \text {; } \\
& \omega_{t} \leq \sum_{i} \beta_{i t} \leq 1 \quad t=1 \ldots T \\
& \alpha_{i t} \leq z_{i t} \\
& i=1 \ldots N, t=1 \ldots T \\
& \beta_{i t} \leq z_{i t} \\
& i=1 \ldots N, t=1 \ldots T \text {; } \\
& \alpha_{i t}+\beta_{i t} \leq 2-\delta_{t} \quad i=1 \ldots N, t=1 \ldots T \text {; } \\
& \sum_{i} \gamma_{i t}=1 \\
& V_{i t}, O_{i t} \geq 0 \\
& t=1 \ldots T \text {; } \\
& 0 \leq \delta_{t} \leq 1 \\
& i=1 \ldots N, t=1 \ldots T \text {; } \\
& t=1 \ldots T \text {; } \\
& N_{t}, \omega_{t} \geq 0 \\
& t=1 \ldots T \text {; } \\
& S_{i t}, \alpha_{i t}, \beta_{i t}, \gamma_{i t} \in\{0,1\}
\end{aligned}
$$

A função objetivo (2.17) visa minimizar a soma dos custos de preparação e de estoque e, também, do custo fixo referente ao número total de preparações que ocorrem no horizonte de planejamento. As restrições (2.7), (2.8), (2.10) e (2.11) são as mesmas do modelo anterior. As restrições (2.18) garantem que a capacidade de produção seja respeitada. As restrições em (2.19) contabilizam a quantidade total de preparações ocorridas em cada período. O total inclui as preparações do primeiro e do último item do período $\left(S_{i t}\right.$ e $V_{i t}$, respectivamente) e de quaisquer itens produzidos durante o período $\left(z_{i t}\right)$, assim como as preparações feitas em tempo ocioso $\left(O_{i t}\right)$. Em (2.20) as restrições indicam se existirá ou não preservação de preparação no período $t$. Quando a preservação ocorre, a variável $S_{i t}$ assume o valor 0 . Em (2.21), $V_{i t}$ assume o valor 1 apenas quando há a necessidade de realizar uma preparação no final do período. Nas 
restrições (2.22), se não existe preparação no período atual $\left(\gamma_{i t}\right)$, não houve preservação de preparação do período anterior $\left(\gamma_{i t-1}\right)$ e nenhum item foi produzido $\left(\omega_{t}=0\right)$, significa que o período é ocioso e pode ser utilizado para preparar um item para o próximo período. Isto é representado quando a variável $O_{i t}$ assume o valor 1 . As restrições (2.23) e (2.24) indicam que só vai existir preparação de um produto caso haja a produção de ao menos 1 item no período. Nas restrições (2.24) a variável P (um número inteiro grande) representa um limite superior da produção de itens. As restrições (2.25) indicam que apenas um item pode produzido primeiro e (2.26) indicam que apenas um pode ser produzido por último. As restrições (2.27) e (2.28) forçam o valor de $\alpha_{i t}$ e $\beta_{i t}$ serem iguais a 0 , caso não haja produção durante o período. Restrições (2.29) indicam que se apenas um item foi produzido no período, tanto $\alpha_{i t}$ quanto $\beta_{i t}$ são iguais a 1 (forçando $\delta_{t}=0$ ). Caso ocorra a produção de mais de um item no mesmo período, então $\alpha_{i t} \neq \beta_{i t}$, e, portanto, $\delta_{t} \geq 0$. As restrições (2.30) determinam que a máquina só poderá estar preparada para a produção de um único item no fím de um período. As restrições (2.31)-(2.34) garantem as condições de não-negatividade e domínio das variáveis.

Os autores também propõem uma modelagem abrangendo múltiplas máquinas, nas quais múltiplas famílias de itens são produzidas. Nesta situação, é possível a produção de múltiplos itens dentro de uma família em um mesmo período. Itens que pertencem à mesma família compartilham a mesma preparação; o tempo de preparação para os itens de uma mesma família não consome tempo significativo e, portanto, é ignorado. Para se produzir um item, é necessário usar uma ferramenta específica para cada item pertencente a uma família em uma máquina. Uma vez selecionada, a ferramenta fica fixa à máquina. Como este trabalho se restringe a uma máquina apenas, optou-se por não apresentar tal modelo.

Em Gopalakrishnan (2000), o autor propôs uma modificação do modelo proposto em Gopalakrishnan et al. (1995), de forma a abranger a produção de itens considerando preparações dependentes dos itens $\left(q_{i}\right)$. O novo modelo, que utiliza as mesmas variáveis do modelo anterior, é apresentado a seguir: 


\section{Modelo 4}

$$
\begin{array}{lll}
\text { Min } & \sum_{i} \sum_{t} h_{i t} I_{i t}+\sum_{i} \sum_{t} F_{i} N_{i t}+\sum_{i} \sum_{t} K_{t} z_{i t} & \\
\text { s.a: } & (2.7) ;(2.8) ;(2.24)-(2.30) ;(2.32) ;(2.34) & \\
& \sum_{i}\left(a_{i} x_{i t}+q_{i} N_{i t}\right) \leq C_{t} & t=1 \ldots T \\
& N_{i t}=z_{i t}-S_{i t}+V_{i t} & i=1 \ldots N, t=1 \ldots T \\
2 S_{i t} \geq \gamma_{i t-1}-\alpha_{i t} & i=1 \ldots N, t=1 \ldots T \\
V_{i t} \geq \gamma_{i t}-\beta_{i t} & i=1 \ldots N, t=1 \ldots T \\
V_{i t}, N_{i t} \geq 0 & i=1 \ldots N, t=1 \ldots T \\
& \alpha_{i t}, \beta_{i t}, \gamma_{i t}, S_{i t} \in\{0,1\} & i=1 \ldots N, t=1 \ldots T \\
\omega_{t} \geq 0 & t=1 \ldots T
\end{array}
$$

Este modelo é muito semelhante ao anterior, as modificações se encontram na função objetivo (2.35) e nas restrições (2.36), (2.37), (2.38) e (2.39). A função objetivo visa minimizar a somatória dos custos de estoque, custos de preparação e custos fixos de produção. As restrições (2.36) foram modificadas e agora possuem um índice especifico para o tempo de preparação de cada item. As restrições (2.37) representam a preservação de preparação para um item em um período em função do período anterior. As restrições (2.38) contabilizam o número de preparações de cada item em cada período, enquanto (2.39) indica a preparação no fim do período comparando o estado da máquina e o último item produzido em um período. As restrições (2.40)-(2.42) asseguram as condições de não-negatividade e o domínio das variáveis.

As modificações tornaram o novo modelo mais estruturado, uma vez que o autor remodelou as variáveis $N_{i t}, S_{i t}$ e $V_{i t}$ de forma a acomodar preparações dependentes dos itens e dos custos de preparação. Em Gopalakrishnan et al. (2001) os autores apresentaram um método para resolver o problema proposto em Gopalakrishnan et al. (1995). O método consiste em uma busca tabu, chamada TABU-CLSPSC.

Sox e Gao (1999) propuseram um modelo com duas vezes menos variáveis que o modelo proposto em Gopalakrishnan et al. (1995) para o PDLC com preservação de preparação. O modelo proposto é apresentado a seguir. Além das variáveis descritas anteriormente, para este modelo, os autores definem:

$\zeta_{i t}=1$ caso a preparação do item $i$ seja preservada do período $t-1$ para o período $t$ e 0 caso contrário.

\section{Modelo 5}




$$
\begin{aligned}
& \operatorname{Min} \sum_{i=1}^{N} \sum_{t=1}^{T}\left(h_{i t} I_{i t}+p_{i t} x_{i t}+K_{i t} z_{i t}\right) \\
& \text { s.a: } \quad(2.7) ;(2.9)-(2.11) \\
& x_{i t} \leq M\left(z_{i t}+\zeta_{i t}\right) \quad i=1 \ldots N, t=1 \ldots T ; \\
& \sum_{i=1}^{N} \zeta_{i t}=1 \quad t=2 \ldots T \\
& \zeta_{i t}-z_{i t}-\zeta_{i t-1} \leq 0 \quad i=1 \ldots N, t=2 \ldots T \text {; } \\
& \zeta_{i t}+z_{j t-1}+\zeta_{i t-1} \leq 2 \quad i=1 \ldots N, t=2 \ldots T \text { e } j \neq i \\
& \zeta_{i t} \in\{0,1\} \\
& i=1 \ldots N, t=1 \ldots T \text {; }
\end{aligned}
$$

As restrições (2.43) garantem que só há a produção de um produto em um período caso exista preparação neste período ou caso a preparação tenha sido preservada do período anterior. As restrições (2.44) asseguram que apenas uma preparação seja preservada por período. Em (2.45) é imposto que para um dado período $t$ e um item $i$, uma preparação só pode ser preservada caso no período anterior $t$ - 1 tenha ocorrido preparação para a produção do item $i$ ou, se no período $t$ - 1, somente o item $i$ foi produzido e a preparação foi preservada do período $t$ - 2. As restrições (2.46) estabelecem a sincronia caso uma mesma preparação seja preservada por mais de um período. As restrições (2.47) definem o domínio das variáveis de preservação de preparação.

Os autores discutem adaptações do modelo para outros tipos de PDL, tais como o problema em que apenas um item pode ser produzido por período. Como para o problema estudado vários itens podem ser produzidos em cada período, optou-se por não incluir tais modelos neste capítulo.

Além da modelagem, os autores propuseram uma reformulação do modelo, utilizando grafos. A partir desta reformulação, propuseram um método para resolver o problema baseado em programação dinâmica e em uma heurística de decomposição utilizando relaxação lagrangiana.

Briskorn (2005) propõe uma revisão do modelo de Sox e Gao (1999). O autor destaca que a preservação da preparação é uma possibilidade e não uma obrigatoriedade, logo as restrições (2.44) devem ser reescritas como:

$$
\sum_{i=1}^{N} \zeta_{i t} \leq 1 \quad t=2, \ldots T
$$

O autor também destaca que quando Sox e Gao (1999) aplicam relaxação lagrangiana ao modelo para solução do problema, os subproblemas gerados são resolvidos utilizando o 
algoritmo de Wagner e Whitin (1958). No entanto, como a preservação da preparação é permitida, as soluções ótimas geradas, na verdade, podem não ser ótimas. O autor propõe um novo algoritmo de programação dinâmica para a solução dos subproblemas.

Porkka et al. (2003) também apresentam uma modelagem alternativa para o PDLC com preservação de preparação. Os autores argumentam que, em casos onde o tempo de preparação é muito grande em relação ao tamanho dos períodos, a modelagem com preservação de preparação apresenta resultados significativamente melhores quando comparada ao modelo sem preservação. A modelagem é dada pelo Modelo 6, em que:

$\mathrm{c}=$ custo por unidade de capacidade utilizada.

\section{Modelo 6.}

$$
\begin{array}{lll}
\text { Min } & \sum_{t=1}^{T} \sum_{i=1}^{N}\left[c\left(p_{i} x_{i t}+q_{i} z_{i t}\right)+h_{i t} I_{i t}\right] & \\
\text { s.a: } & (2.7) ;(2.10) ;(2.11) ;(2.43) ;(2.45)-(2.47) & \\
& \sum_{i}\left(a_{i} x_{i t}+q_{i} z_{i t}\right) \leq C_{t} & t=1 \ldots T \\
& \sum_{i=1}^{N} \zeta_{i t} \leq 1 & t=1 \ldots T .
\end{array}
$$

O modelo apresentado é semelhante ao apresentado em Sox e Gao (1999), com algumas diferenças. A função objetivo (2.48) minimiza a soma dos custos de estoque, de produção e de preparação, levando em conta o custo da capacidade utilizada.

Outra modelagem do PDLC com preservação de preparação também pode ser encontrada em Suerie et al. (2003). Os autores inserem no modelo várias desigualdades válidas, de forma a torná-lo mais apertado. Para resolver o problema, os autores propõem alguns métodos exatos, como o cut-and-branch e o branch-and-cut, sendo o último mais eficiente. Também é proposta uma heurística de decomposição para resolução do problema.

Em Karimi et al. (2005), os autores apresentam uma modelagem do PDLC com preservação de preparação e atraso na demanda. Neste modelo, o tempo de preparação não é considerado, são contabilizados apenas os custos de preparação, de produção, de estoque e de atraso. A modelagem é apresentada no Modelo 7, em que:

$I^{+}{ }_{i t}=$ estoque do item $i$ no final do período $t$ (variável); 
$I^{-}{ }_{i t}=$ quantidade atrasada da demanda do item $i$ no final do período $i$ (variável).

\section{Modelo 7.}

$$
\begin{aligned}
& \operatorname{Min} \sum_{i=1}^{N} \sum_{t=1}^{T}\left(h_{i t} I^{+}{ }_{i t}+B_{i t} I^{-}{ }_{i t}+p_{i t} x_{i t}+K_{i t} z_{i t}\right) \\
& \text { s.a }: \quad(2.9)-(2.10) ;(2.43)-(2.47) \\
& I^{+}{ }_{i, t-1}-I^{-}{ }_{i, t-1}+x_{i t}-I^{+}{ }_{i t}+I^{-}{ }_{i t}=d_{i t} \quad i=1 \ldots N, t=1 \ldots T ; \\
& I^{+}{ }_{i t}, I^{-}{ }_{i t} \geq 0 \quad i=1 \ldots N, t=1 \ldots T \text {; } \\
& \zeta_{i 1}=0 \\
& i=1 \ldots N \text {. } \\
& I^{-}{ }_{i 0}=I^{+}{ }_{i 0}=I^{+}{ }_{i T}=I^{-}{ }_{i T}=0 \quad i=1 \ldots N .
\end{aligned}
$$

A função objetivo (2.51) busca minimizar a soma dos custos de preparação, de produção, de estoque e de atraso. As restrições (2.52) representam o balanço de estoque. As restrições (2.53) definem as condições de não-negatividade das variáveis de estoque e atraso, enquanto as restrições (2.54a) e (2.54b) representam o estado inicial e final das variáveis.

O modelo utilizado nos testes realizados neste trabalho inclui as correções propostas em Briskorn (2005), substituindo o conjunto de restrições $\sum_{i=1}^{N} \zeta_{i t}=1$ por $\sum_{i=1}^{N} \zeta_{i t} \leq 1$.

\subsection{PDL com set-up crossover}

Existem outras possibilidades que podem ser consideradas ao modelar o problema de dimensionamento de lotes com restrição de capacidade. Em Sung e Maravelias (2008), os autores apresentaram um modelo para o PDLC que inclui: a possibilidade de atraso ao atender a demanda e a possibilidade de preservação de preparação. O modelo inclui custos e tempos de preparação. Os autores consideraram também a possibilidade de existir tempos de preparação que excedem um período. São definidas então duas novas características ao PDLC para representar estas situações. Os autores definem set-up crossover quando o tempo de preparação começa em um período e termina no período seguinte. Nota-se que no set-up crossover, o tempo necessário para a preparação para a produção não excede um período, logo ela poderia ser realizada num único período sem dificuldades, caso exista um rearranjo de atividades. Outra característica é o overlapping. Para problemas com overlapping, o tempo necessário para preparar uma determinada máquina pode exceder um ou mais períodos. Para tratar estes casos, os autores propõem uma mudança nos períodos de tempo, fazendo com que 
as preparações sempre acabem no mesmo período em que começam. Estas duas características são ilustradas na Figura 2.4.

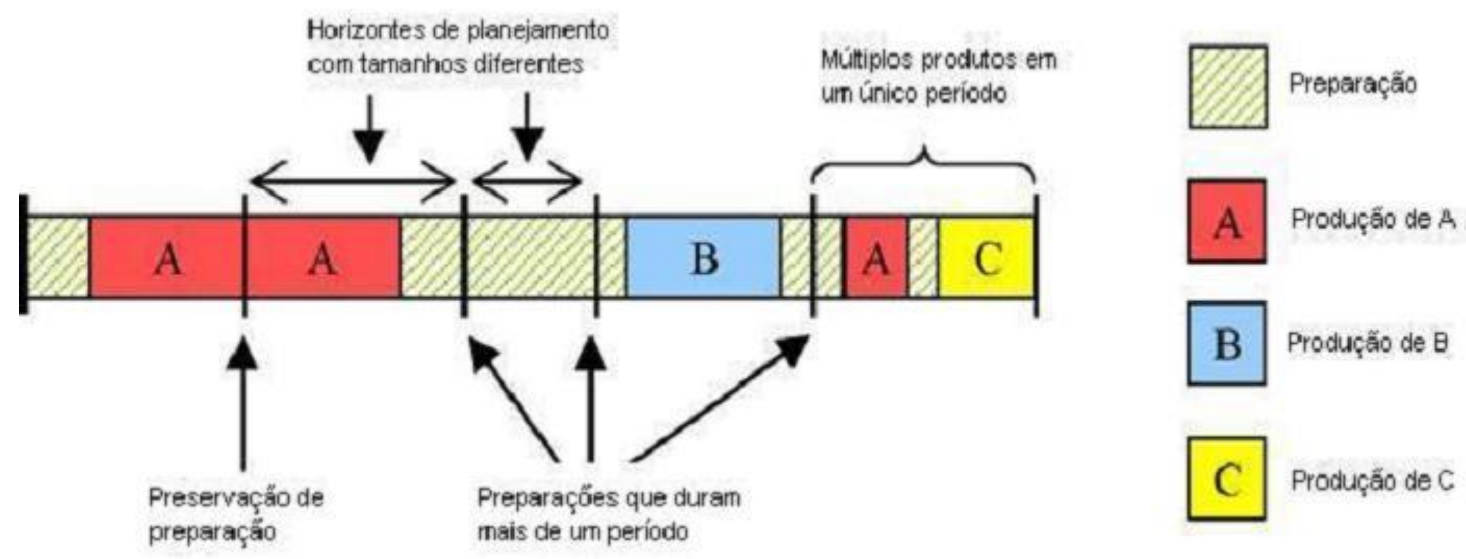

Figura 2.4 - Casos que são abordados pelo modelo proposto em Sung e Maravelias, 2008.

(Adaptado da fonte: Sung e Maravelias, 2008).

A idéia da mudança no período de tempo é permitir que uma preparação que comece no período $t$ e termine no período $t+1$ (cross-over) passe a começar e terminar no período $t$. Para tratar estas situações, os autores definem uma representação do "período de tempo modificado", onde o comprimento de um período de tempo é modificado. Desta forma, seria possível acomodar em $t$ a preparação que seria prolongada até $t+1$. A parte que seria usada para a preparação do item em $t+1$ é transferida para o período $t$, reduzindo-se o comprimento do período $t+1$ e ampliando o comprimento do período $t$.

É possível notar que no modelo que permita a modificação do tamanho dos períodos, as soluções de um modelo com períodos "normais" são factíveis, porém este modelo possibilita o tratamento da preservação de preparação e do atravessamento de preparação de forma efetiva.

O modelo também permite que um item seja produzido mais de uma vez no mesmo período. Isto caracteriza o que os autores chamam de modo RP (return-product).

Com relação à modelagem, primeiramente foi proposto um modelo de produção de múltiplos itens contendo apenas preparações curtas (que não ultrapassam um período). $\mathrm{O}$ modelo completo, assim como os índices, parâmetros e variáveis, são definidos a seguir: 
$T S C_{t}=$ custototal de preparaçãocomeçandono períodot.

$T S T_{t}=$ tempo total de preparaçãocomeçandono períodot.

Idle $t_{t}=$ tempo no períodot em quenãoocorre produção(tempo ocioso).

Late $_{t}=$ comprimento em queo finaldo períodot é atrasado.

$\delta \quad=$ número positivo pequeno.

$G_{t} \quad=$ comprimento do períodot.

$\alpha_{i t}=$ número de preparaçõ $\mathrm{s}$ do itemi que começamno períodot.

$y_{i t}=1$ casoo períodot estejaoperandoem modo return producte 0 caso contrário.

$\beta_{i t}=1$ casoi sejao estado final do períodot.

\section{Modelo 8.}

$$
\begin{aligned}
& \min \sum_{i, t} h_{i} I_{i t}+\sum_{t} T S C_{t} \\
& \text { s.a : (2.7);(2.10);(2.11);(2.47) } \\
& \sum_{i} \beta_{i t}=1 \\
& \beta_{i t-1} \leq z_{i t} \\
& \beta_{i t} \leq z_{i t} \\
& y_{i t} \leq \beta_{i t-1} \\
& y_{i t} \leq \beta_{i t} \\
& y_{i t} \leq \sum_{i^{\prime} \neq i} z_{i^{\prime} t} \\
& y_{i t} \geq \beta_{i t-1}+\beta_{i t}+z_{i^{\prime} t}-z_{i t}-1 \\
& \alpha_{i t}=z_{i t}-\beta_{i t-1}+y_{i t} \\
& \text { TSC }_{t}=\sum_{i} K_{i} \alpha_{i t} \\
& T S T_{t}=\sum_{i}^{i} s_{i} \alpha_{i t} \\
& t=1 \ldots T \text {; } \\
& i=1 \ldots N, t=1 \ldots T \text {; } \\
& i=1 \ldots N, t=1 \ldots T \\
& i=1 \ldots N, t=1 \ldots T \\
& i=1 \ldots N, t=1 \ldots T \\
& i=1 \ldots N, t=1 \ldots T \\
& i=1 \ldots N, i^{\prime}=1 \ldots T, \forall i, i^{\prime} \neq i, t \\
& i=1 \ldots N, t=1 \ldots T \\
& t=1 \ldots T \text {; } \\
& t=1 \ldots T \\
& \sum_{i} \frac{x_{i t}}{r_{i}}+\text { TST }_{t}+\text { Idle }_{t}=G_{t}-\text { Late }_{t-1}+\text { Late }_{t} \quad t=1 \ldots T ; \\
& \text { Late }_{t} \leq \sum_{i}\left(s_{i}-\delta\right) \varsigma_{i t} \\
& t=1 \ldots T \text {; } \\
& \varsigma_{i t} \leq \beta_{i t} \\
& i=1 \ldots N, t=1 \ldots T \text {; } \\
& \varsigma_{i t} \leq \alpha_{i t} \\
& i=1 \ldots N, t=1 \ldots T \mid s_{i} \leq G_{t} ; \\
& y_{i t} \leq \varsigma_{i t} \\
& \frac{x_{i t}}{r_{i}} \leq\left(z_{i t}-\varsigma_{i t}+y_{i t}\right) G_{t} \\
& i=1 \ldots N, t=1 \ldots T \text {; } \\
& i=1 \ldots N, t=1 \ldots T ; \\
& \beta_{i t=T}=0 \\
& i=1 \ldots N, t=1 \ldots T \\
& \text { Idle }_{t}, \text { Late }_{t}, T S T_{t}, \geq 0 \\
& t=1 \ldots T \text {; } \\
& \beta_{i t}, y_{i t}, \in\{0,1\} \\
& i=1 \ldots N, t=1 \ldots T \text {; } \\
& t=1 \ldots T \text {. }
\end{aligned}
$$


A função objetivo (2.55) visa minimizar a soma dos custos de estoque e de produção.

$$
\begin{array}{lll}
\sum_{i} \beta_{i t}=1 & \forall t & (2.56) \\
\beta_{i, t-1} \leq z_{i t} & \forall t & (2.57) \\
\beta_{i t} \leq z_{i t} & \forall t & (2.58)
\end{array}
$$

As restrições (2.56), (2.57) e (2.58) realizam o controle de itens por período. O conjunto de restrições (2.56) indicam que, ao final de um período, apenas um estado pode ser o estado final. A variável $z_{i t}=1$ se o estado $i$ é visitado durante o período de tempo modificado $t$. Restrições (2.57) declaram que o estado $i$ foi alcançado no período $t$ se ele for o estado inicial. De forma semelhante, as restrições (2.58) representam que o estado $i$ foi alcançado em $t$ caso ele seja o estado final.

$$
\begin{array}{ll}
y_{i t} \leq \beta_{i, t-1}, & \forall i, t \\
y_{i t} \leq \beta_{i t}, & \forall i, t \\
y_{i t} \leq \sum_{i^{\prime} \neq i} z_{i^{\prime} t}, & \forall i, t \\
y_{i t} \geq \beta_{i, t-1}+\beta_{i t}+z_{i^{\prime} t}-z_{i t}-1, & \forall i, i^{\prime} \neq i, t
\end{array}
$$

As restrições (2.59), (2.60) e (2.61) definem se o modo RP está ou não ativado $\left(y_{i t}=\right.$ 1). A ativação do modo RP se dá quando um item $i$ é produzido no começo e no final do período (restrições (2.59) e (2.60), respectivamente) e, no meio do período, ocorre a produção de um ou mais itens $i$, tal que $i^{\prime} \neq i$, conforme descrito pelas restrições (2.61). Um exemplo das condições de ativação do modo RP é ilustrado na Figura 2.5. Caso estas três condições sejam satisfeitas, o conjunto de restrições (2.62) garante que $y_{i t}$ seja 1.

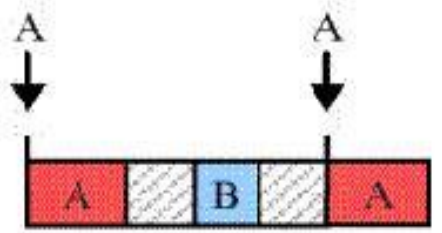

Return Product (RP)

Figura 2.5 - Exemplo de condição em que o modo RP é ativado. (Adaptado da fonte: Sung e Maravelias, 2008). 


$$
\alpha_{i t}=z_{i t}-\beta_{i, t-1}+y_{i t}, \quad \forall i, t
$$

Restrições (2.63) indicam o total de preparações do item $i$ no período $t$. O total é calculado levando em conta o primeiro item $\left(\beta_{i, t-1}\right)$, as preparações que ocorreram durante o período $\left(z_{i t}\right)$ e a variável de RP ( $\left.y_{i t}\right)$, que é utilizada para controlar os casos onde há carryover e modo RP ativados (no caso 2 produções do mesmo item com apenas 1 preparação). A Figura 2.6 ilustra a preservação de preparação de um item em um período para o período seguinte.

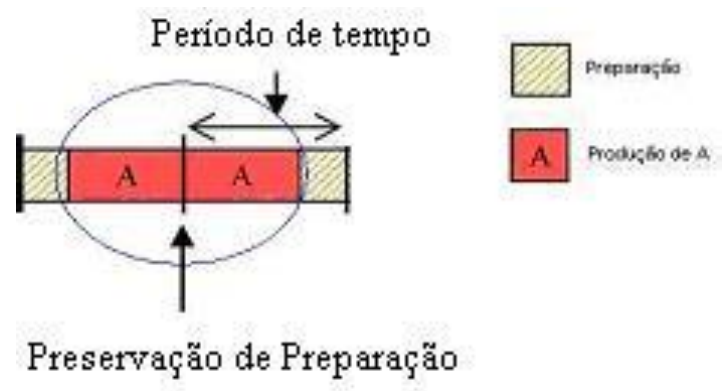

Figura 2.6 - Exemplo de ocorrência do set-up carry-over. (Adaptado da fonte: Sung e Maravelias, 2008).

Restrições (2.64) e (2.65) totalizam o custo total de preparação e o comprimento da preparação, respectivamente, em cada período de tempo modificado.

$$
\begin{array}{ll}
\sum_{i} \frac{x_{i t}}{r_{i}}+\text { TST }_{t}+\text { Idle }_{t}=G_{t}-\text { Late }_{t-1}+\text { Late }_{t}, & \forall t \\
\text { Late }_{t} \leq \sum_{i}\left(s_{i}-\delta\right) \zeta_{i t}, & \forall t \\
\zeta_{i t} \leq \beta_{i t}, & \forall i, t \\
\zeta_{i t} \leq \alpha_{i t}, & \forall i, t \mid s_{i} \leq G_{t} \\
Y_{i t} \leq \zeta_{i t}, & \forall i, t
\end{array}
$$

As restrições (2.66), (2.67), (2.68) e (2.69) controlam os mecanismos de tempo ocioso, tamanhos de período não-uniformes (período de tempo modificado) e set-up crossover. Em (2.66), o tempo de produção, tempo de preparação e de máquina parada são iguais ao comprimento do período de tempo modificado. As restrições (2.67) fazem uma ligação entre o tempo de atraso e um item cuja preparação está continuando. As restrições (2.68) indicam que, se um estado $i$ está sendo preservado do período $t$ para o período $t+1$, este estado é o estado final do período $t$. As restrições (2.69) indicam que uma preparação curta deve começar em $t$ para atravessar o limite de tempo do período $t$ e continuar no período seguinte. Restrições (2.70) indicam que se o período $t$ está em modo RP, então a preparação do estado final deve 
continuar até o período seguinte, fazendo com que $i$ seja o estado inicial do período $t+1$. Uma ilustração do set-up crossover encontra-se na Figura 2.7.
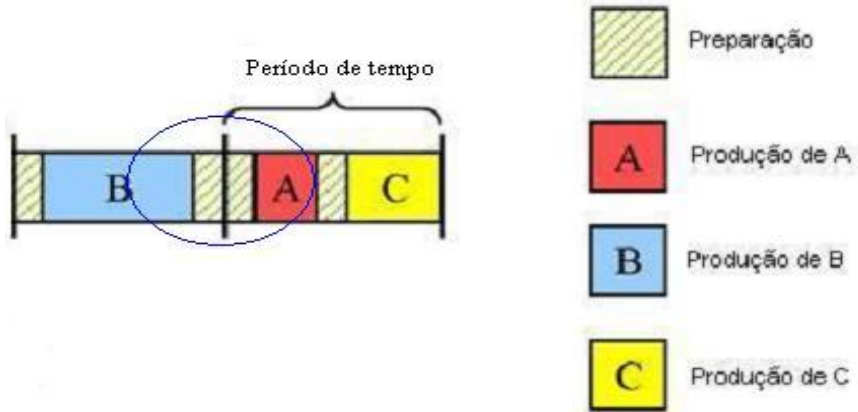

Figura 2.7 - Exemplo de ocorrência do set-up crossover. (Adaptado da fonte: Sung e Maravelias, 2008).

A produção $x_{i t}$ do item $i$ é limitada nas restrições (2.71). Restrições (2.72) impedem que ocorra preparação após o horizonte de planejamento e, por fim, restrições (2.73)-(2.75) representam as condições de não-negatividade e domínio das variáveis.

Uma vez que neste trabalho optou-se por utilizar apenas instâncias em que o tempo de preparação é sempre menor que o tamanho dos períodos, decidiu-se não incluir o modelo que prevê situações onde o tempo de preparação pode ultrapassar o tamanho de um período (overlapping). 


\section{Capítulo 3}

\section{Local branching}

O objeto de pesquisa deste projeto é o problema de dimensionamento de lotes com restrições de capacidade (PDLC). São consideradas neste trabalho variações do problema com relação à possibilidade de preservação de preparação, possibilidade de atraso ao atender a demanda e possibilidade da preparação para a produção iniciar em um período e terminar em outro (set-up crossover). Conforme discutido no Capítulo 2, o PDLC pertence à área de otimização combinatória e é, na maioria das vezes, intratável de maneira exata em situações reais.

Em Fischetti e Lodi (2003), os autores propuseram o uso de uma estratégia genérica para tratar problemas inteiros mistos. Esta estratégia busca explorar as vizinhanças das soluções factíveis obtidas, utilizando para isso a idéia de busca local. Na busca local proposta pelos autores, as vizinhanças são obtidas introduzindo-se diversos cortes no modelo inteiro, chamados local branching cuts.

A fim de facilitar a compreensão do método, considere o seguinte problema de programação inteira mista (PIM):

$$
\begin{array}{lll}
\min & c^{T} x & \\
\text { s.a: } & A x \geq b & \\
& x_{j} \in\{0,1\} & \forall j \in B \neq 0 \\
& x_{j} \geq 0, \text { Inteiro } & \forall j \in G \\
& x_{j} \geq 0 & \forall j \in C
\end{array}
$$

No modelo acima, os índices das variáveis $N=\{1, \ldots, N\}$ são divididos no conjunto $(B, G$ e $C$ ), onde $B$ representa o conjunto de índices das variáveis binárias, $G$ representa o conjunto de índices das variáveis inteiras e $C$ representa o conjunto de índices das variáveis contínuas.

Dada uma solução factível $\bar{x}$, define-se um conjunto $\bar{S}$ chamado de suporte binário de $\bar{x}$, tal que: 


$$
\bar{S}=\{j \in B \mid \bar{x}=1\}
$$

Ou seja, o conjunto $\bar{S}$ contém os índices de todas as variáveis binárias que possuem o valor 1. Também é introduzido um parâmetro $k$, a partir do qual é definida a vizinhança $k$ OPT $N(\bar{x}, k)$ de $\bar{x}$. A função $N(\bar{x}, k)$ representa todas as soluções factíveis do problema que satisfazem a restrição de local branching, dada por:

$$
\Delta(x, \bar{x})=\sum_{j \in \bar{S}}\left(1-x_{j}\right)+\sum_{j \in B \backslash \bar{S}} x_{j} \leq k
$$

$\mathrm{Na}$ restrição (3.6), os termos à esquerda representam as variáveis binárias que terão seus valores trocados de 1 para 0 ou de 0 para 1 , respectivamente, ou seja, o número total de variáveis binárias as quais terão seu valor alterado. Quando esta restrição é acrescentada ao modelo, o espaço de soluções do problema original é reduzido, e pode-se buscar a melhor solução vizinha de $\bar{x}$. Por outro lado, é possível buscar a solução ótima que seja vizinha de $\bar{x}$ na vizinhança complementar a (3.6), definida por:

$$
\Delta(x, \bar{x}) \geq k+1
$$

Utilizando as restrições (3.6) e (3.7), é possível subdividir o espaço de busca por uma solução ótima em dois subproblemas, o primeiro acrescido da restrição (3.6) e o segundo de (3.7), semelhante ao critério de separação do branch-and-bound. Note que os subproblemas são problemas inteiros mistos que podem ser resolvidos por um algoritmo exato (por exemplo: branch-and-bound).

O parâmetro $k$ define o tamanho da vizinhança a ser percorrida na ramificação à esquerda e é um parâmetro importante, pois deve ser escolhido de forma a tornar a vizinhança $N(\bar{x}, k)$ suficientemente grande para conter soluções melhores que a atual, e ao mesmo tempo suficientemente pequena, para que possa ser percorrida em tempo computacional aceitável, ou seja, para que o algoritmo exato consiga encontrar a solução ótima do subproblema. Em seus testes, os autores identificaram que uma boa faixa de valores para $k$ seria um número no intervalo $[10,20]$.

A idéia geral do local branching é a seguinte. Primeiramente, é introduzida no modelo a restrição de local branching (3.6), de forma a definir uma vizinhança. O novo problema é resolvido, na esperança de se encontrar uma solução melhor do que a atual. Caso uma solução inteira de melhor qualidade seja encontrada, ela passa a ser a solução atual, a restrição de local branching é removida e a restrição (3.7) é adicionada ao modelo. Em seguida, a restrição de local branching é novamente adicionada ao modelo, só que desta vez, partindo da nova 
solução. O procedimento é repetido até que seja encontrado um subproblema cuja solução não seja melhor do que a solução atual.

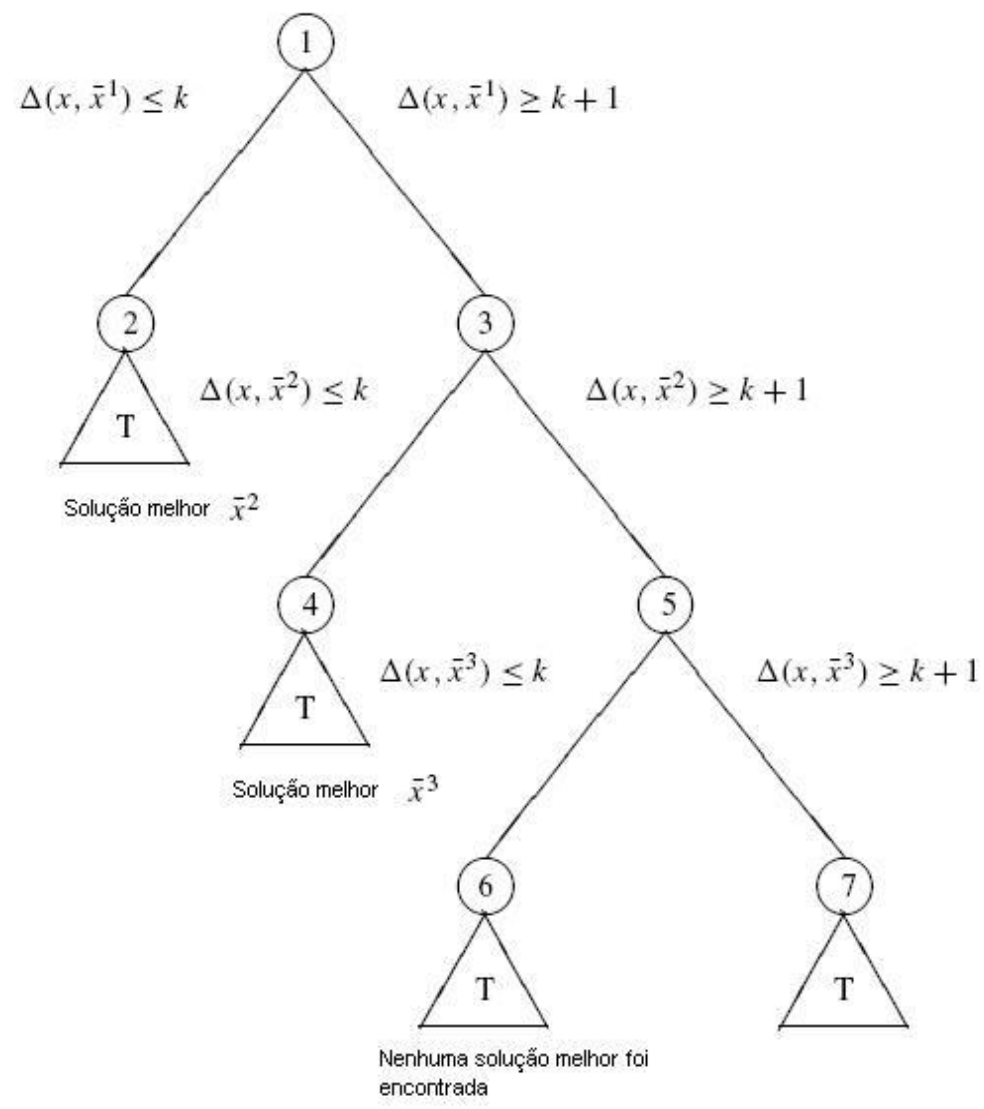

Figura 3.1 - Exemplo do funcionamento do local branching. (Adaptado da fonte: Fischetti e Lodi, 2003).

A Figura 3.1 ilustra um exemplo de aplicação do local branching. Assume-se que o nó inicial é o nó em que $\bar{x}^{1}$ é uma solução factível do problema. O lado esquerdo contendo o nó (2) corresponde a otimização dentro da vizinhança $k-O P T N(\bar{x}, k)$, na qual é obtida uma solução (em tempo computacional aceitável) chamada $\bar{x}^{2}$. Caso esta solução seja melhor do que a atual, $\bar{x}^{2}$ se torna a nova solução. O procedimento é repetido com o nó da direita (3), onde a exploração de $N\left(\bar{x}^{2}, k\right) \backslash N\left(\bar{x}^{1}, k\right)$ no nó (4) produz uma nova solução atual $\bar{x}^{3}$. O nó (5) é então referenciado, o qual corresponde ao problema inicial com as duas restrições adicionais $\Delta\left(x, \bar{x}^{1}\right) \geq k+1$ e $\Delta\left(x, \bar{x}^{2}\right) \geq k+1$. No exemplo, o nó (6) produz um subproblema cuja solução não é melhor do que a solução atual. Nesta situação, a adição da constante $\Delta\left(x, \bar{x}^{3}\right) \geq k+1$ leva ao nó (7), da direita. 
O local branching é um método exato. Porém, o custo computacional pode ser muito alto uma vez que os subproblemas são problemas inteiros mistos que nem sempre são facilmente resolvidos. Este fato pode tornar o método inviável. Logo, Fischetti e Lodi (2003) propuseram algumas modificações para o método, tais como impor um limite de tempo nos nós da esquerda ou aplicar mecanismos de diversificação. Com estas modificações o local branching passa a se comportar como uma heurística, melhorando cada vez mais a solução atual e tentando se aproximar do valor ótimo.

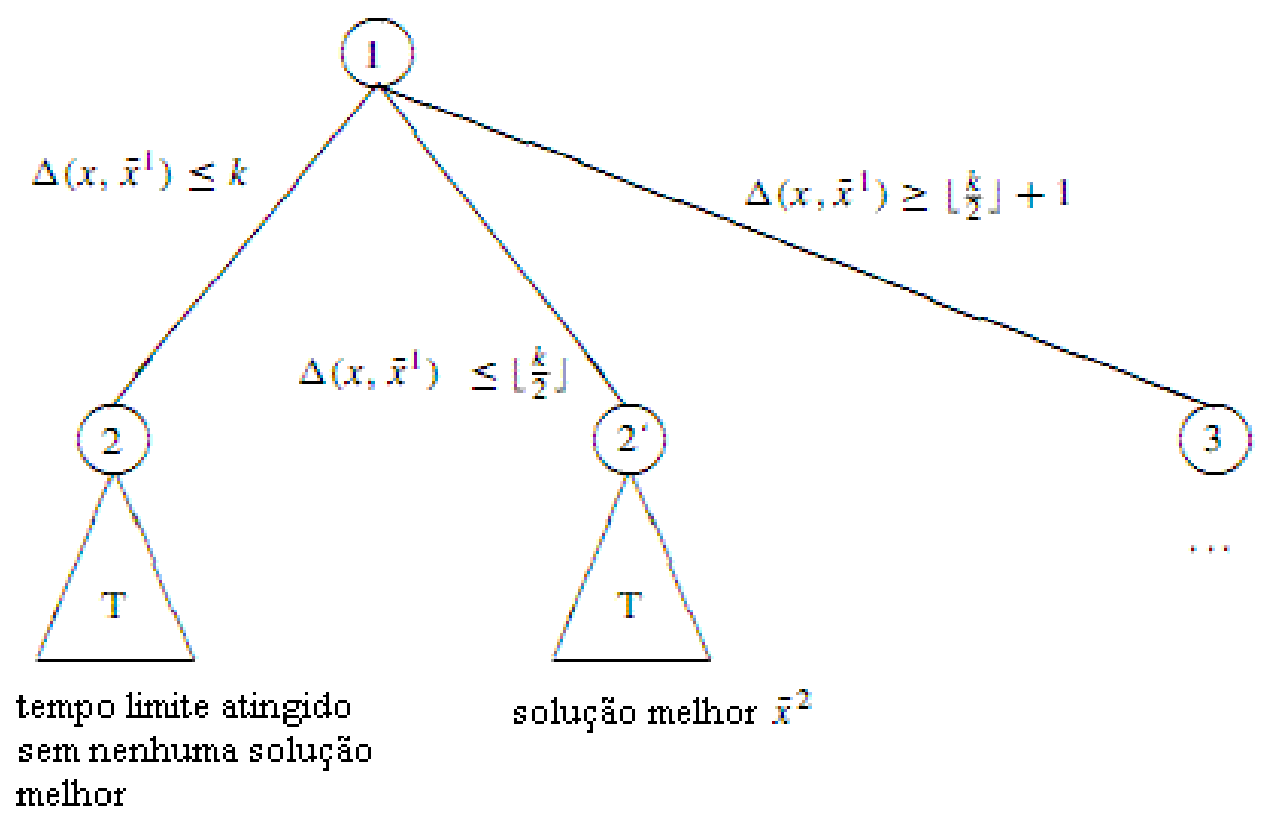

Figura 3.2 - Limite de tempo nos nós: caso 1. (Adaptado da fonte: Fischetti e Lodi, 2003).

Considerando as modificações propostas pelos autores podemos ter duas situações distintas, apresentadas respectivamente nas Figuras 3.2 e 3.3. Analisando a primeira situação, representada na Figura 3.2, ao chegar ao nó (2) é possível que não seja encontrada nenhuma solução dentro do limite de tempo estabelecido. Isto significa que, apesar de nenhuma solução melhor que a atual ter sido encontrada, ainda é possível que esta solução exista, uma vez que as vizinhanças não foram totalmente exploradas. Para evitar que potenciais soluções sejam perdidas, o método realiza novamente a busca no nó (2'), porém com uma redução do $k$ (que passaria a ser: $k / 2$ ). Desta forma, com o tamanho da vizinhança reduzido, o local branching possui uma chance maior de pesquisar todas as soluções da nova vizinhança. Da mesma forma que o tamanho da vizinhança pode ser reduzido (visando uma busca local mais rápida), ele também pode ser aumentado, visando aumentar a diversidade. Isto pode ser feito aumentando o valor do $k$ (que passaria a ser: $2 k$ ). Este aumento na diversidade (que é caracterizado pelos 
autores como "diversificação leve") pode ser interessante sempre que for provado que o nó atual da esquerda não contém soluções melhores.

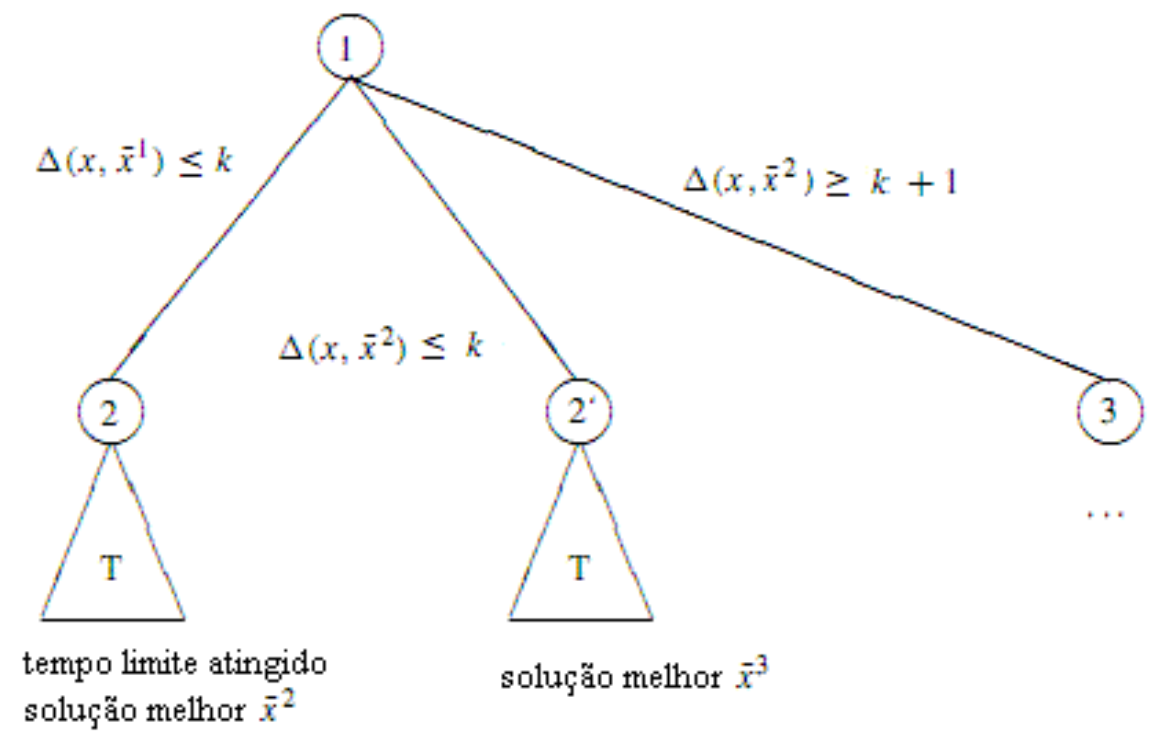

Figura 3.3 - Limite de tempo nos nós: caso 2. (Adaptado da fonte: Fischetti e Lodi, 2003).

A segunda situação que pode ocorrer, ilustrada na Figura 3.3, ocorre quando ao chegar ao nó (2), uma solução melhor $\bar{x}^{2}$ é encontrada, porém o método tem sua execução interrompida devido ao limite de tempo. Quando isto ocorre, a restrição $\Delta\left(x, \bar{x}^{1}\right) \leq k$ é substituída pela restrição $\Delta\left(x, \bar{x}^{2}\right) \leq k$ e o método volta a buscar a solução ótima no nó (2'). Caso todas as vizinhanças do nó (2') sejam pesquisadas dentro do limite de tempo, o método segue normalmente, com a melhor solução encontrada (no caso, $\bar{x}^{3}$ ).

Os autores mostraram que, ao utilizarem o local branching, em 23 dos 29 casos testados (os testes ocorreram em problemas inteiros de diferentes tipos), uma solução melhor foi encontrada em tempo computacional aceitável. Outras aplicações do local branching podem ser vistas em (Fischetti e Lodi, 2006 e Hansen et al. 2006).

\subsection{Local branching para o PDL}

Neste trabalho, o método proposto em Fischetti e Lodi (2003) foi codificado em linguagem $\mathrm{C}++$ utilizando o Concert, que é um conjunto de bibliotecas com funções do software de otimização CPLEX. 
Como descrito na seção anterior, a estratégia local branching está baseada no método branch-and-bound cuja eficiência está diretamente relacionada à obtenção de bons limitantes superiores e inferiores para o problema a ser resolvido. Para o PDLC, como o objetivo é minimizar a soma dos custos, a solução relaxada do problema fornece um limitante inferior e as soluções factíveis encontradas ao longo do processo são limitantes superiores do problema.

Como estratégia para obter a primeira solução factível para local branching e, por conseqüência, o primeiro limitante superior do problema, a proposta aqui apresentada foi obter a melhor solução para o PDLC padrão, ou seja, sem possibilidade de atraso, preservação ou set-up crossover. Nesta primeira etapa, o tempo de execução do CPLEX foi limitado em 50 segundos.

A partir desta solução a estratégia local branching, como proposto por Fischetti e Lodi (2003) é executada. Vale destacar que cada um dos subproblemas gerados é resolvido utilizando o software de otimização CPLEX e que três critérios de parada foram adotados. $O$ primeiro critério de parada é atingido se a solução ótima do subproblema foi encontrada. A segunda condição ocorre quando o problema é infactível. A terceira condição é ativada quando um tempo limite de execução preestabelecido é atingido. $\mathrm{O}$ método adaptado para o problema estudado é resumido pelo algoritmo a seguir. 


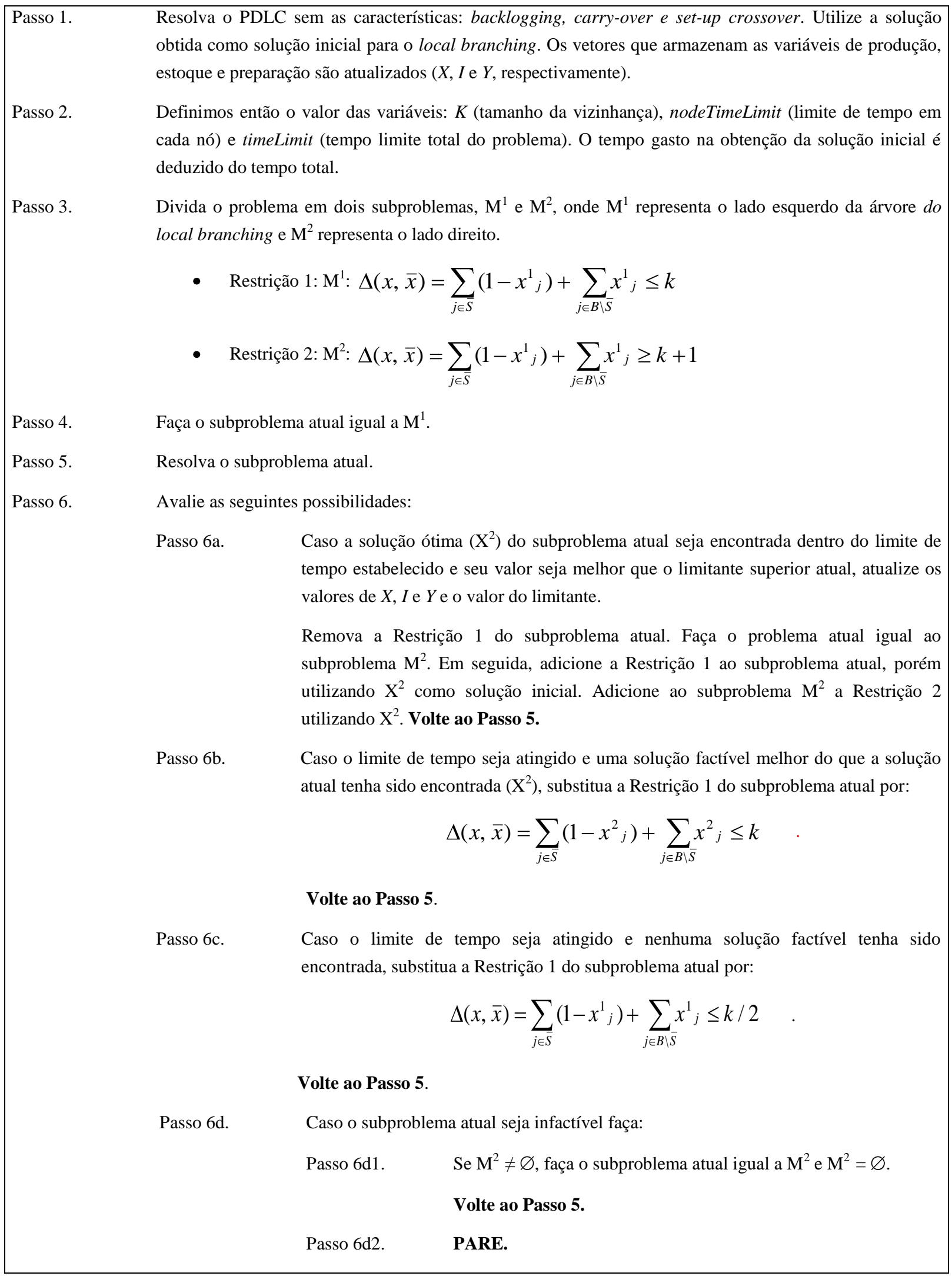


Em resumo, primeiramente, é resolvido o PDLC sem backlogging, carry-over e crossover. Uma vez que este é um problema relativamente fácil de ser resolvido computacionalmente, a solução ótima é obtida. Esta solução é armazenada nas variáveis X, Y e I, onde $\mathrm{X}$ representa o total produzido de cada item ao final de cada período, $\mathrm{Y}$ representa as preparações de cada item em cada período e I representa a quantidade em estoque de cada item no final de cada período. Em seguida, é aplicado o método local branching.

Conforme explicado anteriormente, é necessário definir o valor de alguns dos parâmetros. O parâmetro $K$ foi fixado no valor 13, dentro do intervalo sugerido pelos autores. $\mathrm{O}$ parâmetro nodeTimeLimit representa o tempo limite de cada nó, e foi fixado em 50 segundos. Já o parâmetro timeLimit representa o tempo total do método, e foi fixado em 200 segundos. Quando o valor da variável timeLimit é excedido, o método resolve mais uma vez o problema, atribuindo como solução base a melhor solução encontrada. Desta forma, o tempo máximo de execução de cada problema é fixado em 250 segundos. 


\section{Capítulo 4}

\section{Testes Computacionais}

Neste capítulo são resumidos os testes computacionais realizados para validação das propostas apresentadas. Para realizar os testes, foi desenvolvido um programa em $\mathrm{C}++$ a partir da estratégia local branching proposta em Fischetti e Lodi (2003), que para resolver os problemas inteiros mistos utiliza as bibliotecas do CPLEX 11 (ILOG, 2007). O computador utilizado para testar as instâncias foi um PC Core 2 Duo $2.33 \mathrm{GHz}, 3 \mathrm{~GB}$ de memória RAM e sistema operacional Linux Debian 4.

Como discutido anteriormente, este trabalho tem três objetivos principais. O primeiro consiste em avaliar o desempenho de diferentes configurações do software CPLEX quando utilizado para resolver os PDLC estudados, utilizando para isto os Modelos 7 e 8. O segundo foi avaliar os benefícios da estratégia local branching para resolver os problemas estudados, tanto no CPLEX quando para o programa em $\mathrm{C}++$ especialmente desenvolvido a partir desta estratégia. O terceiro objetivo dos testes foi avaliar o comportamento dos problemas quando são consideradas diferentes características para os problemas de dimensionamento de lotes, tais como possibilidade de atraso na demanda, de preservação de preparação e de set-up crossover.

Os testes foram realizados em quatro diferentes etapas, que foram organizadas e discutidas em subseções específicas. A primeira etapa teve como objetivo mostrar o comportamento do software comercial CPLEX 11 (ILOG, 2007) diante de diferentes configurações, tais como uso de cortes, de heurísticas e, mais especificamente, de local branching, para diferentes problemas de dimensionamento de lotes. Na segunda etapa, os mesmos testes foram realizados para o programa em $\mathrm{C}++$ desenvolvido neste trabalho. No final desta etapa, foram selecionadas a melhor configuração do CPLEX e a melhor configuração do programa em $\mathrm{C}++$. A terceira etapa consiste em analisar o comportamento da estratégia local branching quando uma solução inicial é fornecida como ponto de partida para o problema. Os testes foram realizados para as duas configurações selecionadas no final da primeira fase dos testes. No final desta etapa, foi selecionada a melhor configuração dentre as duas. Na quarta etapa, o objetivo foi verificar a influência na resolução dos problemas de diferentes características do problema de dimensionamento de lotes, tais como a possibilidade 
de atraso na demanda, de preservação de preparação e de set-up crossover. Foram avaliados: valor da função objetivo, tempo computacional e grau de complexidade do problema.

Os testes foram realizados utilizando as instâncias propostas em Trigeiro et al. (1989) com as adaptações necessárias. As instâncias propostas pelos autores estão divididas em cinco grupos: E, W, F, G e X. O número de itens e períodos de cada grupo de instâncias é descrito na Tabela 4.1. Deve-se destacar que as instâncias dos grupos "E" e "W", segundo os autores, têm características diversas e foram criadas para testar a heurística por eles proposta. Os grupos $\mathrm{F}$ e $\mathrm{G}$ contém instâncias mais complexas do que os do grupo $\mathrm{EW}$, sendo cinco das instâncias do grupo $\mathrm{G}$ de difícil resolução. Os problemas do grupo $\mathrm{X}$ são os mais difíceis dentre as instâncias testadas. Neste trabalho, por questões de tempo de execução, em algumas circunstâncias os testes foram restringidos a esses dois grupos.

\begin{tabular}{|c|c|c|c|}
\hline Instâncias & $\mathbf{N}^{\mathbf{0}}$ de Itens & $\mathbf{N}^{\mathbf{0}}$ de Períodos & $\mathbf{N}^{\mathbf{0}}$ de instâncias \\
\hline $\mathrm{E}$ & 6 & 15 & 58 \\
\hline \multirow{3}{*}{$\mathrm{W}$} & 4 & 15 & 6 \\
\cline { 2 - 4 } & 6 & 15 & 6 \\
\hline \multirow{3}{*}{$\mathrm{F}$} & 6 & 15 & 70 \\
\hline \multirow{4}{*}{$\mathrm{G}$} & 6 & 15 & 46 \\
\cline { 2 - 4 } & 12 & 15 & 5 \\
\cline { 2 - 4 } & 24 & 15 & 5 \\
\cline { 2 - 4 } & 12 & 30 & 5 \\
\cline { 2 - 4 } & 24 & 30 & 5 \\
\hline \multirow{5}{*}{$\mathrm{X}$} & 10 & 30 & 180 \\
\cline { 2 - 4 } & 20 & 20 & 180 \\
\cline { 2 - 4 } & 30 & 20 & 180 \\
\hline
\end{tabular}

Tabela 4.1 - Dados dos grupos de instâncias propostas em Trigeiro et al. 1989.

Para todos os exemplos estudados, o formato dos arquivos de dados é o mesmo, variando apenas os dados numéricos. Conforme descrito pelos autores, os tempos de preparação foram gerados uniformemente no intervalo de 5 a 150. Os custos de preparação foram gerados no intervalo de 200 a 1500, enquanto os custos de estoque foram gerados no intervalo de 0,8 a 5,0. O número de máquinas utilizadas é sempre igual a 1 para todas as instâncias. Para os problemas que consideram atraso na demanda, optou-se por calcular o custo de atraso multiplicando-se o custo de estoque por 1,5. O tempo computacional dedicado à resolução de cada exemplar foi limitado em 250 segundos. 


\subsection{Experimentos computacionais com o CPLEX}

Nesta seção são apresentados os resultados dos testes computacionais realizados para definir uma configuração adequada do software comercial CPLEX 11 (ILOG, 2007) quando aplicado para resolver os problemas de dimensionamento de lotes estudados. Foram estudadas algumas configurações possíveis do CPLEX e dentre as quais foi indicada a que melhor se adapta aos problemas abordados.

Primeiramente são discutidos os testes com o CPLEX que foram realizados usando apenas os problemas estudados nos grupos "E" e "W", uma vez que, como destacado anteriormente, em Trigeiro et al. (1989) estes foram criados especialmente para definir os parâmetros da heurística proposta pelos autores. Os problemas foram resolvidos a partir de cinco configurações diferentes. É importante destacar que, em sua configuração padrão, o CPLEX possui cortes e heurísticas ativados As configurações testadas foram:

1. CPLEX sem cortes, sem local branching e sem heurísticas (CPLEX_S).

2. CPLEX sem cortes, com local branching e sem heurísticas (CPLEX_LB).

3. CPLEX com cortes e sem heurísticas (CPLEX_CC).

4. CPLEX com cortes, com local branching e sem heurísticas (CPLEX_CCLB).

5. CPLEX padrão com local branching (CPLEX_PLB).

Tais configurações foram testadas para os seguintes problemas de dimensionamento de lotes:

1. Problema com custo de preparação e limite de capacidade (PDLC) - Modelo 7.

2. PDLC com possibilidade de atender a demanda com atraso - Modelo 7.

3. PDLC com possibilidade de preservação de preparação - Modelo 7.

4. PDLC com possibilidade de preservação de preparação e set-up crossover Modelo 8.

Os três primeiros tipos de problema foram modelados conforme proposto em Karimi et al. (2005), enquanto o quarto tipo foi modelado de acordo com a proposta de Sung e Maravelias (2008).

Para uma melhor leitura, ambos os modelos serão apresentados novamente a seguir, respectivamente. Os resultados dos testes são discutidos nas subseções seguintes. 


\subsubsection{PDL com limite de capacidade e custo de preparação}

Os problemas discutidos nesta subseção se referem ao problema estudado em Trigeiro et al. (1989), ou seja, o problema de dimensionamento de lotes com custos e tempos de preparação e com restrições de capacidade, para os quais a preservação de preparação e o atraso para atender a demanda não são permitidos. As cinco configurações do CPLEX discutidas foram utilizadas e uma análise dos resultados obtidos é apresentada.

Para facilitar a visualização dos resultados, foram gerados gráficos comparando o resultado das cinco configurações do CPLEX estudadas. Para completar os dados apresentados nos gráficos, incluímos também as tabelas com os resultados obtidos para cada um dos exemplares. Nas tabelas, a coluna que possui o valor em negrito representa a configuração que apresentou o melhor resultado para o exemplar. Algumas instâncias estão com o valor $\mathrm{NaN}$, indicando que nenhuma solução factível foi encontrada dentro do limite de tempo de 250 segundos, estabelecido anteriormente. Nas Tabela 4.2 e 4.3 são reportados os valores da função objetivo obtidos para cada configuração, no grupo de exemplos "E" e "W", respectivamente. As Figuras 4.3 e 4.4 ilustram os gráficos construídos conforme a proposta apresentada em Dolan e Moré (2002). Para estes exemplos (grupos "E" e "W"), o gráfico compara os valores das funções objetivos de cada configuração, mostrando qual delas se sobressaiu. É importante lembrar que os problemas estudados são de minimização, então quanto menor for o valor da função objetivo, melhor.

Tanto as Tabelas 4.2 e 4.3 quanto os gráficos das Figuras 4.3 e 4.4 mostram que, como esperado, a CPLEX_S não apresentou bons resultados para ambos os grupos de problemas. Ao considerarmos a estratégia local branching (CPLEX_LB), os resultados melhoram de forma significativa para os exemplos do Grupo "W", porém não tendo um bom desempenho para os exemplos do Grupo "E". As versões CPLEX_CC e CPLEX_CCLB geram bons resultados, o que nos leva a concluir que para o PDL o uso de cortes é adequado. No entanto, como podemos observar, a melhor configuração é a CPLEX_PLB que além dos cortes possibilita também o uso de heurísticas do CPLEX. 


\begin{tabular}{|c|c|c|c|c|c|}
\hline Instâncias & CPLEX_S & CPLEX_LB & CPLEX_CC & CPLEX_CCLB & CPLEX_PLB \\
\hline E01 & 35621 & 34393 & 34393 & 34393 & 34393 \\
\hline E02 & 29551 & 28836 & 28836 & 28836 & 28836 \\
\hline E03 & 43281 & 42057 & 42253 & 42057 & 42057 \\
\hline E04 & 36630 & 35581 & 36237 & 35600 & 35581 \\
\hline E05 & 42021 & 41345 & 41129 & 41129 & 41129 \\
\hline E06 & 42725 & 41449 & 41553 & 41449 & 41449 \\
\hline E07 & 33575 & 32621 & 32952 & 32621 & 32621 \\
\hline E08 & 38331 & 37632 & 37632 & 37632 & 37632 \\
\hline E09 & 39552 & 38369 & 38369 & 38369 & 38369 \\
\hline E10 & 30461 & 30120 & 30120 & 30120 & 30120 \\
\hline E11 & 46028 & 44876 & 44761 & 44735 & 44715 \\
\hline E12 & 31446 & 29432 & 29736 & 29432 & 29432 \\
\hline E13 & 31526 & 29085 & 29085 & 29085 & 29085 \\
\hline E14 & 35096 & 33123 & 33123 & 33123 & 33123 \\
\hline E15 & 38624 & 36704 & 36704 & 36704 & 36704 \\
\hline E16 & 31793 & 30272 & 30754 & 30581 & 30257 \\
\hline E17 & 33590 & 31666 & 32085 & 31574 & 31520 \\
\hline E18 & 46595 & 43093 & 43389 & 43119 & 42895 \\
\hline E19 & 44351 & 41996 & 42425 & 41262 & 41148 \\
\hline E20 & 32493 & 32116 & 32135 & 31842 & 31543 \\
\hline E21 & 36468 & 34951 & 35774 & 35017 & 34951 \\
\hline E22 & 37708 & 35888 & 36470 & 35919 & 35888 \\
\hline E23 & 31668 & 30528 & 30528 & 30528 & 30528 \\
\hline E24 & 40052 & 37874 & 37725 & 37585 & 37585 \\
\hline E25 & 35871 & 35710 & 35710 & 35710 & 35710 \\
\hline E26 & 30446 & 27417 & 27846 & 27310 & 27228 \\
\hline E27 & 41870 & 40266 & 40266 & 40266 & 40266 \\
\hline E28 & 28261 & 27355 & 27351 & 27289 & 27276 \\
\hline E29 & 45430 & 41273 & 41421 & 41273 & 41273 \\
\hline E30 & 31988 & 30341 & 30524 & 30341 & 30341 \\
\hline E31 & 38845 & 37863 & 39447 & 37863 & 37863 \\
\hline E32 & 41045 & 39411 & 39822 & 39202 & 39202 \\
\hline E33 & 37599 & 35801 & 36451 & 35801 & 35801 \\
\hline E34 & 40620 & 38812 & 39778 & 38491 & 38130 \\
\hline E35 & 51930 & 51061 & 51274 & 51061 & 51061 \\
\hline E36 & 41491 & 39719 & 40430 & 39882 & 39719 \\
\hline E37 & 41406 & 40154 & 39313 & 38736 & 38736 \\
\hline E38 & 36994 & 35498 & 36169 & 35345 & 35127 \\
\hline E39 & 39286 & 38139 & 38801 & 38139 & 38128 \\
\hline E40 & 49059 & 47864 & 47988 & 47949 & 47638 \\
\hline E41 & 39692 & 37932 & 38076 & 37932 & 37932 \\
\hline E42 & 34642 & 32898 & 33453 & 32504 & 32330 \\
\hline E43 & 29093 & 27536 & 28781 & 27536 & 27536 \\
\hline E44 & 26507 & 23866 & 24504 & 23617 & 23555 \\
\hline
\end{tabular}

Tabela 4.2 - Tabela de resultados dos exemplos do grupo "E". 


\begin{tabular}{|c|c|c|c|c|c|}
\hline E45 & 24568 & 23281 & 23286 & 23281 & $\mathbf{2 3 2 8 1}$ \\
\hline E46 & 36160 & 34086 & 35392 & 33068 & $\mathbf{3 3 0 0 2}$ \\
\hline E47 & 44521 & 41946 & 41328 & 40249 & $\mathbf{4 0 2 0 7}$ \\
\hline E48 & 41971 & 39791 & $N a N$ & $N a N$ & $\mathbf{3 7 5 7 1}$ \\
\hline E49 & 32987 & 31060 & 31362 & 30819 & $\mathbf{3 0 8 1 9}$ \\
\hline E50 & 41120 & 37484 & 38764 & 37345 & $\mathbf{3 7 1 7 5}$ \\
\hline E51 & 53371 & 49003 & 52339 & 49153 & $\mathbf{4 8 8 2 6}$ \\
\hline E53 & 37283 & 33656 & 35140 & 33384 & $\mathbf{3 3 2 1 4}$ \\
\hline E54 & 45546 & 42806 & 43930 & 41790 & $\mathbf{4 1 2 5 5}$ \\
\hline E55 & 48076 & 43216 & 44767 & 43195 & $\mathbf{4 1 9 6 5}$ \\
\hline E56 & 39243 & 34428 & 39202 & 34251 & $\mathbf{3 4 2 5 1}$ \\
\hline E57 & 36709 & 34541 & 35853 & 34501 & $\mathbf{3 4 1 5 7}$ \\
\hline E59 & 46681 & 43210 & 44813 & 43751 & $\mathbf{4 2 9 7 5}$ \\
\hline E60 & 32631 & 29647 & 29743 & 29490 & $\mathbf{2 9 2 9 0}$ \\
\hline
\end{tabular}

Tabela 4.2 - Tabela de resultados dos exemplos do grupo "E" (continuação).

\begin{tabular}{|c|c|c|c|c|c|}
\hline Instâncias & CPLEX_S & CPLEX_LB & CPLEX_CC & CPLEX_CCLB & CPLEX_PLB \\
\hline W13 & 66165 & 61723 & 64704 & 61994 & $\mathbf{6 1 4 2 2}$ \\
\hline W14 & 61580 & 60146 & 62002 & 59906 & $\mathbf{5 9 4 9 5}$ \\
\hline W15 & 60285 & 58217 & 60694 & 58217 & $\mathbf{5 7 8 0 9}$ \\
\hline W16 & 53114 & 48757 & 51186 & 49129 & $\mathbf{4 8 6 6 2}$ \\
\hline W17 & 48209 & 45074 & 47089 & 44916 & $\mathbf{4 4 9 1 6}$ \\
\hline W18 & 46194 & 43990 & 45782 & 43903 & $\mathbf{4 3 9 0 3}$ \\
\hline W19 & 151962 & 143549 & 152969 & 142974 & $\mathbf{1 4 1 8 1 7}$ \\
\hline W20 & 142187 & 138232 & 144165 & 138946 & $\mathbf{1 3 7 6 4 1}$ \\
\hline W21 & 140642 & 138739 & 150182 & 138743 & $\mathbf{1 3 7 4 7 3}$ \\
\hline W22 & 98048 & 91482 & 96638 & 91359 & $\mathbf{9 0 4 8 9}$ \\
\hline W23 & 92331 & 88495 & 91240 & 88780 & $\mathbf{8 7 9 4 3}$ \\
\hline W24 & 88592 & 86418 & 89482 & 86279 & $\mathbf{8 6 2 7 9}$ \\
\hline
\end{tabular}

Tabela 4.3 - Tabela de resultados dos exemplos do grupo "W".

Nas Figuras 4.3 e 4.4 são exibidos os gráficos gerados conforme a proposta de Dolan e Moré (2002). Estes gráficos mostram o percentual de instâncias em que cada método obteve o melhor resultado, assim como a quantidade de instâncias em que a solução ótima foi encontrada (quando esta foi atingida). Analisando o gráfico dos exemplos "E”, podemos observar que a configuração CPLEX_S não obteve o melhor resultado em nenhuma instância, enquanto a CPLEX_CC obteve o melhor resultado em aproximadamente $20 \%$ das instâncias, a CPLEX_LB obteve melhor resultado em 50\% das instâncias e a CPLEX_CCLB em aproximadamente $60 \%$. Estes percentuais contêm as instâncias para as quais todas as configurações obtiveram o mesmo resultado, o que resulta na possibilidade de mais de uma 
configuração achar a melhor solução para um determinado exemplo. A configuração CPLEX_PLB obteve o melhor resultado em 100\% das instâncias. Para o grupo "W", as configurações CPLEX_S, CPLEX_CC e CPLEX_LB apresentaram melhores resultados em apenas $10 \%$ das instâncias, a CPLEX_CCLB gerou os melhores resultados para 25\% das instâncias, enquanto a CPLEX_PLB obteve, novamente, o melhor resultado em 100\% das instâncias.

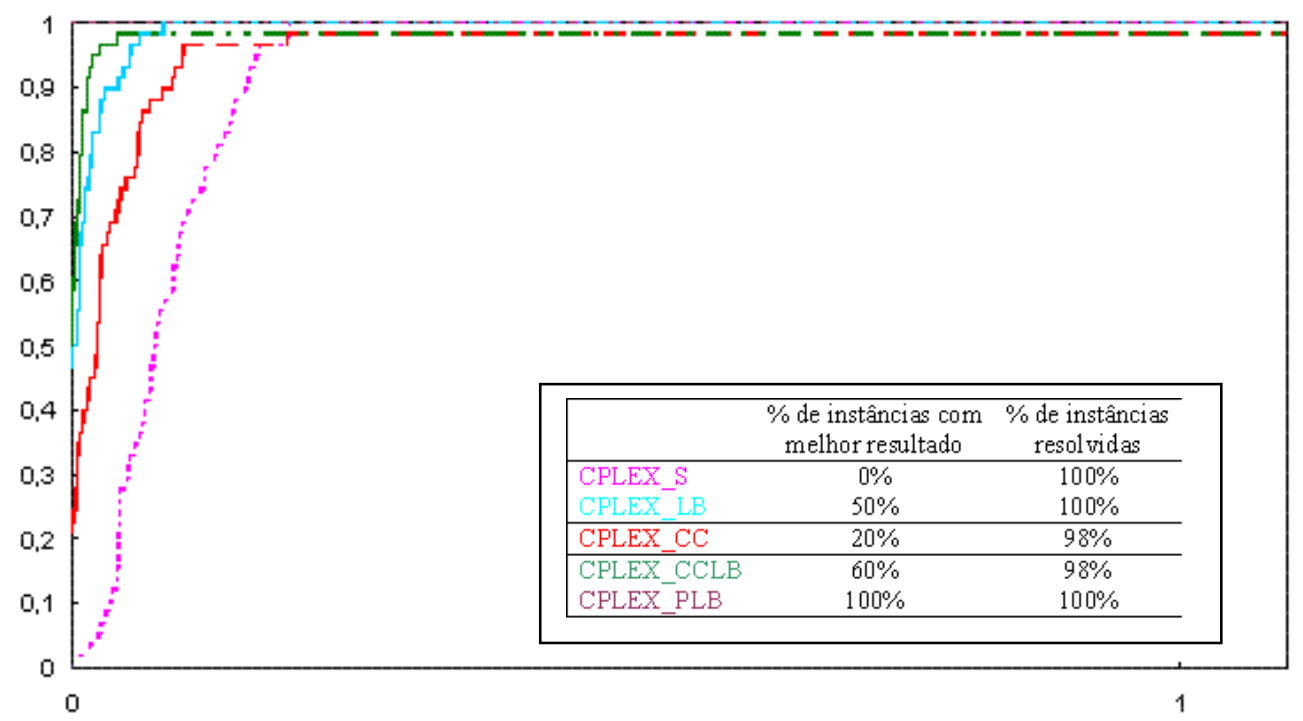

Figura 4.1 - Gráfico de Dolan e Moré para o grupo de exemplos “E”.

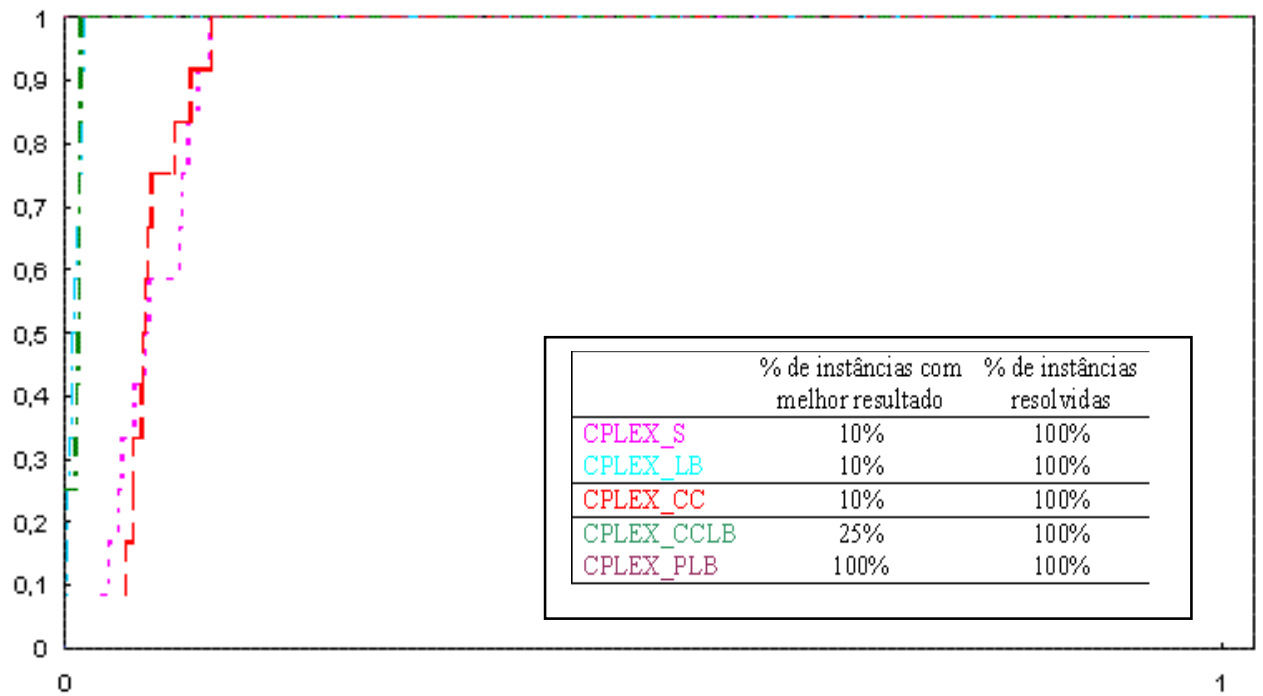

Figura 4.2 - Gráfico de Dolan e Moré para o grupo de exemplos "W”. 


\subsubsection{PDL com atraso na demanda}

Nesta seção, o problema resolvido foi o PDL considerando a possibilidade de atraso para atender a demanda. Foram avaliadas as cinco configurações apresentadas anteriormente.

É possível notar uma descontinuidade para as versões CPLEX_CC e CPLEX_CCLB, decorrentes do fato de nenhuma solução factível ter sido encontrada dentro do tempo limite de 250 segundos. Estas descontinuidades podem ser verificadas nas Tabelas 4.4 e 4.5 que contêm os valores da melhor solução obtida para os exemplares respeitando o tempo limite estipulado.

\begin{tabular}{|c|c|c|c|c|c|}
\hline Instâncias & CPLEX_S & CPLEX_LB & CPLEX_CC & CPLEX_CCLB & CPLEX_PLB \\
\hline E01 & 34909 & 34308 & 34713 & 34307 & $\mathbf{3 4 3 0 5}$ \\
\hline E02 & 29434 & 28836 & 28836 & 28836 & $\mathbf{2 8 8 3 6}$ \\
\hline E03 & 42087 & 40939 & 45084 & 40689 & $\mathbf{4 0 5 9 2}$ \\
\hline E04 & 35971 & 35305 & 37723 & 34785 & $\mathbf{3 4 7 8 5}$ \\
\hline E05 & 42148 & 40739 & 41800 & 40739 & $\mathbf{4 0 7 3 9}$ \\
\hline E06 & 39544 & 38617 & 42650 & 38530 & $\mathbf{3 8 5 1 1}$ \\
\hline E07 & 32770 & 31444 & 33626 & 31134 & $\mathbf{3 1 0 6 2}$ \\
\hline E08 & 38038 & 37181 & 37181 & 37181 & $\mathbf{3 7 1 8 1}$ \\
\hline E09 & 39316 & 38048 & 39973 & 38048 & $\mathbf{3 8 0 4 8}$ \\
\hline E10 & 30602 & 29656 & 31859 & 29612 & $\mathbf{2 9 5 5 8}$ \\
\hline E11 & 46548 & 44411 & 45286 & 44185 & $\mathbf{4 4 0 9 9}$ \\
\hline E12 & 30599 & 28631 & 46868 & 28963 & $\mathbf{2 8 1 5 9}$ \\
\hline E13 & 31332 & 29031 & 29402 & 29031 & $\mathbf{2 9 0 3 1}$ \\
\hline E14 & 34893 & 33026 & 33148 & 33026 & $\mathbf{3 3 0 2 6}$ \\
\hline E15 & 38966 & 35775 & 36366 & 35775 & $\mathbf{3 5 7 7 5}$ \\
\hline E16 & 32063 & 29804 & 32240 & 29432 & $\mathbf{2 9 4 3 2}$ \\
\hline E17 & 34019 & 30972 & $N a N$ & $N a N$ & $\mathbf{3 0 6 5 2}$ \\
\hline E18 & 46052 & 42063 & 46883 & 42156 & $\mathbf{4 1 7 3 0}$ \\
\hline E19 & 44463 & 39570 & 40673 & 39349 & $\mathbf{3 9 3 4 9}$ \\
\hline E20 & 33562 & 31968 & 38204 & 31697 & $\mathbf{3 0 9 3 5}$ \\
\hline E21 & 36079 & 34033 & 36264 & 33994 & $\mathbf{3 3 9 9 4}$ \\
\hline E22 & 37289 & 34994 & 37097 & 34736 & $\mathbf{3 4 7 3 6}$ \\
\hline E23 & 32484 & 30247 & 31370 & 30247 & $\mathbf{3 0 2 4 7}$ \\
\hline E24 & 42701 & 37404 & 39189 & 37445 & $\mathbf{3 7 4 0 4}$ \\
\hline E25 & 35789 & 35710 & 35742 & 35710 & $\mathbf{3 5 7 1 0}$ \\
\hline E26 & 31449 & 27076 & 29720 & 26899 & $\mathbf{2 6 8 1 7}$ \\
\hline E27 & 42371 & 40073 & 40917 & 40073 & $\mathbf{4 0 0 7 3}$ \\
\hline E28 & 28329 & 26847 & 27448 & 26871 & $\mathbf{2 6 8 4 7}$ \\
\hline E29 & 43995 & 40482 & 43007 & 40489 & $\mathbf{4 0 4 8 2}$ \\
\hline
\end{tabular}

Tabela 4.4 - Tabela de resultados dos exemplos do grupo "E", considerando atraso na demanda. 


\begin{tabular}{|l|l|c|c|c|c|}
\hline E30 & 32456 & 29620 & 30669 & 29620 & $\mathbf{2 9 6 2 0}$ \\
\hline E31 & 37700 & 36593 & 42930 & 36721 & $\mathbf{3 6 5 9 3}$ \\
\hline E32 & 40096 & 37915 & $N a N$ & $N a N$ & $\mathbf{3 7 3 1 2}$ \\
\hline E33 & 40197 & 35285 & $N a N$ & $N a N$ & $\mathbf{3 5 2 2 7}$ \\
\hline E34 & 39159 & 37584 & 62420 & 35484 & $\mathbf{3 4 8 5 8}$ \\
\hline E35 & 52076 & 50858 & 53754 & 50757 & $\mathbf{5 0 7 5 7}$ \\
\hline E36 & 40187 & 38320 & 42396 & 38158 & $\mathbf{3 8 1 3 5}$ \\
\hline E37 & 39993 & 37687 & $N a N$ & $N a N$ & $\mathbf{3 7 5 4 3}$ \\
\hline E38 & 36497 & 34668 & $N a N$ & $N a N$ & $\mathbf{3 4 1 0 4}$ \\
\hline E39 & 38922 & 36093 & $N a N$ & $N a N$ & $\mathbf{3 5 9 1 7}$ \\
\hline E40 & 47316 & 45878 & 49586 & 45953 & $\mathbf{4 5 8 5 5}$ \\
\hline E41 & 38061 & 35680 & 39237 & 35961 & $\mathbf{3 5 6 1 3}$ \\
\hline E42 & 35133 & 31855 & 37514 & 31956 & $\mathbf{3 1 7 6 7}$ \\
\hline E43 & 28852 & 27177 & 28877 & 27149 & $\mathbf{2 7 1 4 9}$ \\
\hline E44 & 25200 & 22951 & 27598 & 22845 & $\mathbf{2 2 8 3 4}$ \\
\hline E45 & 24569 & 23116 & 25071 & 23116 & $\mathbf{2 3 1 1 6}$ \\
\hline E46 & 37640 & 31685 & $N a N$ & $N a N$ & $\mathbf{3 1 6 2 4}$ \\
\hline E47 & 45902 & 39369 & 44298 & 39549 & $\mathbf{3 9 1 1 3}$ \\
\hline E48 & 44304 & 36596 & $N a N$ & $N a N$ & $\mathbf{3 6 0 2 3}$ \\
\hline E49 & 32487 & 29980 & $N a N$ & $N a N$ & $\mathbf{2 9 9 3 9}$ \\
\hline E50 & 42187 & 36382 & $N a N$ & $N a N$ & $\mathbf{3 6 2 3 2}$ \\
\hline E51 & 56554 & 47525 & $N a N$ & $N a N$ & $\mathbf{4 7 2 3 0}$ \\
\hline E53 & 37374 & 32603 & $N a N$ & $N a N$ & $\mathbf{3 2 4 6 9}$ \\
\hline E54 & 44006 & 37835 & $N a N$ & $N a N$ & $\mathbf{3 7 2 8 5}$ \\
\hline E55 & 52370 & 41626 & $N a N$ & $N a N$ & $\mathbf{4 1 2 4 9}$ \\
\hline E56 & 44503 & 34169 & 39287 & 33794 & $\mathbf{3 3 5 9 8}$ \\
\hline E57 & 42447 & 33846 & 39052 & 33761 & $\mathbf{3 3 5 0 0}$ \\
\hline E59 & 47449 & 42552 & 52471 & 42630 & $\mathbf{4 2 0 3 3}$ \\
\hline E60 & 33595 & 28927 & 29868 & 28927 & $\mathbf{2 8 9 0 0}$ \\
\hline
\end{tabular}

Tabela 4.4 - Tabela de resultados dos exemplos do grupo "E", considerando atraso na demanda (continuação).

\begin{tabular}{|c|c|c|c|c|c|}
\hline Instâncias & CPLEX_S & CPLEX_LB & CPLEX_CC & CPLEX_CCLB & CPLEX_PLB \\
\hline W13 & 68376 & 60132 & 69262 & 60305 & $\mathbf{5 9 9 1 6}$ \\
\hline W14 & 65088 & 58339 & 62869 & 58291 & $\mathbf{5 8 2 9 1}$ \\
\hline W15 & 61144 & 57354 & 62270 & 57089 & $\mathbf{5 7 0 8 9}$ \\
\hline W16 & 54092 & 46312 & $N a N$ & $N a N$ & $\mathbf{4 6 2 1 6}$ \\
\hline W17 & 47378 & 43569 & 45346 & 43569 & $\mathbf{4 3 5 6 9}$ \\
\hline W18 & 45953 & 42836 & 45964 & 42836 & $\mathbf{4 2 8 3 6}$ \\
\hline W19 & 163081 & 139814 & $N a N$ & $N a N$ & $\mathbf{1 3 8 0 1 7}$ \\
\hline W20 & 147696 & 135710 & 162679 & 135726 & $\mathbf{1 3 5 1 3 9}$ \\
\hline W21 & 142816 & 135313 & 147959 & 135560 & $\mathbf{1 3 4 6 0 6}$ \\
\hline W22 & 109048 & 87053 & $N a N$ & $N a N$ & $\mathbf{8 6 7 3 8}$ \\
\hline W23 & 91375 & 85159 & $N a N$ & $N a N$ & $\mathbf{8 5 0 5 4}$ \\
\hline W24 & 88734 & 83692 & 91260 & 84295 & $\mathbf{8 3 6 9 2}$ \\
\hline
\end{tabular}

Tabela 4.5 - Tabela de resultados dos exemplos do grupo "W", considerando atraso na demanda. 
Nas Figuras 4.7 e 4.8 encontram-se os gráficos gerados conforme a proposta de Dolan e Moré (2002) para ambos os grupos. Observando a Figura 4.7, é possível ver que nas configurações CPLEX_CC e CPLEX_CCLB a linha não atinge o ponto 1, indicando que houve instâncias em que estas configurações não encontraram nenhuma solução factível. Entre estas duas, a CPLEX_CCLB apresentou melhores resultados. As configurações CPLEX_S e CPLEX_LB encontraram soluções factíveis para todas as instâncias, com a CPLEX_LB apresentando resultados melhores. Porém, a mais eficiente foi, novamente, a CPLEX_PLB, que obteve resultados iguais ou superiores às outras configurações para $100 \%$ das instâncias. O mesmo pode ser concluído analisando a Figura 4.8.

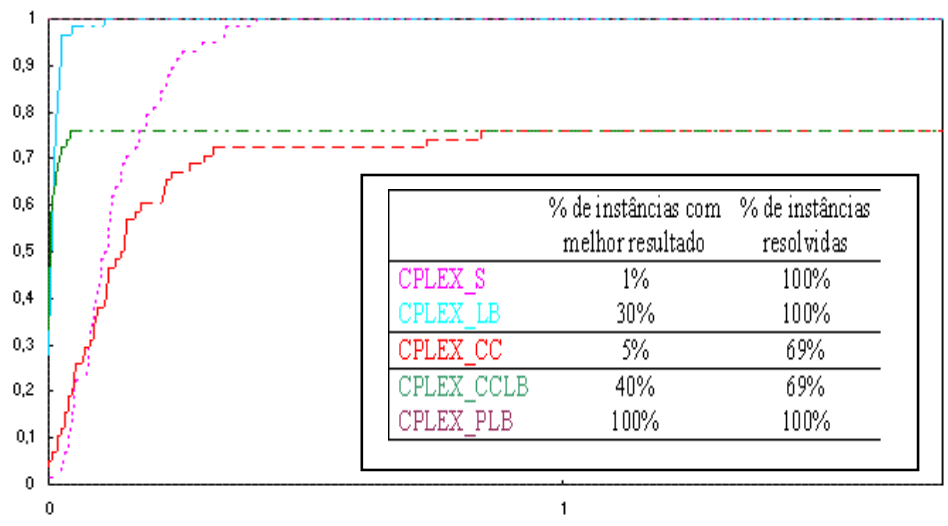

Figura 4.3 - Gráfico de Dolan e Moré para o grupo de exemplos "E”, considerando atraso na demanda.

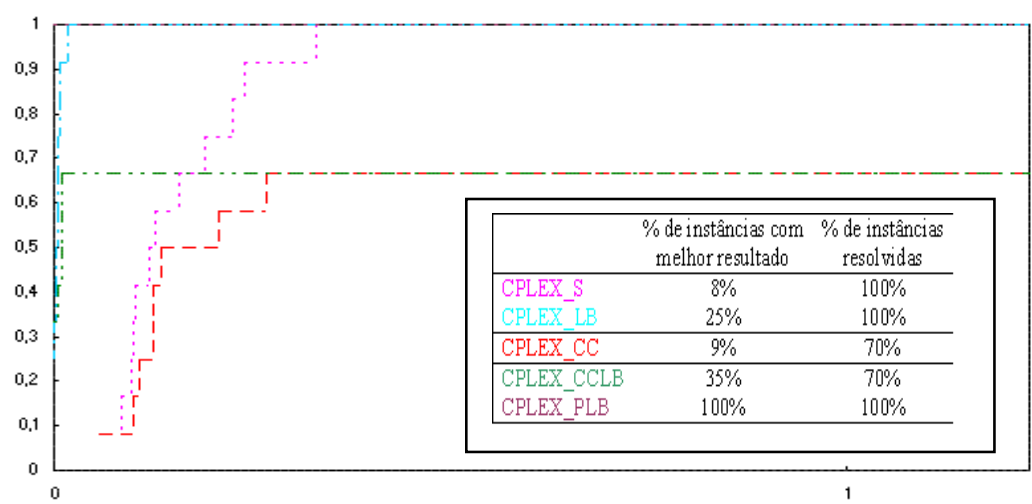

Figura 4.4 - Gráfico de Dolan e Moré para o grupo de exemplos "W", considerando atraso na demanda. 
Devido aos resultados não-satisfatórios das configurações CPLEX_S e CPLEX_CC para os testes anteriores, os próximos testes foram restringidos apenas para as configurações CPLEX_LB, CPLEX_CCLB e CPLEX_PLB.

\subsubsection{PDL com preservação de preparação}

Nesta seção, estudamos o PDL sem a possibilidade de atraso para atender a demanda, porém admitindo a preservação de preparação. Para este problema, nenhuma das configurações do CPLEX avaliadas encontrou uma solução comprovadamente ótima para todas as instâncias de ambos os grupos, no entanto, a estratégia CPLEX_PLB apresentou os melhores resultados. Nas Tabelas 4.6 e 4.7 são apresentados os resultados obtidos para os grupos "E" e "W", respectivamente.

\begin{tabular}{|c|c|c|c|}
\hline Instâncias & CPLEX_LB & CPLEX_CCLB & CPLEX_PLB \\
\hline E01 & 35718 & 35740 & $\mathbf{3 4 0 9 9}$ \\
\hline E02 & 30982 & 30735 & $\mathbf{2 8 6 7 1}$ \\
\hline E03 & 43187 & 42629 & $\mathbf{4 1 6 2 3}$ \\
\hline E04 & 38663 & 37297 & $\mathbf{3 5 8 1 2}$ \\
\hline E05 & 43633 & 43465 & $\mathbf{4 0 7 3 7}$ \\
\hline E06 & 42210 & 43268 & $\mathbf{4 0 3 1 2}$ \\
\hline E07 & 32356 & 34895 & $\mathbf{3 1 9 2 8}$ \\
\hline E08 & 38923 & 39225 & $\mathbf{3 7 3 9 3}$ \\
\hline E09 & 39833 & 40704 & $\mathbf{3 7 9 5 7}$ \\
\hline E10 & 32282 & 30910 & $\mathbf{2 9 6 7 9}$ \\
\hline E11 & NaN & NaN & $\mathbf{4 4 5 1 2}$ \\
\hline E12 & 31820 & 31378 & $\mathbf{2 8 7 6 8}$ \\
\hline E13 & 30464 & 30420 & $\mathbf{2 7 8 6 6}$ \\
\hline E14 & 35618 & 34153 & $\mathbf{3 3 0 8 5}$ \\
\hline E15 & NaN & 39473 & $\mathbf{3 5 6 9 4}$ \\
\hline E16 & NaN & 31732 & $\mathbf{3 0 3 2 7}$ \\
\hline E17 & 33101 & 32206 & $\mathbf{3 1 4 8 5}$ \\
\hline E18 & NaN & NaN & $\mathbf{4 2 8 9 5}$ \\
\hline E19 & NaN & 42771 & $\mathbf{4 0 5 9 3}$ \\
\hline E20 & NaN & 33185 & $\mathbf{3 1 5 9 2}$ \\
\hline E21 & 39130 & $N a N$ & $\mathbf{3 4 6 1 5}$ \\
\hline E22 & 38478 & 37199 & $\mathbf{3 5 9 9 7}$ \\
\hline E23 & 32735 & 31336 & $\mathbf{3 0 5 2 8}$ \\
\hline
\end{tabular}

Tabela 4.6 - Tabela de resultados dos exemplos do grupo "E", considerando preservação de preparação. 


\begin{tabular}{|c|c|c|c|}
\hline E24 & 40786 & 39197 & $\mathbf{3 7 9 0 6}$ \\
\hline E25 & 37161 & 36498 & $\mathbf{3 5 3 3 8}$ \\
\hline E26 & $N a N$ & $N a N$ & $\mathbf{2 7 3 1 0}$ \\
\hline E27 & 43007 & 41788 & $\mathbf{3 9 6 7 4}$ \\
\hline E24 & 40786 & 39197 & $\mathbf{3 7 9 0 6}$ \\
\hline E25 & 37161 & 36498 & $\mathbf{3 5 3 3 8}$ \\
\hline E26 & $N a N$ & $N a N$ & $\mathbf{2 7 3 1 0}$ \\
\hline E27 & 43007 & 41788 & $\mathbf{3 9 6 7 4}$ \\
\hline E28 & 29378 & 27655 & $\mathbf{2 6 7 7 6}$ \\
\hline E29 & 42895 & 44001 & $\mathbf{4 1 2 7 3}$ \\
\hline E30 & 31961 & 30561 & $\mathbf{2 9 8 1 9}$ \\
\hline E31 & $N a N$ & 38097 & $\mathbf{3 7 8 8 4}$ \\
\hline E32 & $N a N$ & $N a N$ & $\mathbf{3 9 4 1 0}$ \\
\hline E33 & $N a N$ & $N a N$ & $\mathbf{3 5 8 0 1}$ \\
\hline E34 & $N a N$ & $N a N$ & $\mathbf{3 8 1 7 6}$ \\
\hline E35 & 54223 & $N a N$ & $\mathbf{5 1 4 2 4}$ \\
\hline E36 & 42031 & $N a N$ & $\mathbf{3 9 8 2 6}$ \\
\hline E37 & $N a N$ & 41967 & $\mathbf{3 8 8 8 2}$ \\
\hline E38 & $N a N$ & $N a N$ & $\mathbf{3 5 6 7 5}$ \\
\hline E39 & $N a N$ & $N a N$ & $\mathbf{3 8 3 8 0}$ \\
\hline E40 & 51387 & 51266 & $\mathbf{4 7 6 3 8}$ \\
\hline E41 & 39258 & $N a N$ & $\mathbf{3 6 9 1 6}$ \\
\hline E42 & $N a N$ & $N a N$ & $\mathbf{3 2 5 7 4}$ \\
\hline E43 & $N a N$ & 28213 & $\mathbf{2 7 4 3 2}$ \\
\hline E44 & 27243 & $N a N$ & $\mathbf{2 3 5 5 5}$ \\
\hline E45 & $N a N$ & 24403 & $\mathbf{2 2 9 5 8}$ \\
\hline E46 & $N a N$ & $N a N$ & $\mathbf{3 3 4 2 7}$ \\
\hline E47 & $N a N$ & $N a N$ & $\mathbf{4 0 5 2 4}$ \\
\hline E48 & $N a N$ & $N a N$ & $\mathbf{3 8 3 8 8}$ \\
\hline E49 & 34001 & $N a N$ & $\mathbf{3 0 9 2 3}$ \\
\hline E50 & 44997 & $N a N$ & $\mathbf{3 7 7 8 5}$ \\
\hline E51 & $N a N$ & $N a N$ & $\mathbf{4 9 3 8 7}$ \\
\hline E53 & 36218 & $N a N$ & $\mathbf{3 3 8 0 3}$ \\
\hline E54 & $N a N$ & $N a N$ & $\mathbf{4 1 2 9 7}$ \\
\hline E55 & $N a N$ & $N a N$ & $\mathbf{4 2 8 8 7}$ \\
\hline E56 & $N a N$ & $N a N$ & $\mathbf{3 4 2 5 1}$ \\
\hline E57 & $N a N$ & $N a N$ & $\mathbf{3 4 1 5 7}$ \\
\hline E59 & $N a N$ & $N a N$ & $\mathbf{4 3 0 2 5}$ \\
\hline E60 & $N a N$ & $N a N$ & $\mathbf{2 9 2 9 0}$ \\
\hline
\end{tabular}

Tabela 4.6 - Tabela de resultados dos exemplos do grupo "E", considerando preservação de preparação (continuação). 


\begin{tabular}{|c|c|c|c|}
\hline Instâncias & CPLEX_LB & CPLEX_CCLB & CPLEX_PLB \\
\hline W13 & $N a N$ & $N a N$ & $\mathbf{6 1 6 2 1}$ \\
\hline W14 & 62323 & 61568 & $\mathbf{5 9 2 6 6}$ \\
\hline W15 & 59760 & $N a N$ & $\mathbf{5 7 2 6 7}$ \\
\hline W16 & 49071 & 50023 & $\mathbf{4 6 2 0 1}$ \\
\hline W17 & 46453 & 44815 & $\mathbf{4 3 0 6 2}$ \\
\hline W18 & 49735 & 43551 & $\mathbf{4 1 9 7 6}$ \\
\hline W19 & $N a N$ & $N a N$ & $\mathbf{1 4 3 8 8 7}$ \\
\hline W20 & $N a N$ & $N a N$ & $\mathbf{1 3 9 6 9 1}$ \\
\hline W21 & 144292 & 143251 & $\mathbf{1 3 8 4 0 3}$ \\
\hline W22 & $N a N$ & $N a N$ & $\mathbf{9 0 8 7 9}$ \\
\hline W23 & 92405 & $N a N$ & $\mathbf{8 9 1 2 6}$ \\
\hline W24 & 89657 & 88694 & $\mathbf{8 6 9 4 8}$ \\
\hline
\end{tabular}

Tabela 4.7 - Tabela de resultados dos exemplos do grupo "W", considerando preservação de preparação.

As Figuras 4.11 e 4.12 ilustram os gráficos gerados como proposto por Dolan e Moré (2002) para ambos os grupos. Conforme se pode observar, as configurações CPLEX_LB e CPLEX_CCLB não apresentam bons resultados. Isto pode ser notado pela quantidade de instâncias em que estes métodos não obtiveram soluções factíveis. No grupo " $E$ " o CPLEX_CCLB apresentou resultados melhores que o CPLEX_LB, enquanto no grupo "W" ocorreu o inverso. Quanto à qualidade da solução, mais uma vez o CPLEX_PLB obteve os melhores resultados, sendo superior às outras configurações em 100\% das instâncias, para ambos os grupos. 


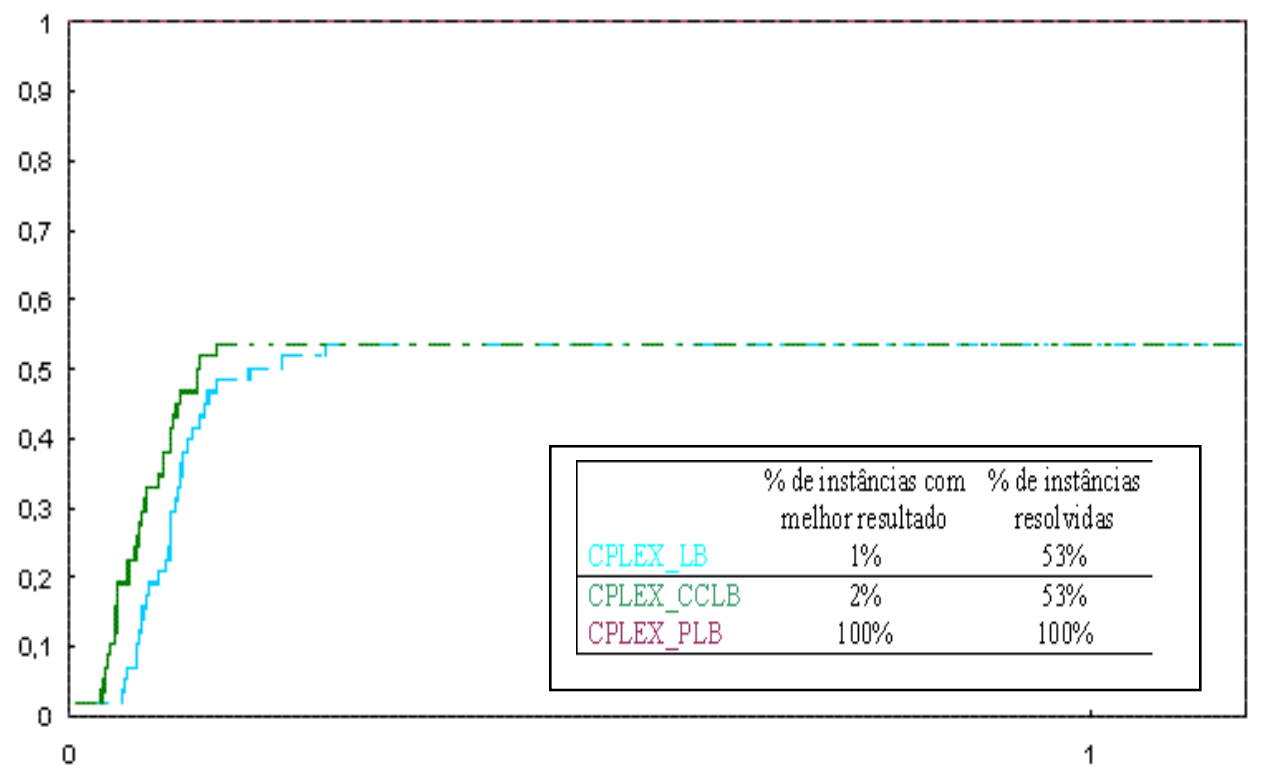

Figura 4.5 - Gráfico de Dolan e Moré para o grupo de exemplos "E", considerando preservação de preparação.

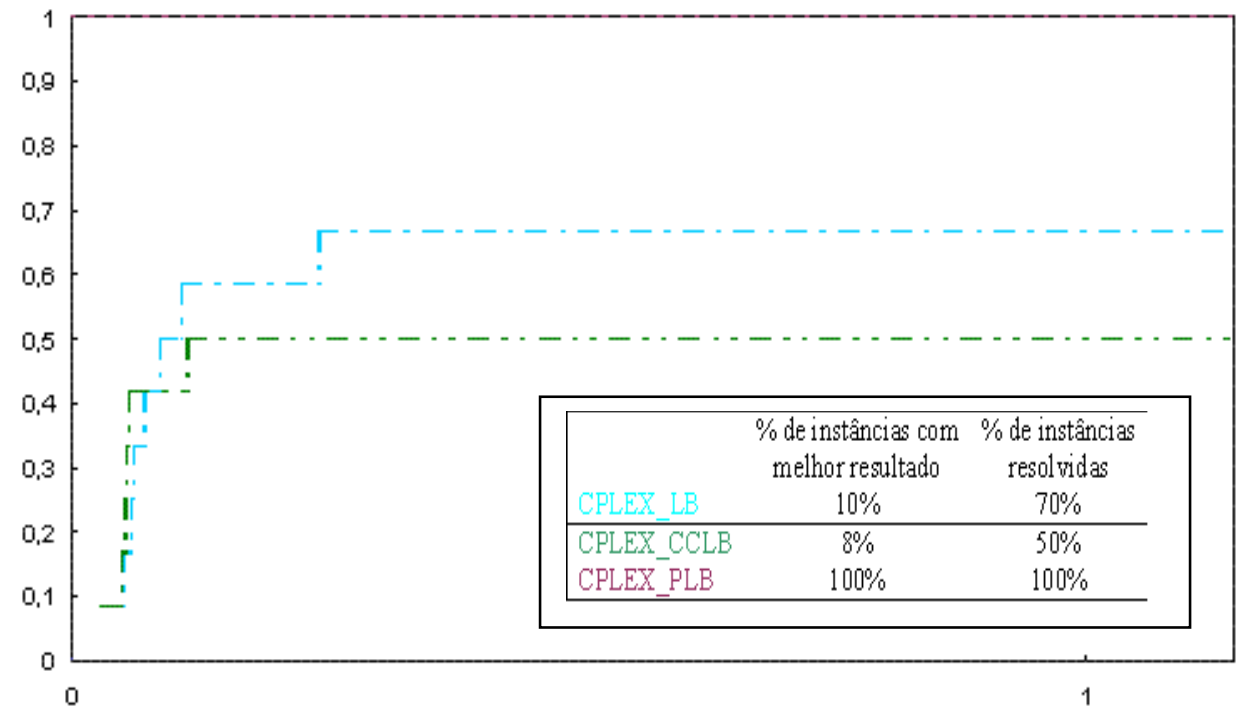

Figura 4.6 - Gráfico de Dolan e Moré para o grupo de exemplos "W", considerando preservação de preparação. 
Como esperado, a configuração CPLEX_PLB encontrou os melhores resultados. Concluímos, portanto, que as heurísticas disponíveis no CPLEX e os cortes são essenciais para a obtenção de soluções factíveis.

\subsubsection{PDL com preservação de preparação e set-up crossover}

Nesta seção, o problema resolvido foi o PDL sem a possibilidade de atraso para atender a demanda, porém considerando preservação de preparação e set-up crossover. Para que estas características fossem incorporadas, foi utilizado o Modelo 8. Novamente, foram consideradas apenas as configurações CPLEX_LB, CPLEX_CCLB e CPLEX_PLB. As Tabelas 4.8 e 4.9 apresentam os resultados dos grupos "E" e "W", respectivamente.

\begin{tabular}{|c|c|c|c|}
\hline Instâncias & CPLEX_LB & CPLEX_CCLB & CPLEX_PLB \\
\hline E01 & 27208 & 27322 & $\mathbf{2 7 0 3 0}$ \\
\hline E02 & 21825 & $N a N$ & $\mathbf{2 1 8 2 5}$ \\
\hline E03 & 34422 & 35837 & $\mathbf{3 3 4 5 5}$ \\
\hline E04 & $N a N$ & $N a N$ & $\mathbf{2 8 2 8 7}$ \\
\hline E05 & $N a N$ & $N a N$ & $\mathbf{3 2 6 7 5}$ \\
\hline E06 & 33924 & 34872 & $\mathbf{3 3 4 4 1}$ \\
\hline E07 & 26065 & 25814 & $\mathbf{2 5 5 5 4}$ \\
\hline E08 & 28265 & $N a N$ & $\mathbf{2 8 2 6 5}$ \\
\hline E09 & 30717 & $N a N$ & $\mathbf{3 0 6 0 0}$ \\
\hline E10 & 24595 & 23993 & $\mathbf{2 3 7 8 9}$ \\
\hline E11 & $N a N$ & $N a N$ & $\mathbf{3 5 0 8 5}$ \\
\hline E12 & 24236 & 24166 & $\mathbf{2 3 8 7 9}$ \\
\hline E13 & 22297 & 22297 & $\mathbf{2 2 2 9 7}$ \\
\hline E14 & 25607 & $N a N$ & $\mathbf{2 5 6 0 7}$ \\
\hline E15 & 29519 & $N a N$ & $\mathbf{2 9 3 1 4}$ \\
\hline E16 & $N a N$ & $N a N$ & $\mathbf{2 3 0 9 8}$ \\
\hline E17 & $N a N$ & $N a N$ & $\mathbf{2 5 0 0 8}$ \\
\hline E18 & $N a N$ & $N a N$ & $\mathbf{3 4 0 3 9}$ \\
\hline E19 & $N a N$ & $N a N$ & $\mathbf{3 2 8 1 4}$ \\
\hline
\end{tabular}

Tabela 4.8 - Tabela de resultados dos exemplos do grupo "E", considerando preservação de preparação e set-up crossover. 


\begin{tabular}{|l|c|c|c|}
\hline E20 & 26080 & $N a N$ & $\mathbf{2 5 3 8 7}$ \\
\hline E21 & $N a N$ & $N a N$ & $\mathbf{2 7 0 1 8}$ \\
\hline E22 & $N a N$ & $N a N$ & $\mathbf{2 8 2 0 5}$ \\
\hline E23 & $N a N$ & $N a N$ & $\mathbf{2 4 0 8 2}$ \\
\hline E24 & $N a N$ & $N a N$ & $\mathbf{2 8 6 1 6}$ \\
\hline E25 & $N a N$ & 27984 & $\mathbf{2 7 8 6 2}$ \\
\hline E26 & $N a N$ & $N a N$ & $\mathbf{2 1 2 4 0}$ \\
\hline E27 & $N a N$ & 31414 & $\mathbf{3 1 4 1 2}$ \\
\hline E28 & $N a N$ & $N a N$ & $\mathbf{2 0 1 4 3}$ \\
\hline E29 & $N a N$ & $N a N$ & $\mathbf{3 2 0 2 2}$ \\
\hline E30 & 23940 & $N a N$ & $\mathbf{2 3 2 6 6}$ \\
\hline E31 & $N a N$ & $N a N$ & $\mathbf{2 9 5 2 3}$ \\
\hline E32 & $N a N$ & $N a N$ & $\mathbf{3 1 2 6 8}$ \\
\hline E33 & $N a N$ & $N a N$ & $\mathbf{2 8 3 2 2}$ \\
\hline E34 & $N a N$ & $N a N$ & $\mathbf{3 0 5 2 7}$ \\
\hline E35 & 42294 & $N a N$ & $\mathbf{4 2 0 6 1}$ \\
\hline E36 & $N a N$ & $N a N$ & $\mathbf{3 2 1 5 3}$ \\
\hline E37 & $N a N$ & 33239 & $\mathbf{3 1 5 9 9}$ \\
\hline E38 & $N a N$ & $N a N$ & $\mathbf{2 7 8 0 0}$ \\
\hline E39 & $N a N$ & $N a N$ & $\mathbf{2 9 9 4 5}$ \\
\hline E40 & $N a N$ & 39318 & $\mathbf{3 7 2 5 0}$ \\
\hline E41 & $N a N$ & $N a N$ & $\mathbf{2 8 7 0 0}$ \\
\hline E42 & 34671 & 25824 & $\mathbf{2 5 3 3 7}$ \\
\hline E43 & $N a N$ & $N a N$ & $\mathbf{2 0 4 7 1}$ \\
\hline E44 & $N a N$ & $N a N$ & $\mathbf{1 7 6 2 8}$ \\
\hline E45 & $N a N$ & 18456 & $\mathbf{1 8 0 5 1}$ \\
\hline E46 & $N a N$ & $N a N$ & $\mathbf{2 5 3 1 3}$ \\
\hline E47 & $N a N$ & $N a N$ & $\mathbf{3 2 7 0 6}$ \\
\hline E48 & $N a N$ & $N a N$ & $\mathbf{3 0 1 2 5}$ \\
\hline E49 & $N a N$ & $N a N$ & $\mathbf{2 3 9 9 0}$ \\
\hline E50 & $N a N$ & $N a N$ & $\mathbf{2 9 4 4 7}$ \\
\hline E51 & $N a N$ & $N a N$ & $\mathbf{3 8 3 6 4}$ \\
\hline E53 & $N a N$ & $N a N$ & $\mathbf{2 6 8 5 4}$ \\
\hline E54 & $N a N$ & $N a N$ & $\mathbf{3 2 2 0 0}$ \\
\hline E55 & $N a N$ & $N a N$ & $\mathbf{3 2 6 9 6}$ \\
\hline E56 & $N a N$ & $N a N$ & $\mathbf{2 5 9 9 5}$ \\
\hline E57 & $N a N$ & $N a N$ & $\mathbf{2 5 6 4 4}$ \\
\hline E59 & $N a N$ & $N a N$ & $\mathbf{3 3 9 1 3}$ \\
\hline E60 & $N a N$ & $N a N$ & $\mathbf{2 1 8 9 0}$ \\
\hline \\
\hline & & & \\
\hline
\end{tabular}

Tabela 4.8 - Tabela de resultados dos exemplos do grupo "E", considerando preservação de preparação e set-up crossover (continuação). 


\begin{tabular}{|c|c|c|c|}
\hline Instâncias & CPLEX_LB & CPLEX_CCLB & CPLEX_PLB \\
\hline W13 & 47430 & $N a N$ & $\mathbf{4 7 2 8 2}$ \\
\hline W14 & 45689 & $N a N$ & $\mathbf{4 4 9 3 7}$ \\
\hline W15 & $N a N$ & $N a N$ & $\mathbf{4 3 0 7 5}$ \\
\hline W16 & 36203 & 35447 & $\mathbf{3 5 2 8 7}$ \\
\hline W17 & $N a N$ & 33588 & $\mathbf{3 2 7 9 8}$ \\
\hline W18 & 31872 & 31675 & $\mathbf{3 1 6 6 4}$ \\
\hline W19 & $N a N$ & 123828 & $\mathbf{1 2 1 3 6 6}$ \\
\hline W20 & $N a N$ & $N a N$ & $\mathbf{1 1 8 0 3 3}$ \\
\hline W21 & $N a N$ & $N a N$ & $\mathbf{1 1 7 3 5 0}$ \\
\hline W22 & $N a N$ & $N a N$ & $\mathbf{7 4 9 4 9}$ \\
\hline W23 & 74894 & $N a N$ & $\mathbf{7 2 2 5 2}$ \\
\hline W24 & $N a N$ & $N a N$ & $\mathbf{7 1 4 0 5}$ \\
\hline
\end{tabular}

Tabela 4.9 - Tabela de resultados dos exemplos do grupo "W", considerando preservação de preparação e set-up crossover.

As Figuras 4.15 e 4.16 ilustram os gráficos gerados conforme a proposta de Dolan e Moré (2002) para ambos os grupos. É possível notar que pouquíssimas instâncias foram resolvidas pelas configurações CPLEX_LB e CPLEX_CCLB. As instâncias resolvidas apresentaram resultados de boa qualidade, principalmente pela CPLEX_LB. A CPLEX_PLB continua sendo mais eficiente, obtendo solução factível para $100 \%$ das instâncias de ambos os grupos com os melhores resultados em todas. 


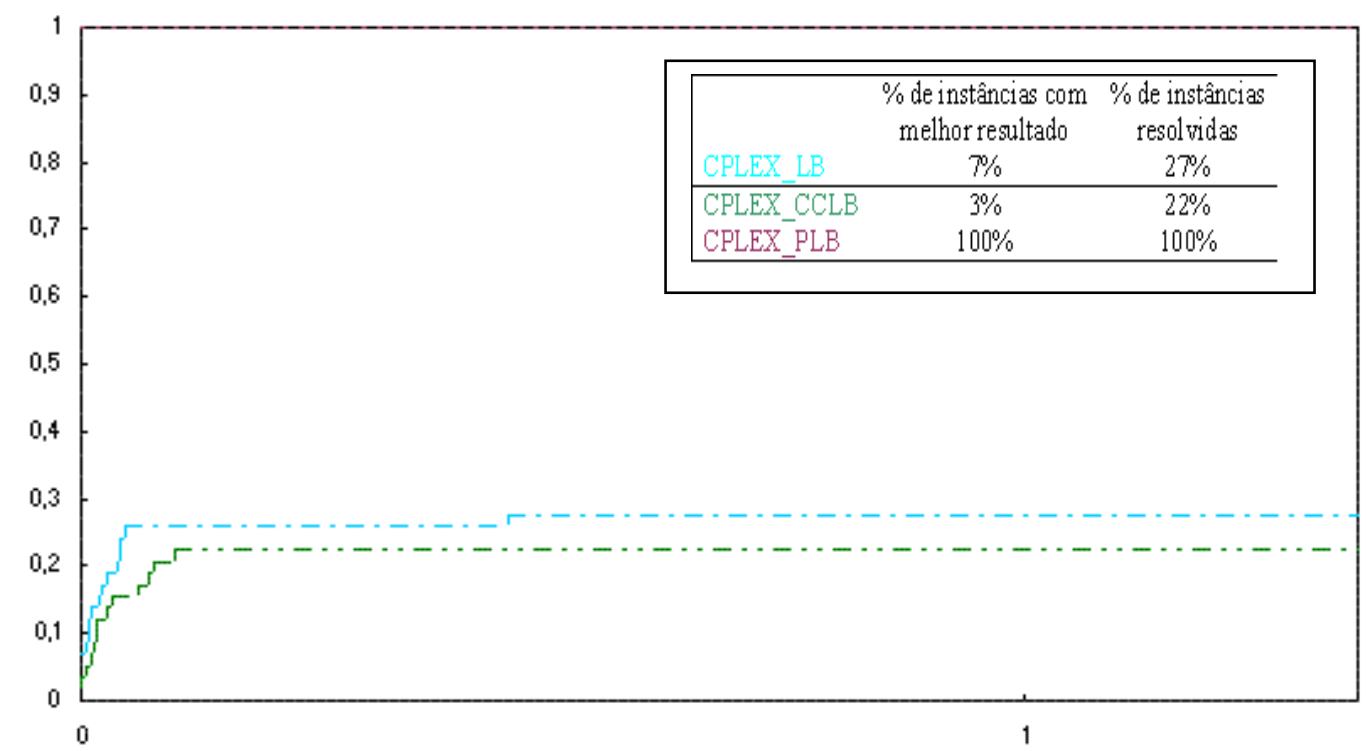

Figura 4.7 - Gráfico de Dolan e Moré para o grupo de exemplos "E", considerando preservação de preparação e set-up crossover.

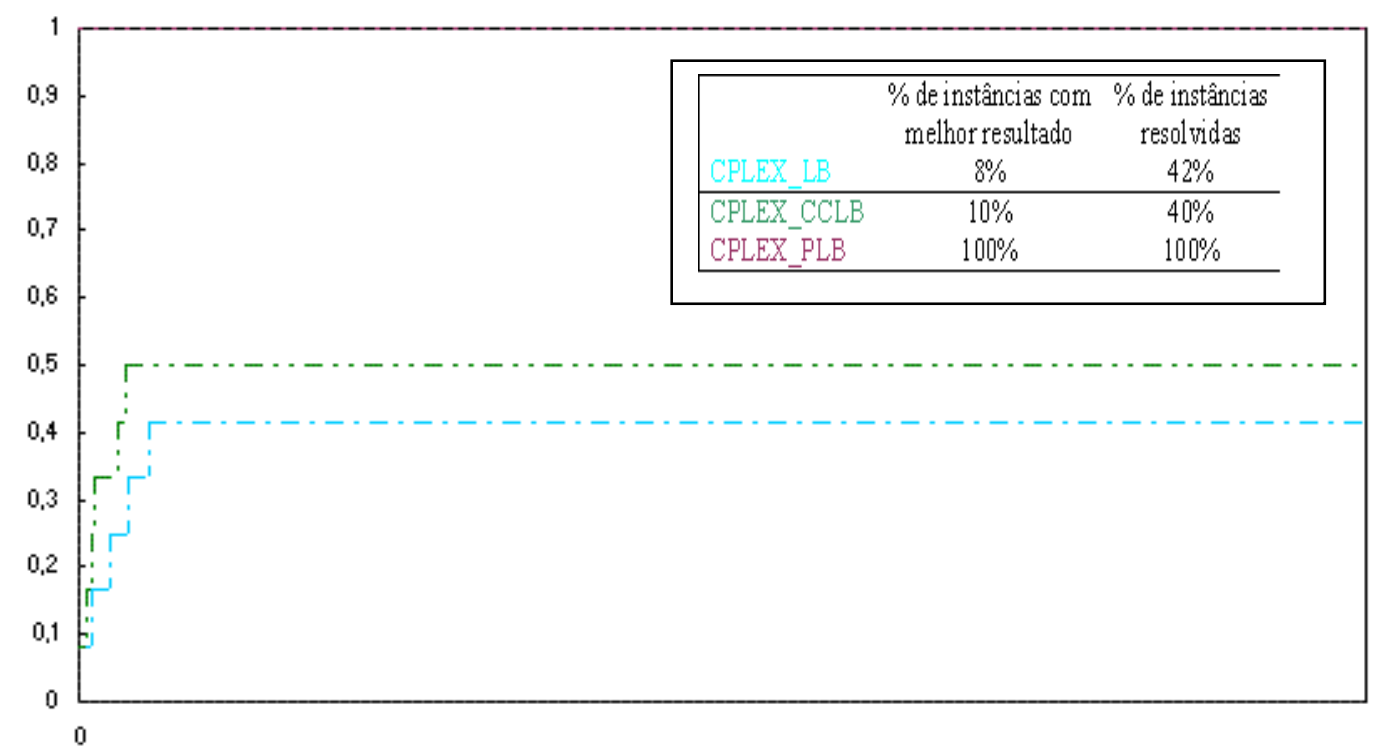

Figura 4.8 - Gráfico de Dolan e Moré para o grupo de exemplos "W", considerando preservação de preparação e set-up crossover. 


\subsubsection{Conclusão}

Analisando todos os gráficos, percebe-se que CPLEX_PLB apresentou os melhores resultados quando comparada as outras configurações. Na Tabela 4.10 são resumidos os resultados obtidos. A primeira coluna da tabela descreve a configuração do CPLEX, em cada uma das demais colunas são destacados os modelos. Em cada uma das linhas são marcadas com $\mathrm{X}$ as configurações que foram testadas para os diferentes problemas. Destacamos em negrito a configuração do CPLEX_PLB por ter gerado os melhores resultados para todos os problemas avaliados.

\begin{tabular}{|l|c|c|c|c|}
\hline \multirow{2}{*}{$\begin{array}{c}\text { Parâmetros } \\
\text { CPLEX }\end{array}$} & \multicolumn{4}{|c|}{ Características } \\
\cline { 2 - 5 } & PDLC & Backlogging & Carry-Over & $\begin{array}{c}\text { Carry-Over, Set-up } \\
\text { Crossover }\end{array}$ \\
\hline CPLEX_S & $\mathrm{x}$ & $\mathrm{x}$ & & $\mathrm{x}$ \\
\hline CPLEX_LB & $\mathrm{x}$ & $\mathrm{x}$ & $\mathrm{x}$ & $\mathrm{x}$ \\
\hline CPLEX_CC & $\mathrm{x}$ & $\mathrm{x}$ & & $\mathbf{x}$ \\
\hline CPLEX_CCLB & $\mathrm{x}$ & $\mathrm{x}$ & $\mathrm{x}$ & $\mathbf{x}$ \\
\hline CPLEX_PLB & $\mathbf{x}$ & $\mathbf{x}$ & & \\
\hline
\end{tabular}

Tabela 4.10 - Comparação entre diferentes configurações do CPLEX 11.

\subsection{Experimentos computacionais para a implementação proposta}

Os testes apresentados na Seção 4.1 foram repetidos utilizando como método de solução a implementação da estratégia local branching para os problemas de dimensionamento de lotes estudados. Estes testes tiveram como objetivo avaliar o desempenho do programa desenvolvido em $\mathrm{C}++$ e do local branching implementado.

Da mesma forma que os testes anteriores, apenas os grupos de exemplos "E" e "W" foram utilizados. Os problemas foram resolvidos apenas pelas três configurações que geraram os melhores resultados, ou seja:

1. $\mathrm{C}++$ sem cortes e com local branching $\left(\mathrm{C}++\_\mathrm{LB}\right)$.

2. $\mathrm{C}++$ com cortes e com local branching (C++_CCLB).

3. $\mathrm{C}++$ com cortes, com heurísticas e com local branching (C++_PLB). 
Estas configurações foram testadas para os seguintes problemas de dimensionamento de lotes:

1. Problema com custo de preparação e limite de capacidade (PDLC) - Modelo 7

2. PDLC com atraso - Modelo 7.

3. PDLC com preservação de preparação - Modelo 7.

4. PDLC com preservação de preparação e set-up crossover - Modelo 8.

Por serem mais ilustrativos, restringimos a apresentação dos resultados aos gráficos gerados segundo a proposta de Dolan e More (2002). As tabelas e os demais gráficos estão disponíveis no Apêndice A.

\subsubsection{PDL com limite de capacidade e custo de preparação}

Os problemas discutidos nesta subseção se referem ao problema de dimensionamento de lotes com custos e tempos de preparação e com restrições de capacidade, para os quais a preservação de preparação e o atraso para atender a demanda não são considerados.

As três configurações do programa em $\mathrm{C}++$ apresentadas foram utilizadas e uma análise dos resultados obtidos é apresentada nas Figuras 4.19 e 4.20. No grupo "E" os exemplos apresentam resultados muito próximos, como se pode ver na Figura 4.19. Nos exemplos "W" a diferença nos resultados foi mais aparente. Em ambos os grupos, a configuração C++_CCLB obteve resultados superiores aos da C++_LB, porém os melhores resultados foram obtidos pela C++_PLB.

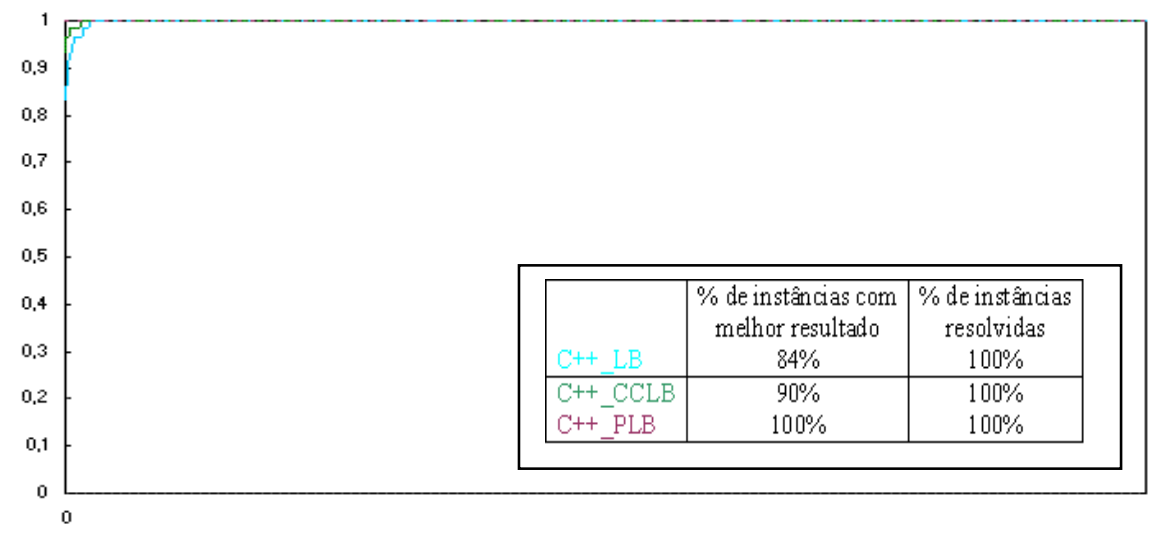

Figura 4.9 - Gráfico de Dolan e Moré para o grupo de exemplos "E". 


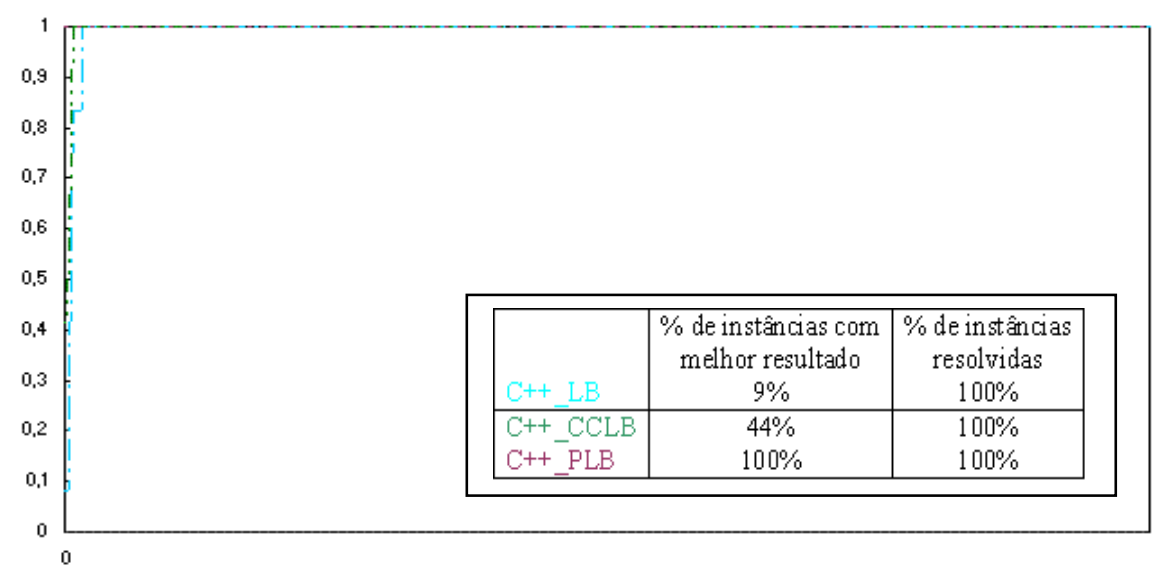

Figura 4.10 - Gráfico de Dolan e Moré para o grupo de exemplos "W".

Conforme observado nos gráficos, as três configurações apresentaram resultados muito próximos, mostrando que não houve muita influência dos cortes e das heurísticas para o problema. Ainda assim, a configuração CPLEX_PLB apresentou os melhores resultados.

\subsubsection{PDL com atraso na demanda}

Nesta seção, o problema resolvido foi o PDL considerando atraso na demanda, porém sem preservação de preparação. Foram testadas as três configurações descritas anteriormente. Os grupos de exemplos utilizados nos testes foram os grupos "E" e "W".

As três configurações apresentaram o mesmo resultado, no entanto, utilizando as configurações C++_LB e C++_CCLB não foi possível provar a otimalidade das soluções, os dois métodos foram interrompidos ao atingir o tempo limite. Destacamos, no entanto, que para configuração CPLEX_PLB as soluções encontradas estavam a no máximo 0,01\% do ótimo.

\subsubsection{PDL com preservação de preparação}

Nesta seção, foi avaliado o PDL considerando a possibilidade de preservação de preparação. Mais uma vez, as três configurações foram comparadas. Nenhuma solução comprovadamente ótima foi encontrada pelas configurações do programa em C++. 
É importante notar que, embora a configuração C++_PLB não tenha obtido a melhor solução em todas as instâncias, ela se mostrou mais eficiente em aproximadamente $90 \%$ dos problemas de ambos os grupos (ver Figuras 4.23 e 4.24).

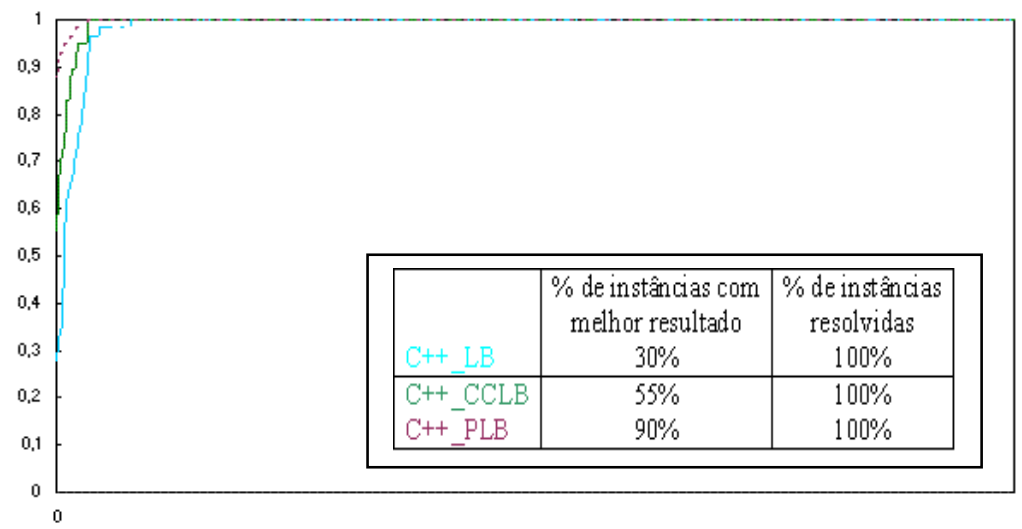

Figura 4.11 - Gráfico de Dolan e Moré para o grupo de exemplos “E”, considerando preservação de preparação.

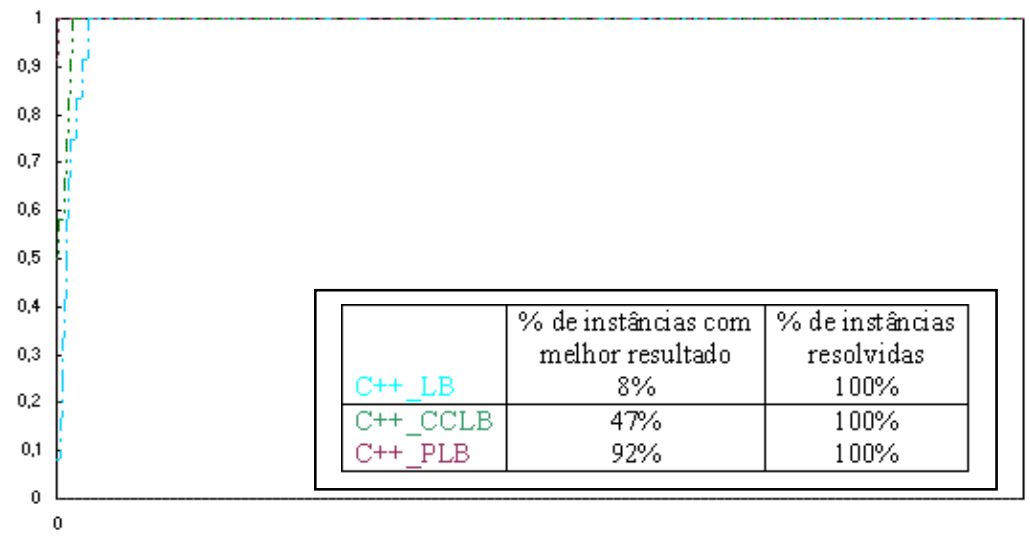

Figura 4.12 - Gráfico de Dolan e Moré para o grupo de exemplos “W”, considerando preservação de preparação. 


\subsubsection{PDL com preservação de preparação e set-up crossover}

Nesta seção, foi testado o PDL considerando a possibilidade de preservação de preparação e de set-up crossover. Neste problema, várias instâncias de ambos os grupos foram resolvidas em sua otimalidade.

Os gráficos gerados conforme proposto em (Dolan e Moré, 2002) para cada grupo são ilustrados nas Figuras 4.27 e 4.28. A C++_LB se mostrou pouco eficiente, obtendo o melhor resultado em apenas $11 \%$ das instâncias do grupo "E" e $8 \%$ do grupo "W". Enquanto isso, a C++_CCLB obteve um resultado melhor, encontrando melhores soluções em aproximadamente $58 \%$ das instâncias do grupo "E" e $42 \%$ do grupo "W". Conforme esperado, a configuração C++_PLB obteve os melhores resultados, chegando a ser superior em aproximadamente $85 \%$ das instâncias do grupo "E" e 100\% do grupo "W".

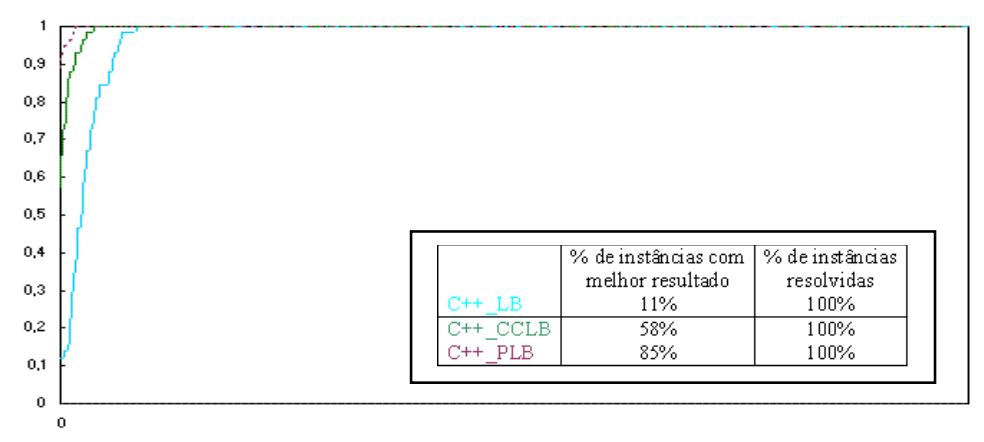

Figura 4.13 - Gráfico de Dolan e Moré para o grupo de exemplos "E”, considerando preservação de preparação e set-up crossover. 


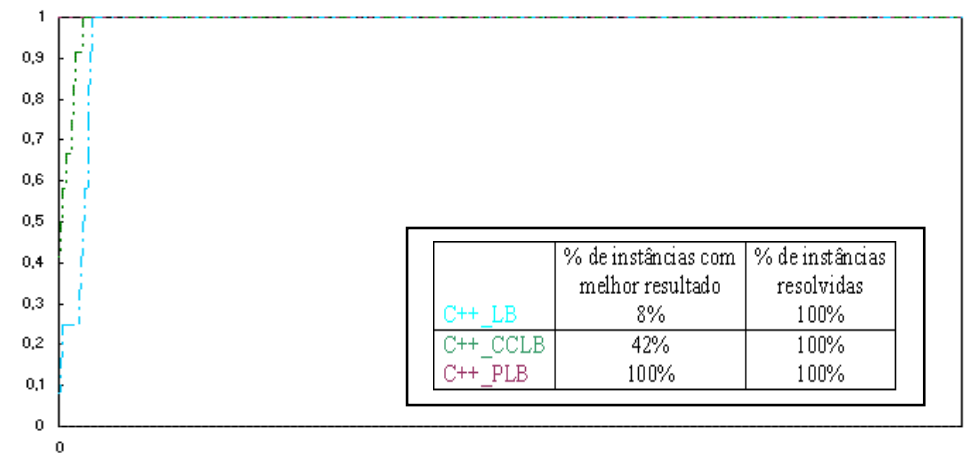

Figura 4.14 - Gráfico de Dolan e Moré para o grupo de exemplos “W”, considerando preservação de preparação e set-up crossover.

\subsubsection{Conclusão}

As configurações foram avaliadas para os problemas de dimensionamento de lotes apresentados na Tabela 4.11. Em negrito, destacamos a configuração que gerou os melhores resultados para as instâncias testadas.

\begin{tabular}{|l|c|c|c|c|}
\hline \multirow{2}{*}{$\begin{array}{c}\text { Parâmetros } \\
\text { CPLEX }\end{array}$} & \multicolumn{4}{|c|}{ Características } \\
\cline { 2 - 5 } & PDLC & Backlogging & Carry-Over & $\begin{array}{c}\text { Carry-Over, Set-up } \\
\text { Crossover }\end{array}$ \\
\hline C++_LB & $\mathrm{x}$ & $\mathrm{x}$ & $\mathrm{x}$ & $\mathrm{x}$ \\
\hline C++_CCLB & $\mathrm{x}$ & $\mathrm{x}$ & $\mathrm{x}$ & $\mathrm{x}$ \\
\hline C++_PLB & $\mathbf{x}$ & $\mathbf{x}$ & $\mathbf{x}$ & $\mathbf{x}$ \\
\hline
\end{tabular}

Tabela 4.11 - Comparação entre diferentes configurações da implementação em C++. 


\subsection{Efeito da solução inicial}

A estratégia local branching proposta em Fischetti e Lodi (2003) assume que se tenha em mãos uma solução inicial como ponto de partida. Embora esta solução inicial não precise ser necessariamente factível, conforme visto em Fischetti e Lodi (2006), todas as soluções iniciais fornecidas para o local branching neste trabalho foram factíveis.

Embora não seja obrigatório possuir uma solução inicial, fazer uso dela pode resultar em ganho de tempo computacional. Para comprovar esta afirmação, foram realizados testes nos grupos "E" e "W", tanto usando o CPLEX quanto o programa em C++. Os problemas testados consideram atraso na demanda, sem preservação de preparação.

A solução inicial fornecida aos programas foi obtida resolvendo as instâncias dos grupos "E" e "W" sem atraso e sem preservação, utilizando as melhores configurações para cada programa, no caso a CPLEX_PLB e a C++_PLB. Nestes problemas, as soluções ótimas foram encontradas rapidamente, sendo então utilizadas como ponto de partida para o local branching. O tempo computacional necessário para encontrar as soluções iniciais é deduzido do tempo limite de 250 segundos atribuído à solução de cada exemplar.

Conforme os resultados obtidos, existiu ganho em tempo computacional de ambas as partes (CPLEX_PLB e C++_PLB). O ganho no tempo computacional no CPLEX foi muito pequeno, indicando que o uso de uma solução inicial (para os problemas testados) não é significativo. Já para o programa em $\mathrm{C}++$ esta diferença foi significativa, chegando a melhorar o tempo computacional em aproximadamente $60 \%$ indicando que é promissor investir na busca de uma solução inicial de boa qualidade para tornar o método mais eficiente. A diferença entre as configurações C++_PLB com e sem solução inicial pode ser observada no gráfico da Figura 4.29, onde a linha em azul representa a configuração C++_PLB com solução inicial e a linha rosa representa a configuração C++_PLB sem solução inicial. 


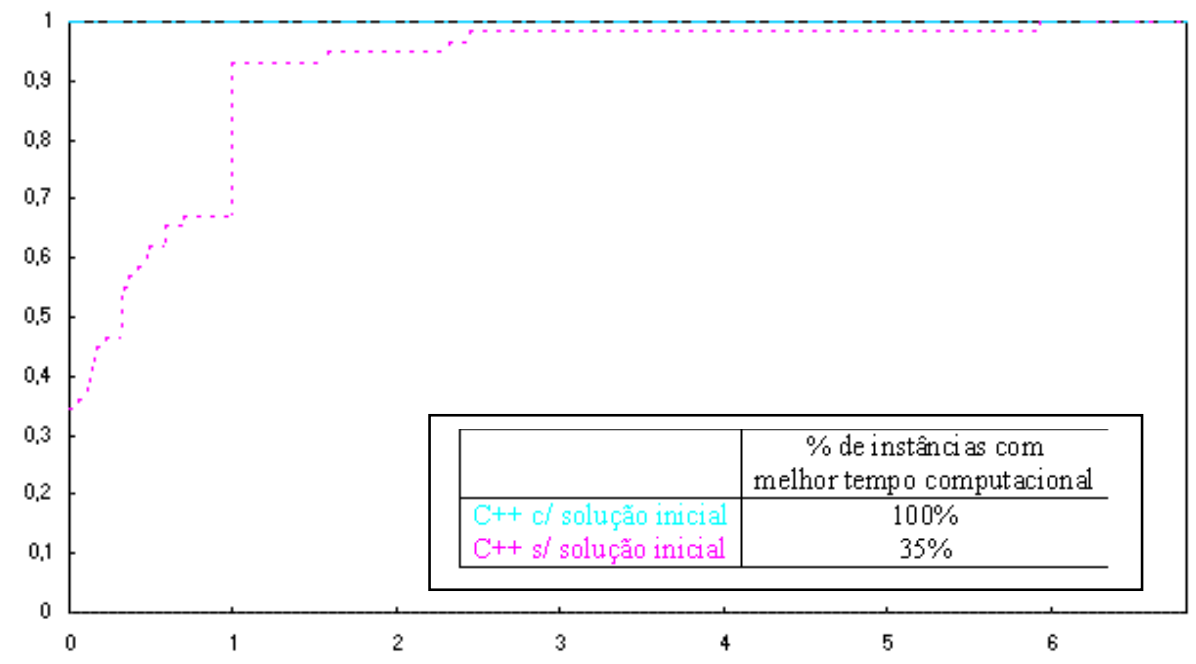

Figura 4.15 - Comparação de tempo computacional da C++_PLB com e sem solução inicial para os exemplos dos grupos "E” e "W".

Ao comparar o tempo computacional das instâncias resolvidas pelas configurações CPLEX_PLB e C++_PLB, ambas partindo de uma solução inicial, confirmamos que C++_PLB apresenta tempo computacional menor do que CPLEX_PLB, tanto nas instâncias do grupo "E" quanto do grupo "W". A configuração C++_PLB chega a ser superior em 87\% das instâncias do grupo "E" e 92\% das instâncias do grupo "W". Os resultados da comparação podem ser visualizados nos gráficos das Figuras 4.30 e 4.31. A linha em azul representa a configuração C++_PLB, enquanto a linha em rosa representa a CPLEX_PLB.

$\mathrm{Na}$ Tabela 4.12 são resumidos os resultados da comparação do valor da função objetivo obtidas pelo CPLEX 11 e pela implementação em $\mathrm{C}++$. Os resultados apresentados na tabela mostram o percentual de soluções ótimas obtidas em cada um dos grupos de exemplos. Destacamos em negrito os melhores resultados para cada um dos grupos.

\begin{tabular}{|c|c|c|}
\hline \multirow{2}{*}{$\begin{array}{c}\text { Grupos de } \\
\text { Exemplos }\end{array}$} & Melhores Soluções (PDLC com backlogging, carry-over e crossover) \\
\cline { 2 - 3 } & CPLEX_PLB & C++_PLB \\
\hline EW & $43 \%$ & $\mathbf{1 0 0 \%}$ \\
\hline F & $26 \%$ & $\mathbf{1 0 0 \%}$ \\
\hline G & $23 \%$ & $\mathbf{9 6 \%}$ \\
\hline X & $55 \%$ & $\mathbf{9 1 \%}$ \\
\hline
\end{tabular}

Tabela 4.12 - Comparação entre desempenho do CPLEX e implementação em C++. 


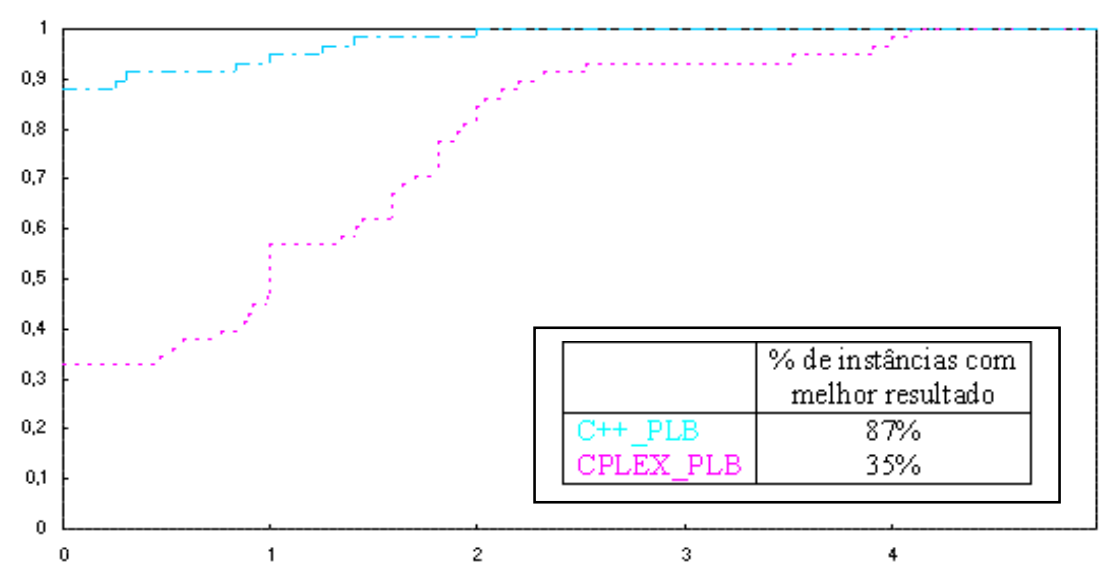

Figura 4.16 - Comparação de tempo computacional nos exemplos do grupo "E”, considerando atraso na demanda.

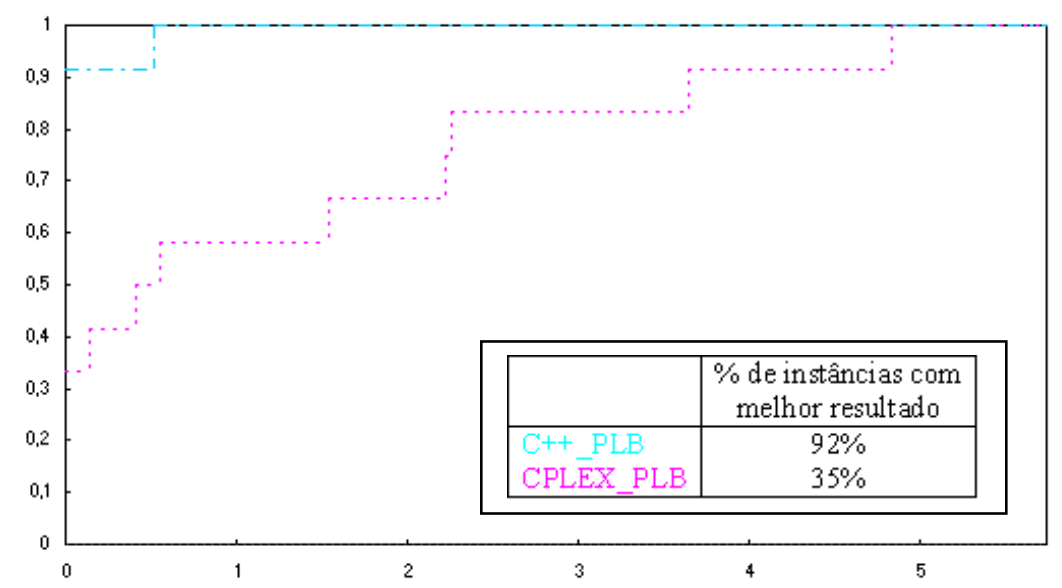

Figura 4.17 - Comparação de tempo computacional nos exemplos do grupo "W”, considerando atraso na demanda. 


\subsection{Características do PDL}

Esta seção tem como objetivo discutir os resultados obtidos e as diferenças no grau de dificuldade dos exemplos quando são consideradas características como a possibilidade de atender a demanda com atraso, de preservação de preparação e de set-up crossover.

Foram avaliadas as seguintes variações do problema de dimensionamento de lotes:

1. Problema com custo de preparação e limite de capacidade (PDLC_S) - Modelo 7.

2. PDLC com possibilidade de atraso para atender a demanda (PDLC_A) - Modelo 7.

3. PDLC com possibilidade de preservação de preparação (PDLC_PP) - Modelo 7.

4. PDLC com possibilidade de atraso e de preservação de preparação (PDLC_APP) Modelo 7.

5. PDLC com possibilidade de atraso, de preservação de preparação e set-up crossover (PDLC_APPO) - Modelo 7.

O modelo adotado nestes testes foi o modelo proposto em Karimi et al. (2005) para as Variações de 1 a 4, para a Variação 5 o modelo utilizado foi o proposto em Sung e Maravelias (2008). A configuração utilizada nos testes foi a C++_PLB, pois apresentou os melhores resultados.

Primeiramente, foram testadas as 70 instâncias dos grupos "E" e "W". Os resultados são ilustrados no gráfico da Figura 4.32. A linha rosa representa o PDLC_S, a linha azul representa o PDLC_A, a linha vermelha representa o PDLC_PP, a linha verde representa o PDLC_APP e a linha roxa representa o PDLC_APPO. Para facilitar a leitura, todos os gráficos nesta subseção seguirão esta mesma notação. 


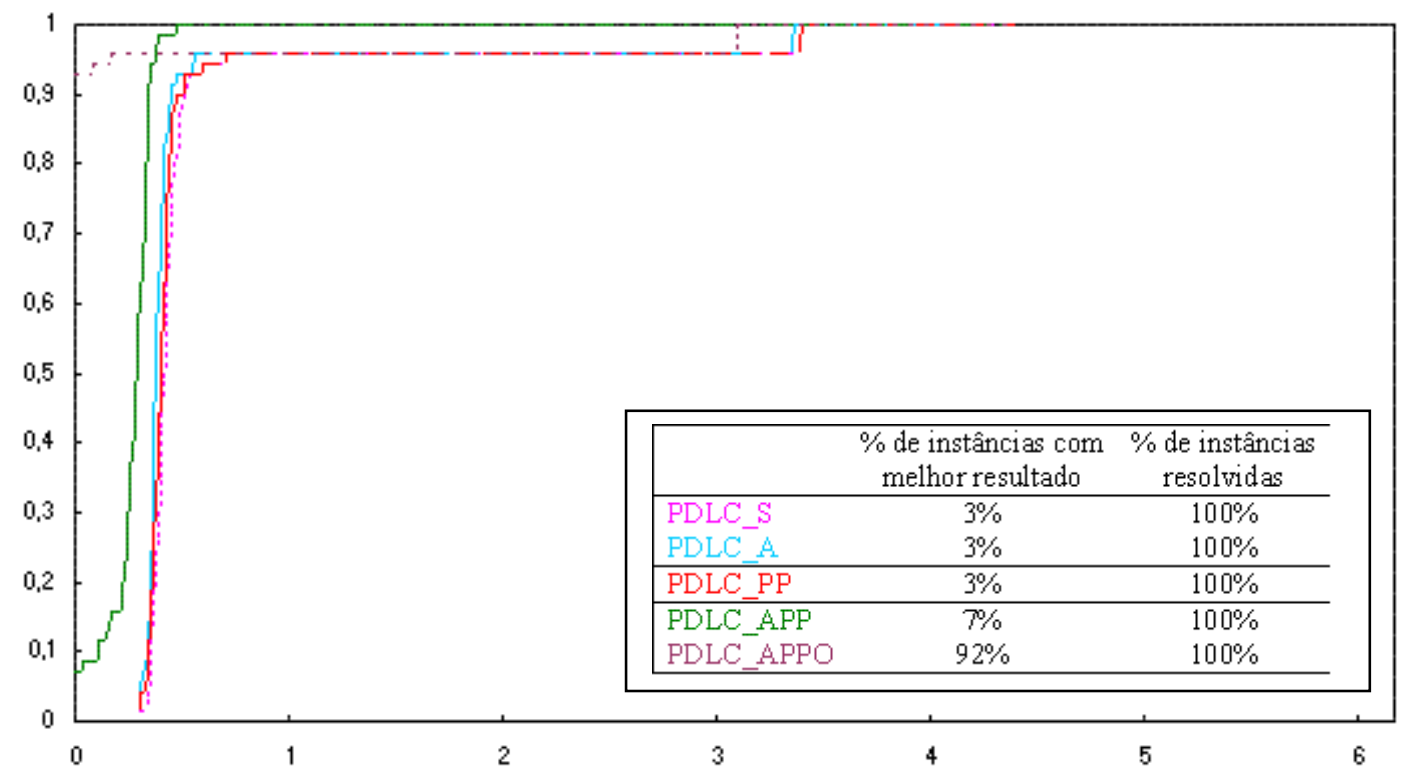

Figura 4.18 - Comparação do valor da melhor solução obtida: Grupos "E" e "W".

O PDLC_S e o PDLC_A puderam ser resolvidos na otimalidade, enquanto o PDLC_PP e o PDLC_APP tiveram sua execução interrompida ao atingir o limite de tempo. O PDLC_APPO encontrou solução ótima em $90 \%$ das instâncias e obteve os melhores resultados para todas as instâncias, mostrando que, para os problemas estudados, considerar a possibilidade de atraso para atender a demanda, de preservação de preparação e de set-up crossover é vantajoso, uma vez que existe redução significativa do custo total de produção.

Os mesmos testes foram realizados para as instâncias dos grupos "F", "G" e "X". Os resultados são ilustrados nos gráficos das Figuras 4.33, 4.34 e 4.35. Para todos os grupos de exemplos, o modelo PDLC_APPO apresentou os melhores valores da função objetivo para quase todas as instâncias, teve um desempenho pior apenas em 2\% dos casos. Estes resultados confirmam a vantagem de incorporar estas características ao ambiente de produção. 


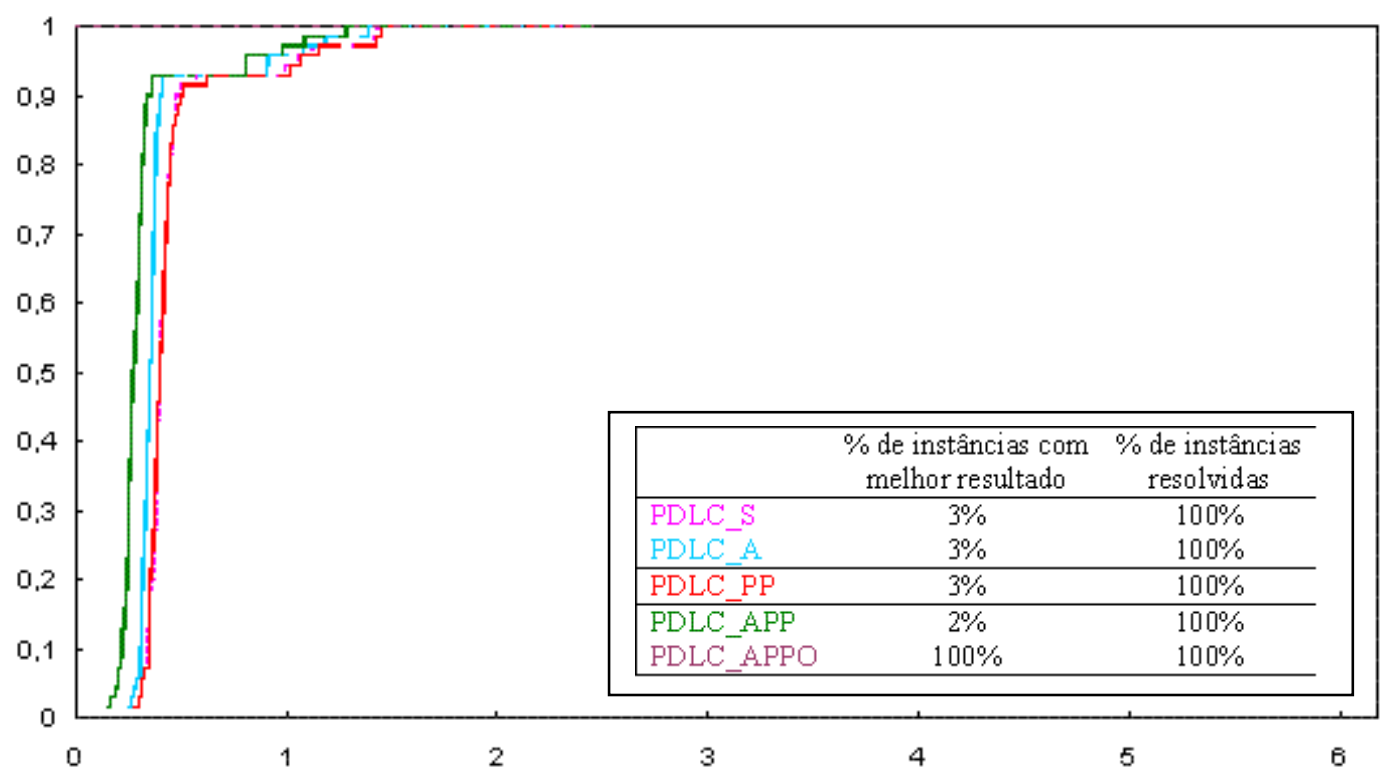

Figura 4.19 - Comparação do valor da melhor solução obtida: Grupo "F".

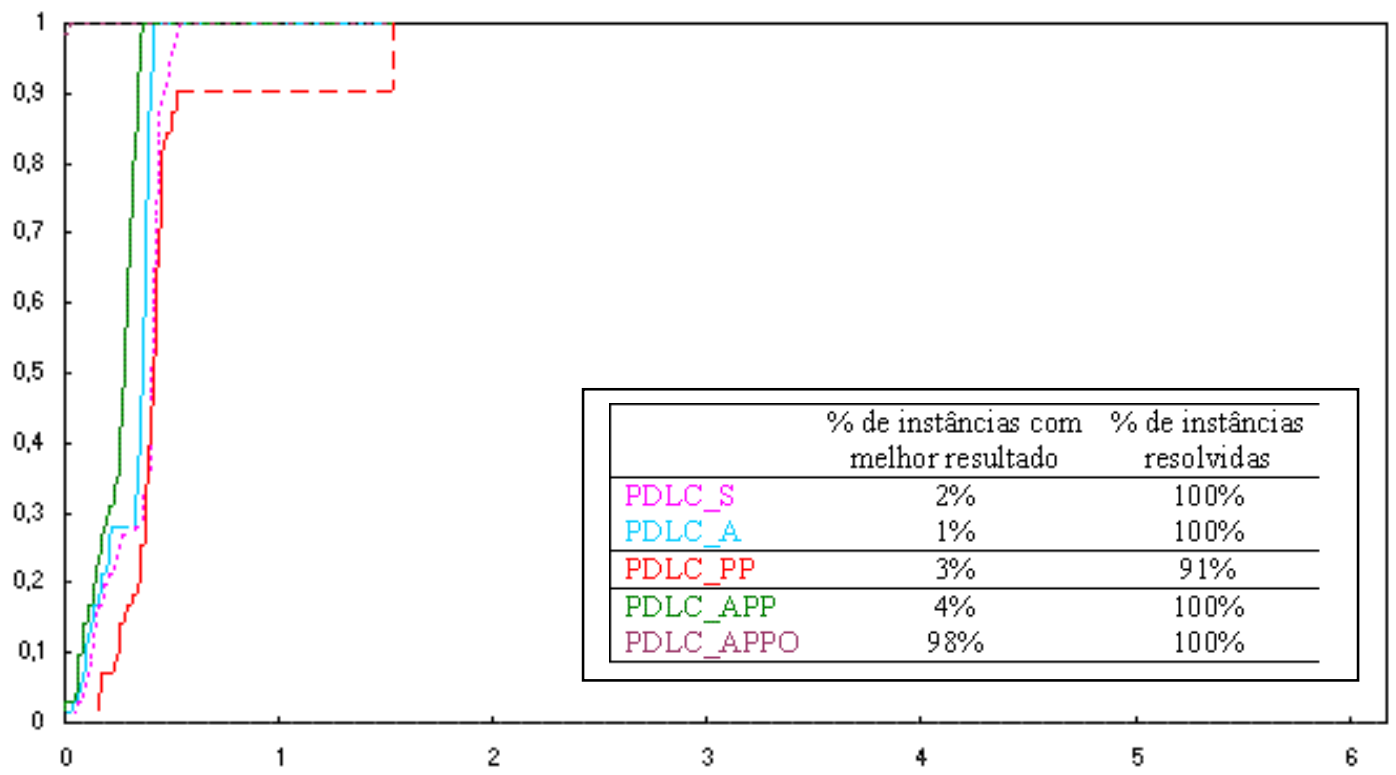

Figura 4.20 - Comparação do valor da melhor solução obtida: Grupo "G". 


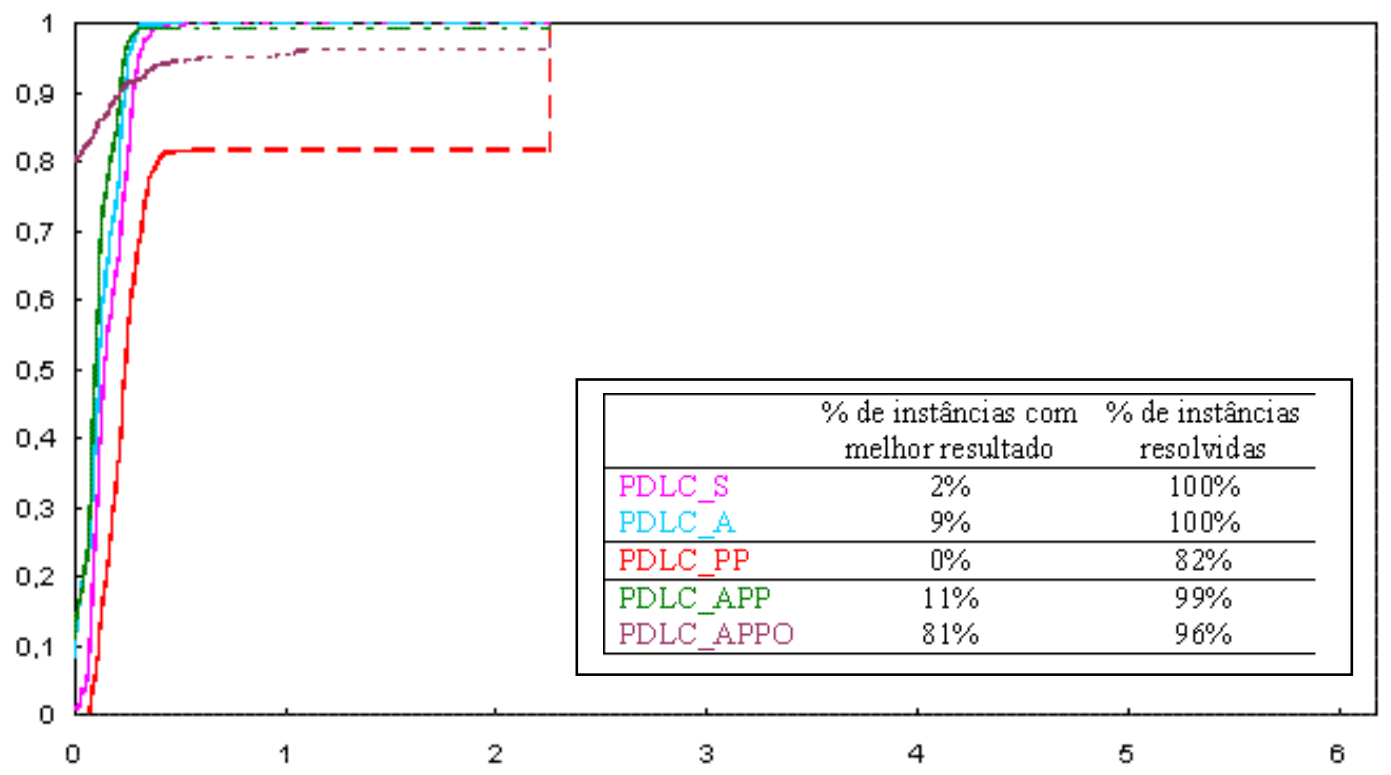

Figura 4.21 - Comparação do valor da melhor solução obtida: Grupo "X".

Além dos gráficos, foi feita uma comparação visando determinar o ganho de cada uma das características, com relação ao PDLC padrão (sem backlogging, carry-over e set-up crossover). Os resultados obtidos estão resumidos na Tabela 4.13. Para esta comparação, foram utilizados os exemplos dos grupos "E" e "W" e a implementação do local branching em $\mathrm{C}++$, visto que esta apresentou resultados melhores do que o CPLEX.

\begin{tabular}{|l|c|c|c|c|c|c|}
\hline \multirow{2}{*}{ Características } & \multirow{2}{*}{$\begin{array}{c}\% \\
\text { Soluções } \\
\text { Factíveis }\end{array}$} & $\begin{array}{c}\text { Soluções } \\
\text { Ótimas }\end{array}$ & \multirow{2}{*}{$\begin{array}{c}\text { \% Melhor } \\
\text { Solução }\end{array}$} & \multicolumn{3}{|c|}{$\%$ Ganho em relação ao PDLC } \\
\cline { 5 - 8 } & $100 \%$ & $100 \%$ & $2 \%$ & - & - & - \\
\hline PDLC & $100 \%$ & $100 \%$ & $7 \%$ & $19 \%$ & $12 \%$ & $25 \%$ \\
\hline PDLC_B & $86 \%$ & $0 \%$ & $1 \%$ & $3 \%$ & $0 \%$ & $6 \%$ \\
\hline PDLC_C & $99 \%$ & $0 \%$ & $9 \%$ & $11 \%$ & $1 \%$ & $32 \%$ \\
\hline PDLC_BC & $9 \%$ & & & & \\
\hline PDLC_BCS & $96 \%$ & $52 \%$ & $85 \%$ & $23 \%$ & $16 \%$ & $32 \%$ \\
\hline
\end{tabular}

Tabela 4.13 - Comparação de ganho resultante das características propostas no PDLC.

O PDLC com backlogging, carry-over e crossover (PDDLC_BCS) foi o que apresentou o maior grau de melhoria, obtendo um percentual de ganho médio de $23 \%$. Desta 
forma, esta configuração foi testada com os outros grupos de exemplos, visando determinar o percentual de ganho em relação ao PDLC em todas as instâncias testadas. Os resultados são apresentados na Tabela 4.14 .

\begin{tabular}{|c|c|c|c|}
\hline \multirow{2}{*}{ Exemplos } & \multicolumn{3}{|c|}{ PDLC com backlogging, carry-over e crossover (PDLC_BCS) } \\
\cline { 2 - 4 } & $\begin{array}{c}\text { \% médio de ganho em } \\
\text { relação ao PDLC }\end{array}$ & $\begin{array}{c}\text { \% mínimo de ganho em } \\
\text { relação ao PDLC }\end{array}$ & $\begin{array}{c}\text { \% máximo de ganho em } \\
\text { relação ao PDLC }\end{array}$ \\
\hline EW & $23 \%$ & $16 \%$ & $32 \%$ \\
\hline F & $27 \%$ & $18 \%$ & $63 \%$ \\
\hline G & $22 \%$ & $2 \%$ & $31 \%$ \\
\hline X & $10 \%$ & $2 \%$ & $30 \%$ \\
\hline
\end{tabular}

Tabela 4.14 - Grau de melhoria das soluções obtidas em cada um dos grupos de exemplos utilizando a implementação em C++. 


\section{Capítulo 5}

\section{Conclusões e Pesquisas Futuras}

Neste trabalho foi abordado o problema de dimensionamento de lotes com custo de preparação e limite de capacidade (PDL), considerando possibilidade de preservação de preparação, de atraso para atender a demanda e de set-up crossover.

A dissertação foi desenvolvida tendo como meta três objetivos. O primeiro foi avaliar o desempenho de diferentes configurações do CPLEX quando aplicado à solução dos problemas de dimensionamento de lotes estudados. Neste sentido, se buscou verificar o grau de influência dos cortes, das heurísticas e da estratégia local branching para a solução dos PDL estudados. Os testes computacionais realizados permitiram definir a melhor configuração para o CPLEX.

O segundo objetivo foi desenvolver um método a partir do local branching para resolver os PDL estudados e comparar os resultados obtidos com a melhor configuração definida para o CPLEX. Para tanto, foi feita uma implementação em C++ do local branching proposto em Fischetti e Lodi (2003), que para resolver os problemas inteiros mistos utiliza as bibliotecas do CPLEX (ILOG, 2007). O programa foi testado com diferentes configurações, as mesmas testadas para o CPLEX. A implementação que apresentou o melhor resultado foi selecionada. Esta configuração foi comparada com a melhor configuração do CPLEX e mostrou-se mais eficiente para os PDL estudados.

O terceiro objetivo foi avaliar a influência de diversas características no PDL na qualidade da solução dos problemas e no tempo necessário para que uma solução seja encontrada. Foram avaliadas: a possibilidade de preservação de preparação, de atraso na demanda e de set-up crossover.

As instâncias utilizadas para os testes foram propostas por Trigeiro et al. (1989). Para resolvê-las foram utilizados os dois programas acima citados. Conforme os testes computacionais realizados, concluímos que os cortes e as heurísticas do CPLEX são essenciais para que a resolução dos problemas de dimensionamento de lotes estudados ocorra de forma mais rápida e eficiente, uma vez que a qualidade da solução e dos limitantes (e por conseqüência o desvio da solução ótima) melhoram de forma significativa, conforme visto no Capitulo 4. A configuração do CPLEX que apresentou o melhor resultado foi a que utilizou 
heurísticas, cortes e local branching (CPLEX_PLB). No programa em C++, a melhor configuração foi a que utilizou heurísticas, cortes e local branching (C++_PLB).

Para a resolução dos problemas, ter uma boa solução inicial como ponto de partida reduz bastante o tempo computacional necessário para resolvê-los. Logo, foi utilizada uma estratégia para obter uma solução inicial, o que em algumas instâncias, levou a redução no tempo computacional de aproximadamente $60 \%$.

Analisando o problema quanto às características, percebe-se que o PDL com possibilidade de atraso na demanda apresenta resultados iguais ou melhores que o PDL padrão com praticamente o mesmo custo computacional. Ao ser acrescida a possibilidade de preservação de preparação, o tempo computacional necessário para solução dos problemas aumenta, fazendo com que todas as instâncias tivessem sua execução interrompida ao atingir o limite de tempo, indicando que a solução ótima não foi encontrada. Apesar das soluções obtidas neste caso não serem comprovadamente ótimas, são melhores do que as do PDL original. Esta melhoria se acentua quando as possibilidades de atraso e de preservação de preparação são consideradas simultaneamente. Porém, a combinação de características que resultou nos melhores resultados para a maioria das instâncias foi o PDL com possibilidade de atraso, preservação de preparação e set-up crossover. Considerar estas características resultou em melhorias consideráveis no custo total da solução, para alguns casos foi obtida uma redução de até $32 \%$ no valor da função objetivo.

Com relação ao tempo computacional, para a maioria das instâncias dos grupos "E" e "W" (em torno de 90\% dos problemas) o programa em $\mathrm{C}++$ obteve tempos computacionais menores do que o CPLEX, ou seja, os problemas foram resolvidos mais rapidamente. Este resultado se deve a diversos fatores, tais como linguagem utilizada, implementação, entre outros. Para obter maiores detalhes, é necessário realizar uma análise mais profunda destes fatores.

Quanto à qualidade das soluções obtidas, nos grupos de exemplos "E", "W" e "F" o programa em $\mathrm{C}++$ obteve um desempenho superior para todas as instâncias. Para o Grupo "G" o CPLEX obteve resultados melhores que o programa em C++ em apenas três instâncias. Nos exemplos do Grupo " $\mathrm{X}$ " os resultados do programa em $\mathrm{C}++$ foram melhores em quase todas as instâncias (perdendo apenas em 27 das 540 instâncias). Para algumas instâncias (seis instâncias no total) o programa em $\mathrm{C}++$ conseguiu encontrar soluções factíveis, enquanto o CPLEX não obteve nenhuma solução factível. Houve 19 instâncias em que nem o programa em C++ e nem o CPLEX conseguiram encontraram uma solução factível. 
Como indicam os resultados apresentados, considerar set-up crossover, preservação de preparação e permitir atender a demanda com atraso geram uma economia significativa com relação aos custos da empresa. Logo, é possível concluir que, caso seja viável, é indicado adaptar o modelo para que essas características sejam consideradas no ambiente produtivo.

Como os problemas são de difícil solução, sugerem-se como pesquisas futuras o desenvolvimento de heurísticas e/ou metaheurísticas para resolvê-los. Considerar a hipótese de tratar produtos perecíveis é outra questão importante para algumas aplicações, e, portanto, é outra sugestão para pesquisas futuras, uma vez que esta questão é pouco explorada na literatura. 


\section{Referências Bibliográficas}

Armentano, V.A., França, P.M. \& Toledo, F.M.B. A network flow model for the capacitated lot-sizing problem. Omega, 1999, v. 27, p. 275-284.

Bahl, H. C., Ritzman, L. P. \& Gupta, J. N. D. Determining lot sizes and resources requirements: a review. Operations Research, 1987, v. 35, p. 329-345.

Bitran, G. R. \& Yanasse, H. H. Computational complexity of the capacitated lot size problem. Management Science, 1982, v. 28, p. 1174-1186.

Brahimi, N., Dauzere-Peres, S., Najid, N. M. \& Nordli, A. Single item lot sizing problems. European Journal of Operational Research, 2006, v. 168, p. 1-16.

Briskorn, D. A note on capacitated lot-sizing with set-up carry-over. IIE Transactions, 2006, v. 38, p. 1045-1047.

Diaby, M., Bahl, H., Karwan, M. H. \& Ziont, S. Capacitated Lot-Sizing and Scheduling by Lagrangean Relaxation. European Journal of Operational Research, 1992a, v. 59, p. 444458.

Diaby, M., Bahl, H., Karwan, M. H. \& Ziont, S. A Lagrangean Relaxation Approach for Very-Large-Scale Capacitated Lot-Sizing. Management Science, 1992b, v. 59, p. 13291340.

Drexl, A. \& Kimms, A. Lot sizing and scheduling - Survey and extensions. European Journal of Operational Research, 1997, v. 99, p. 221-235.

Dolan, E. D. \& Moré, J. J. Benchmarking optimization software with performance profiles. Mathematical Programming, 2002, v. 91, p. 201-213.

Fischetti, M. \& Lodi, A. Local branching. Mathematics Programming, 2003, ser. B 98, p. 2347.

Fischetti, M. \& Lodi, A. Repairing MIP infeasibility through local branching. Computers \& Operations Research, 2006, v. 35, p. 1436-1445.

Florian, M., Lenstra, J. K. \& Rinnoy Kan, A. H. G. Deterministic Production Planning Algorithms and Complexity. Management Science, 1980, v. 26, p. 669-679.

Gopalakrishnan, M., Miller, D.M. \& Schmidt, C.P. A framework for modeling set-up carryover in the capacitated lot-sizing problem. International Journal of Production Research, 1995, v. 33, p. 1973-1988. 
Gopalakrishnan, M. A modified framework for modeling set-up carry-over in the capacitated lot-sizing problem. International Journal of Production Research, 2000, v. 33, p. 19731988.

Gopalakrishnan, M., Ding, K., Bourjolly, J. \& Mohan, S. A tabu-search heuristic for the capacitated lot-sizing problem with set-up carry-over. Management Science, 2001, v. 47, p. 851-863.

Hansen, P., Mladenovic, N. \& Urosevic, D. Variable neighborhood search and local branching. Computers \& Operations Research, 2006, v. 33, p. 3034-3045.

IBM ILOG Inc. Solver CPLEX. http://www.ilog.com/products/cplex/ , 2007.

Jans, R. \& Degreave, Z. Meta-heuristics for dynamic lot sizing: A review and comparison of solution approaches. European Journal of Operational Research, 2007, v. 177, p. 1855-1875.

Jans, R. \& Degreave, Z. Modeling industrial lot-sizing problems: a review. International Journal of Production Research, 2008, v. 46, p. 1619-1643.

Karimi, B., Fatemi Ghomi, S.M.T. \& Wilson, J.M. The capacitated lot sizing problem: a review of models and algorithms. Omega, 2003, v. 31, p. 365-378.

Karimi, B., Fatemi Ghomi, S.M.T. \& Wilson J.M. A tabu search heuristic for solving the CLSP with backlogging and set-up carry-over. Journal of the Operational Research Society, 2005, p. 1-8.

Kuik, R., Salomon, M. \& Van Wassenhove, L. N. Batching decisions: structure and models. European Journal of Operational Research, 1994, v. 75, p. 243-263.

Maes, J., McClain, J. O. \& Van Wassenhove, L. N. Multilevel Capacitated Lotsizing Complexity and LP Based Heuristic. European Journal of Operational Research, 1991, v. 53, p. 131-148.

Porkka, P., Vepsalainen, A.P.J. \& Kuula, M. Multiperiod production planning carrying over set-up time. International Journal of Production Research, 2003, v. 41, p. 1133-1148.

Souza, K. X. S. \& Armentano, V. A. Multi-Item Capacitated Lot-Sizing by a Cross Decomposition Based Algorithm. Annals of Operations Research, 1994, v. 50, p. 557-574.

Sox, C.R. \& Gao, Y. The capacitated lot-sizing problem with set-up carry-over. IIE Transactions, 1999, v. 31, p. 173-181.

Suerie, C. \& Stadtler, H. The Capacitated lot-sizing problem with linked lot sizes. Management Science, 2003, v. 49, p. 1039-1054. 
Sung, C. \& Maravelias, C.T. A mixed-integer programming formulation for the general capacitated lot-sizing problem. Computers and Chemical Engineering, 2008, v. 32, p. 244259 .

Toledo, F. M. B. \& Armentano, V.A. A Lagrangian-based heuristic for the capacitated lotsizing problem in parallel machines. European Journal of Operational Research, 2006, v. 175, p. 1070-1083.

Trigeiro, W. W., Thomas L. J. \& McClain J. O. Capacitated Lot Sizing With Setup Times. Management Science, 1989, v. 35, p. 353-366.

Wagner, H. M. \& Within, T.M. Dynamic version of the economic lot size model. Management Science, 1958, v. 5, p. 89-96.

Wolsey, L. A. Progress with single-item lot-sizing. European Journal of Operational Research, 1995, v. 86, p. 395-401. 


\section{Apêndice A - Resultados Detalhados}

Apresentamos a seguir os resultados detalhados obtidos para os problemas estudados no Capítulo 4.

\begin{tabular}{|c|c|c|c|}
\hline Instâncias & $\mathbf{C + +} \mathbf{L B}$ & C++_CCLB & C++_PLB \\
\hline E01 & 34393 & 34393 & 34393 \\
\hline E02 & 28836 & 28836 & 28836 \\
\hline E03 & 42057 & 42057 & 42057 \\
\hline E04 & 35581 & 35581 & 35581 \\
\hline E05 & 41129 & 41129 & 41129 \\
\hline E06 & 41449 & 41449 & 41449 \\
\hline E07 & 32621 & 32621 & 32621 \\
\hline E08 & 37632 & 37632 & 37632 \\
\hline E09 & 38369 & 38369 & 38369 \\
\hline E10 & 30120 & 30120 & 30120 \\
\hline E11 & 44715 & 44715 & 44715 \\
\hline E12 & 29432 & 29432 & 29432 \\
\hline E13 & 29085 & 29085 & 29085 \\
\hline E14 & 33123 & 33123 & 33123 \\
\hline E15 & 36704 & 36704 & 36704 \\
\hline E16 & 30257 & 30257 & 30257 \\
\hline E17 & 31520 & 31520 & 31520 \\
\hline E18 & 42915 & 42895 & 42895 \\
\hline E19 & 41210 & 41170 & 41148 \\
\hline E20 & 31543 & 31543 & 31543 \\
\hline E21 & 34951 & 34951 & 34951 \\
\hline E22 & 35888 & 35888 & 35888 \\
\hline E23 & 30528 & 30528 & 30528 \\
\hline E24 & 37585 & 37585 & 37585 \\
\hline E25 & 35710 & 35710 & 35710 \\
\hline E26 & 27228 & 27228 & 27228 \\
\hline E27 & 40266 & 40266 & 40266 \\
\hline E28 & 27276 & 27276 & 27276 \\
\hline E29 & 41273 & 41273 & 41273 \\
\hline E30 & 30341 & 30341 & 30341 \\
\hline E31 & 37918 & 37863 & 37863 \\
\hline E32 & 39335 & 39202 & 39202 \\
\hline E33 & 35801 & 35801 & 35801 \\
\hline E34 & 38130 & 38130 & 38130 \\
\hline E35 & 51064 & 51061 & 51061 \\
\hline E36 & 39719 & 39719 & 39719 \\
\hline
\end{tabular}

Tabela A.1 - Tabela de resultados do programa em C++ nos exemplos do grupo "E". 


\begin{tabular}{|c|c|c|c|}
\hline E37 & 38736 & 38736 & $\mathbf{3 8 7 3 6}$ \\
\hline E38 & 35127 & 35127 & $\mathbf{3 5 1 2 7}$ \\
\hline E39 & 38128 & 38128 & $\mathbf{3 8 1 2 8}$ \\
\hline E40 & 47638 & 47638 & $\mathbf{4 7 6 3 8}$ \\
\hline E42 & 37932 & 37932 & $\mathbf{3 7 9 3 2}$ \\
\hline E43 & 32330 & 32330 & $\mathbf{3 2 3 3 0}$ \\
\hline E44 & 27536 & 27536 & $\mathbf{2 3 5 3 5}$ \\
\hline E45 & 23555 & 23555 & $\mathbf{2 3 2 8 1}$ \\
\hline E46 & 23281 & 23281 & $\mathbf{3 3 0 0 2}$ \\
\hline E47 & 33002 & 33002 & $\mathbf{4 0 2 0 7}$ \\
\hline E48 & 40207 & 40207 & $\mathbf{3 7 5 7 1}$ \\
\hline E50 & 37945 & 37919 & $\mathbf{3 7 1 7 5}$ \\
\hline E51 & 30819 & 30819 & $\mathbf{4 8 8 2 6}$ \\
\hline E53 & 37175 & 37175 & $\mathbf{3 3 2 1 4}$ \\
\hline E54 & 48869 & 48941 & $\mathbf{4 1 2 5 5}$ \\
\hline E55 & 33379 & 33214 & $\mathbf{4 1 9 3 9}$ \\
\hline E56 & 41852 & 41255 & $\mathbf{2 5 9 9 5}$ \\
\hline E59 & 42059 & 41965 & $\mathbf{2 5 6 4 4}$ \\
\hline E60 & $N a N$ & $N a N$ & $\mathbf{3 3 9 1 3}$ \\
\hline
\end{tabular}

Tabela A.1 - Tabela de resultados do programa em C++ nos exemplos do grupo "E" (continuação).

\begin{tabular}{|c|c|c|c|}
\hline Instâncias & C++_LB & C++_CCLB & C++_PLB \\
\hline W01 & 61621 & 61621 & $\mathbf{6 1 4 2 2}$ \\
\hline W02 & 59708 & 59708 & $\mathbf{5 9 4 9 5}$ \\
\hline W03 & 57951 & 57951 & $\mathbf{5 7 8 0 9}$ \\
\hline W04 & 48889 & 48889 & $\mathbf{4 8 6 6 2}$ \\
\hline W05 & 45108 & 45108 & $\mathbf{4 4 9 1 6}$ \\
\hline W06 & 44042 & 44042 & $\mathbf{4 3 9 0 3}$ \\
\hline W07 & 142321 & 141817 & $\mathbf{1 3 7 8 1 7}$ \\
\hline W08 & 138989 & 137641 & $\mathbf{1 3 7 4 7 3}$ \\
\hline W09 & 137908 & 137688 & $\mathbf{9 0 4 8 9}$ \\
\hline W11 & 91369 & 90489 & $\mathbf{8 7 9 4 3}$ \\
\hline W12 & 87944 & 87943 & $\mathbf{8 6 2 7 9}$ \\
\hline
\end{tabular}

Tabela A.2 - Tabela de resultados do programa em $\mathrm{C}++$ nos exemplos do grupo "W". 


\begin{tabular}{|c|c|c|c|}
\hline Instâncias & $\mathbf{C}++\_\mathrm{LB}$ & $\mathrm{C}++$ CCLB & C++_PLB \\
\hline E01 & 34393 & 34034 & 33985 \\
\hline E02 & 28487 & 28331 & 28362 \\
\hline E03 & 40911 & 41216 & 40295 \\
\hline E04 & 35501 & 35581 & 35581 \\
\hline E05 & 41129 & 40642 & 40259 \\
\hline E06 & 40271 & 40132 & 39585 \\
\hline E07 & 31910 & 31717 & 31502 \\
\hline E08 & 37632 & 37409 & 37632 \\
\hline E09 & 37899 & 37196 & 37177 \\
\hline E10 & 30120 & 29480 & 30120 \\
\hline E11 & 44715 & 44715 & 44715 \\
\hline E12 & 29161 & 28675 & 28588 \\
\hline E13 & 28289 & 27642 & 27642 \\
\hline E14 & 33123 & 33123 & 32958 \\
\hline E15 & 35738 & 35668 & 35596 \\
\hline E16 & 30257 & 30257 & 30257 \\
\hline E17 & 31369 & 30939 & 30728 \\
\hline E18 & 42915 & 42895 & 42743 \\
\hline E19 & 41282 & 40602 & 40022 \\
\hline E20 & 31543 & 31543 & 31543 \\
\hline E21 & 35017 & 34951 & 34186 \\
\hline E22 & 35888 & 35888 & 35888 \\
\hline E23 & 30528 & 30528 & 30528 \\
\hline E24 & 37585 & 37585 & 37585 \\
\hline E25 & 35471 & 35346 & 35710 \\
\hline E26 & 27228 & 27228 & 27228 \\
\hline E27 & 39708 & 39630 & 39630 \\
\hline E28 & 26754 & 26787 & 26602 \\
\hline E29 & 41273 & 41273 & 41273 \\
\hline E30 & 29513 & 29023 & 29003 \\
\hline E31 & 37937 & 36014 & 36522 \\
\hline E32 & 39431 & 39202 & 39202 \\
\hline E33 & 35904 & 35734 & 35801 \\
\hline E34 & 38180 & 38130 & 38130 \\
\hline E35 & 51061 & 51061 & 51061 \\
\hline E36 & 39125 & 39719 & 38832 \\
\hline E37 & 38736 & 38736 & 38361 \\
\hline E38 & 35227 & 35127 & 35127 \\
\hline E39 & 38128 & 37676 & 37297 \\
\hline E40 & 47091 & 47001 & 46757 \\
\hline E41 & 37139 & 37161 & 36576 \\
\hline E42 & 32519 & 32330 & 32330 \\
\hline E43 & 27536 & 27536 & 27536 \\
\hline
\end{tabular}

Tabela A.3 - Tabela de resultados dos exemplos do grupo "E", considerando preservação de preparação. 


\begin{tabular}{|c|c|c|c|}
\hline E44 & 23555 & 23555 & $\mathbf{2 3 3 0 3}$ \\
\hline E45 & 23281 & 22977 & $\mathbf{2 2 9 5 8}$ \\
\hline E46 & 33121 & 33002 & $\mathbf{3 3 0 0 2}$ \\
\hline E47 & 40450 & 40207 & $\mathbf{4 0 2 0 7}$ \\
\hline E48 & 38402 & 37571 & $\mathbf{3 7 5 7 1}$ \\
\hline E49 & 30819 & 30819 & $\mathbf{3 0 8 1 9}$ \\
\hline E50 & 37175 & 37175 & $\mathbf{3 7 1 7 5}$ \\
\hline E51 & 49177 & 48881 & $\mathbf{4 8 8 2 6}$ \\
\hline E53 & 33379 & 33214 & $\mathbf{3 3 2 1 4}$ \\
\hline E54 & 41992 & 41325 & $\mathbf{4 1 2 5 5}$ \\
\hline E55 & 42283 & 42233 & $\mathbf{4 4 2 5 1}$ \\
\hline E56 & 34251 & 34251 & $\mathbf{3 4 1 5 7}$ \\
\hline E57 & 34157 & 34157 & $\mathbf{4 2 9 7 5}$ \\
\hline E59 & 42992 & 42975 & $\mathbf{2 9 2 9 0}$ \\
\hline
\end{tabular}

Tabela A.3 - Tabela de resultados dos exemplos do grupo "E", considerando preservação de preparação (continuação).

\begin{tabular}{|c|c|c|c|}
\hline Instâncias & C++_LB & C++_CCLB & C++_PLB \\
\hline W01 & 61621 & 61621 & $\mathbf{6 1 1 7 9}$ \\
\hline W02 & 59708 & 59708 & $\mathbf{5 9 2 4 6}$ \\
\hline W03 & 56918 & 56252 & $\mathbf{5 5 7 2 6}$ \\
\hline W04 & 46174 & 46220 & $\mathbf{4 6 0 0 3}$ \\
\hline W05 & 43435 & $\mathbf{4 3 1 8 8}$ & 43225 \\
\hline W06 & 41703 & 41944 & $\mathbf{4 1 5 2 8}$ \\
\hline W07 & 143224 & 141921 & $\mathbf{1 4 1 8 1 7}$ \\
\hline W09 & 140047 & 137641 & $\mathbf{1 3 7 4 7 3}$ \\
\hline W10 & 138368 & 137473 & $\mathbf{9 0 4 8 9}$ \\
\hline W11 & 91646 & 90489 & $\mathbf{8 7 9 4 3}$ \\
\hline W12 & 87944 & 87943 & $\mathbf{8 6 2 7 9}$ \\
\hline
\end{tabular}

Tabela A.4 - Tabela de resultados dos exemplos do grupo "W", considerando preservação de preparação. 


\begin{tabular}{|c|c|c|c|}
\hline Instâncias & C++_LB & C++_CCLB & C++_PLB \\
\hline E01 & 27277 & 27030 & 27030 \\
\hline E02 & 22310 & 21825 & 21825 \\
\hline E03 & 34339 & 33984 & 33979 \\
\hline E04 & 29605 & 28447 & 28287 \\
\hline E05 & 33331 & 32730 & 32675 \\
\hline E06 & 34402 & 33538 & 33536 \\
\hline E07 & 26057 & 25677 & 25615 \\
\hline E08 & 28265 & 28265 & 28265 \\
\hline E09 & 31417 & 30600 & 30600 \\
\hline E10 & 24417 & 23881 & 23881 \\
\hline E11 & 35368 & 35085 & 35085 \\
\hline E12 & 24328 & 23913 & 23879 \\
\hline E13 & 22589 & 22297 & 22297 \\
\hline E14 & 25607 & 25607 & 25607 \\
\hline E15 & 29826 & 29314 & 29314 \\
\hline E16 & 23244 & 23098 & 23098 \\
\hline E17 & 25483 & 25310 & 24937 \\
\hline E18 & 34343 & 34005 & 34084 \\
\hline E19 & 33166 & 32934 & 32767 \\
\hline E20 & 25983 & 25655 & 25387 \\
\hline E21 & 27344 & 27034 & 27018 \\
\hline E22 & 28576 & 28347 & 28205 \\
\hline E23 & 24082 & 24082 & 24082 \\
\hline E24 & 28874 & 28616 & 28616 \\
\hline E25 & 28083 & 27862 & 27862 \\
\hline E26 & 21506 & 21240 & 21240 \\
\hline E27 & 31506 & 31412 & 31412 \\
\hline E28 & 20143 & 20143 & 20143 \\
\hline E29 & 32196 & 32022 & 32022 \\
\hline E30 & 23521 & 23266 & 23266 \\
\hline E31 & 30118 & 29510 & 29371 \\
\hline E32 & 33262 & 32182 & 31403 \\
\hline E33 & 29230 & 28405 & 28400 \\
\hline E34 & 31321 & 30911 & 30767 \\
\hline E35 & 42910 & 42206 & 42230 \\
\hline E36 & 33005 & 32144 & 32201 \\
\hline E37 & 32808 & 31859 & 31641 \\
\hline E38 & 28701 & 27664 & 27981 \\
\hline E39 & 30289 & 30098 & 30312 \\
\hline E40 & 37506 & 37250 & 37250 \\
\hline E41 & 28925 & 28700 & 28700 \\
\hline E42 & 26339 & 25444 & 25337 \\
\hline E43 & 20671 & 20471 & 20471 \\
\hline
\end{tabular}

Tabela A.5 - Tabela de resultados dos exemplos do grupo "E", considerando preservação de preparação e set-up crossover. 


\begin{tabular}{|c|c|c|c|}
\hline E44 & 17896 & 17640 & $\mathbf{1 7 6 2 8}$ \\
\hline E45 & 18332 & 18051 & $\mathbf{1 8 0 5 1}$ \\
\hline E46 & 26321 & 25375 & $\mathbf{2 5 3 2 8}$ \\
\hline E47 & 33294 & 33010 & $\mathbf{3 2 6 5 4}$ \\
\hline E48 & 31209 & 30390 & $\mathbf{2 9 9 0 4}$ \\
\hline E49 & 24389 & 23990 & $\mathbf{2 3 9 9 0}$ \\
\hline E50 & 30119 & $\mathbf{2 9 6 2 5}$ & 29630 \\
\hline E51 & 39969 & 38500 & $\mathbf{3 8 3 6 4}$ \\
\hline E53 & 27426 & 27173 & $\mathbf{2 6 9 1 1}$ \\
\hline E54 & 33351 & $\mathbf{3 2 3 9 7}$ & 32694 \\
\hline E55 & 34516 & 33668 & $\mathbf{3 3 0 1 8}$ \\
\hline E56 & 25995 & 25995 & $\mathbf{2 5 9 9 5}$ \\
\hline E57 & 25644 & 25644 & $\mathbf{2 5 6 4 4}$ \\
\hline E59 & 34155 & 33953 & $\mathbf{3 3 9 1 3}$ \\
\hline E60 & 21890 & 21890 & $\mathbf{2 1 8 9 0}$ \\
\hline
\end{tabular}

Tabela A.5 - Tabela de resultados dos exemplos do grupo "E", considerando preservação de preparação e set-up crossover (continuação).

\begin{tabular}{|c|c|c|c|}
\hline Instâncias & C++_LB & C++_CCLB & C++_PLB \\
\hline W01 & 47579 & 47462 & $\mathbf{4 7 4 6 2}$ \\
\hline W02 & 45121 & 45080 & $\mathbf{4 5 0 8 0}$ \\
\hline W03 & 43837 & 43185 & $\mathbf{4 3 1 8 5}$ \\
\hline W04 & 35424 & 35424 & $\mathbf{3 5 4 2 4}$ \\
\hline W05 & 33607 & 32944 & $\mathbf{3 2 9 1 2}$ \\
\hline W06 & 32282 & 31766 & $\mathbf{1 2 1 5 2 9}$ \\
\hline W07 & 123857 & 122256 & $\mathbf{1 1 8 0 3 3}$ \\
\hline W08 & 120647 & 120034 & $\mathbf{1 1 7 3 5 0}$ \\
\hline W10 & 120218 & 118458 & $\mathbf{7 5 6 9 5}$ \\
\hline W11 & 77468 & 76613 & $\mathbf{7 2 3 1 4}$ \\
\hline W12 & 73594 & 73085 & $\mathbf{7 1 4 3 9}$ \\
\hline
\end{tabular}

Tabela A.6 - Tabela de resultados dos exemplos do grupo "W", considerando preservação de preparação e set-up crossover. 


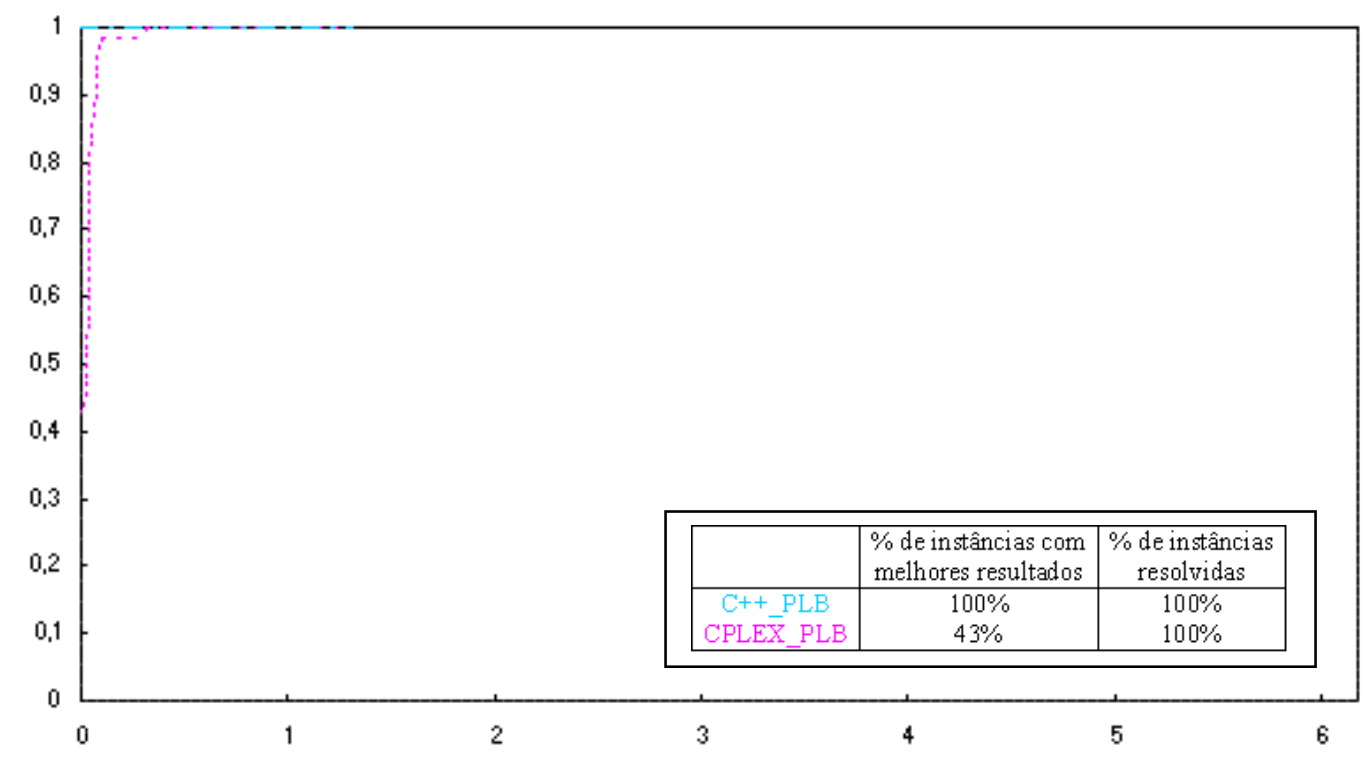

Figura A.1 - Valores da função objetivo dos exemplos dos grupos "E" e "W", considerando atraso, preservação de preparação e set-up crossover.

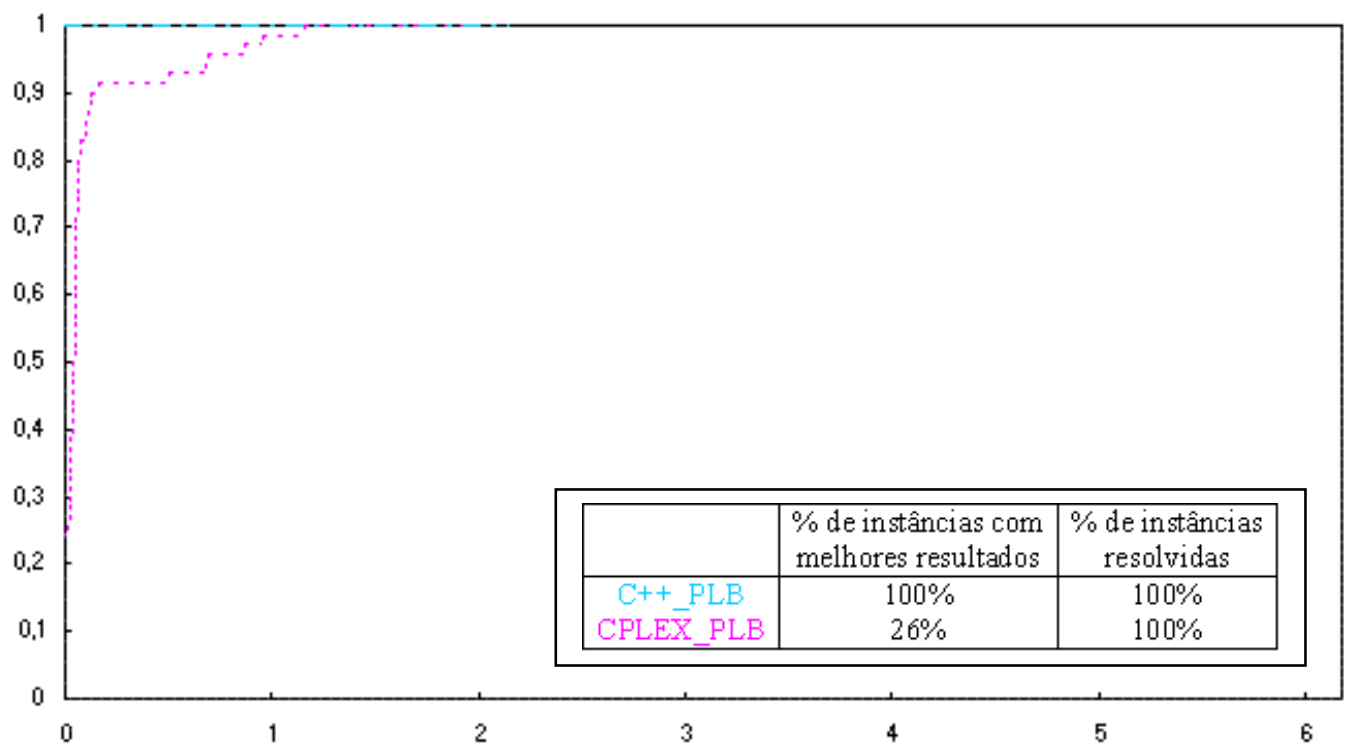

Figura A.2 - Valores da função objetivo dos exemplos do grupo "F", considerando atraso, preservação de preparação e set-up crossover. 


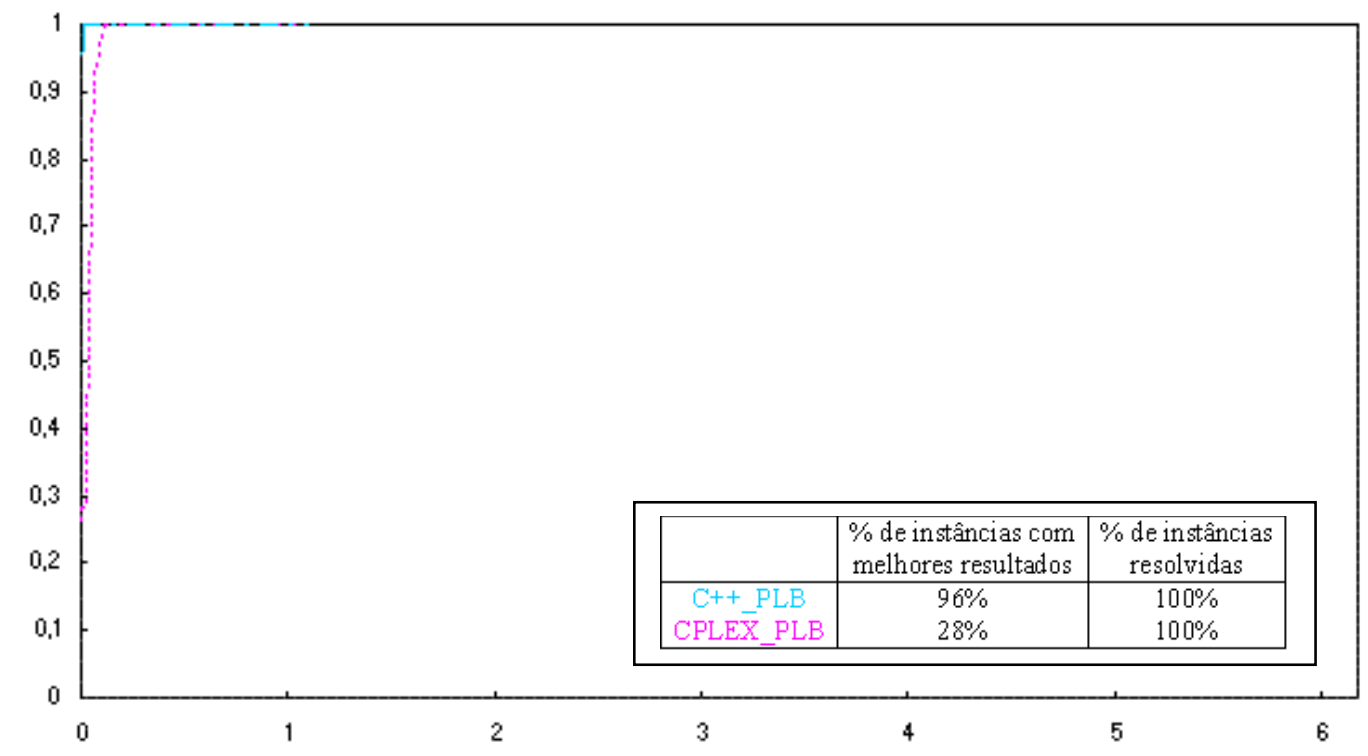

Figura A.3 - Valores da função objetivo dos exemplos do grupo "G", considerando atraso, preservação de preparação e set-up crossover.

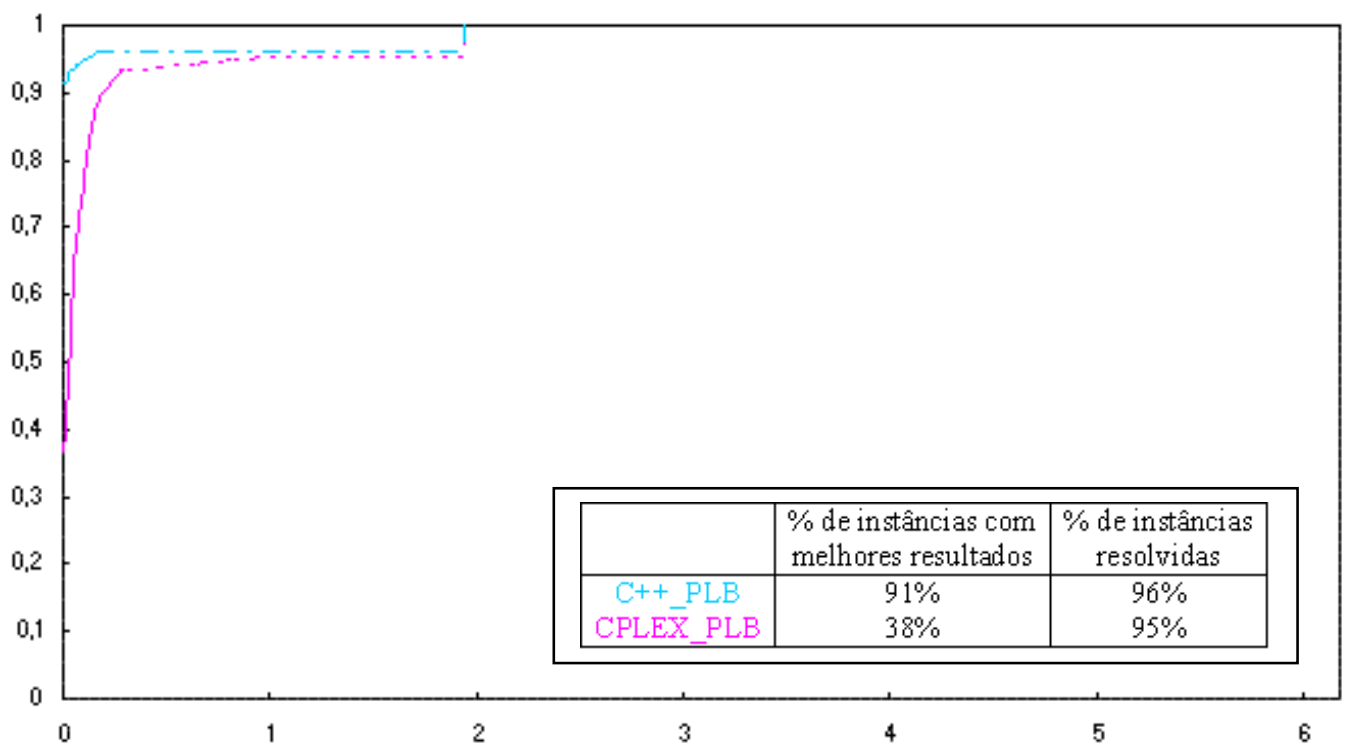

Figura A.4 - Valores da função objetivo dos exemplos do grupo "X", considerando atraso, preservação de preparação e set-up crossover. 